LIGADURAS ORTODÔNTICAS ELASTOMÉRICAS ESTÉTICAS:

ALTERAÇÃO DE COR, ULTRAESTRUTURA DA SUPERFÍCIE (MEV) E PROPRIEDADE ELÁSTICA APÓS USO DE DENTIFRÍCIO CLAREADOR (ESTUDO IN VIVO) 
LIGADURAS ORTODÔNTICAS ELASTOMÉRICAS ESTÉTICAS:

\section{ALTERAÇÃO DE COR, ULTRAESTRUTURA DA SUPERFÍCIE (MEV) \\ E PROPRIEDADE ELÁSTICA APÓS USO DE DENTIFRÍCIO \\ CLAREADOR (ESTUDO IN VIVO)}

Tese apresentada à Faculdade de Odontologia de Ribeirão
Preto da Universidade de São Paulo, para a obtenção do
título de Doutor em Ciências no Programa de
Odontopediatria.
Área de concentração: Odontopediatria
Orientadora: Profa. Dra. Mirian Aiko Nakane Matsumoto 


\section{AUTORIZAÇÃO PARA REPRODUÇÃO}

Autorizo a reprodução e ou divulgação do teor total ou parcial desse trabalho por qualquer meio convencional ou eletrônico, para fins de estudo e ou pesquisa, desde que citada a fonte.

\section{FICHA CATALOGRÁFICA}

Elaborada pela Biblioteca Central do Campus USP - Ribeirão Preto - SP

Matos, Leonardo Gontijo

Ligaduras Ortodônticas Elastoméricas Estéticas: Alteração de cor, Ultraestrutura da Superfície (MEV) e Propriedade Elástica Após Uso de Dentifrício Clareador (Estudo In Vivo). Ribeirão Preto, 2017.

106p.: il.; $30 \mathrm{~cm}$

Tese de Doutorado, apresentada à Faculdade de Odontologia de Ribeirão Preto/USP.

Área de Concentração: Odontopediatria.

Orientadora: Matsumoto, Mirian Aiko Nakane

1. ligadura ortodôntica. 2. espectrofotometria. 3. tração elástica. 4. microscopia eletrônica de varredura. 
FOLHA DE APROVAÇÃO

LEONARDO GONTIJO MATOS

\section{LIGADURAS ORTODÔNTICAS ELASTOMÉRICAS ESTÉTICAS: ALTERAÇÃO \\ DE COR, ULTRAESTRUTURA DA SUPERFÍCIE E PROPRIEDADE ELÁSTICA APÓS USO DE DENTIFRÍCIO CLAREADOR (ESTUDO IN VIVO)}

Tese apresentada à Faculdade de Odontologia de Ribeirão Preto da Universidade de São Paulo, para a obtenção do título de doutor em Ciências no Programa de Odontopediatria.

Área de concentração: Odontopediatria

Orientadora: Profa. Dra. Mirian Aiko Nakane Matsumoto

Data da defesa:

BANCA EXAMINADORA

Prof.(a) Dr.(a)

Julgamento: Assinatura:

Prof.(a) Dr.(a)

Julgamento: Assinatura:

Prof.(a) Dr.(a)

Julgamento: Assinatura:

Prof.(a) Dr.(a)

Julgamento: Assinatura:

Prof.(a) Dr.(a)

Julgamento: Assinatura: 


\section{DADOS CURRICULARES}

Nascimento: 24 de dezembro de 1971

Filiação: José Nascimento de Matos

Maria da Conceição Gontijo Matos

1990-1994: Graduação em Odontologia

Universidade Federal de Uberlândia - UFU

1996-1998: Pós-graduação lato sensu (especialização) em Odontopediatria Universidade Federal de Uberlândia - UFU

1999-2001: Pós-graduação stricto sensu (mestrado) em Odontologia Área de concentração: Ortodontia

Pontifícia Universidade Católica de Minas Gerais - PUC Minas

2013-2017: Pós-graduação stricto sensu (doutorado) em Odontologia Área de concentração: Odontopediatria Faculdade de Odontologia de Ribeirão Preto - USP 
Dedicatória 
Em primeiro lugar, dedico esse trabalho a Deus, na pessoa de seu filho Jesus sem o qual nada do que foi feito seria concretizado. Por ter me guiado nas incontáveis vezes em que estive na estrada, pela direção espiritual, por ter me dado saúde e por ter me concedido essa maravilhosa oportunidade. O Senhor me concedeu saúde e paz de espírito! Ao Senhor quero servir em espírito e em verdade!

Aos meus pais Zizo (in memoriam) e Conceição por terem me educado e ensinado os conceitos morais que me acompanham por toda a vida. Se não tive a sua presença física em todos os momentos, estou certo de que, mesmo silenciosos, estiveram sempre ao meu lado. Minha profunda gratidão e respeito!

À minha amada filha Clara, um presente que me foi concedido para toda a vida. Seu sorriso amável, sua doçura e seu abraço carinhoso a cada volta para casa foram companheiros constantes nessa jornada. Espero ser exemplo para você. Obrigado por seu amor!

À minha querida Marília. Você me incentivou desde o início. Seu entusiasmo pelo estudo foi contagiante. Você esteve ao meu lado em todos os momentos, cuidando, ouvindo e amando. Seu amor, carinho, companheirismo e dedicação foram constantes. Minha gratidão e meu amor serão por toda a vida. Obrigado por tudo!

À querida Tia Ana Maria, meu primeiro exemplo dentro da Odontologia. Você me incentivou nos primeiros passos. Me mostrou como uma vida profissional deve ser pautada na ética e na dedicação. Você me concedeu a oportunidade de ter um local maravilhoso de trabalho. Serei eternamente agradecido!

À minha avó Maria José (in memoriam). Por muitos anos a senhora acompanhou com entusiasmo o meu crescimento profissional. Foram muitas orações. Faz muitos anos que a senhora se foi...mas ainda é tempo de agradecer por tanto carinho e bondade que a senhora dedicou a mim e a toda família. 
Agradecimentos 
Á Profa. Dra. Mirian Aiko Nakane Matsumoto, minha orientadora. Sua sólida formação profissional e sua competência foram estímulos constantes. Sua serenidade e sua paciência foram inspirações para toda a vida. A senfora me deu um grande voto de confiança que espero ter retribuído. Com a senhora aprendi muito mais do que ciência. Ficam o meu profundo agradecimento e minha grande admiração!

Á Profa. Dra. Fernanda Panzeri, por ter me recebido tão bem em seu departamento. Pela atenção e ajuda a mim dispensados. Por ter disponibilizado recursos imprescindíveis para a execução desse estudo. Pela disponibilidade e pelo valiosíssimo auxílio nas correções. Muito obrigado!

Ao reitor da Universidade de São Paulo, campus de Ribeirão Preto, Prof. Dr. Marco Antônio Zago.

À diretora da Faculdade de Odontologia, Profa. Dra. Léa Assed Bezerra da Silva, por conduzir de forma séria e competente a Faculdade de Odontologia, privilegiando a formação de profissionais diferenciados na prática clínica e na pesquisa.

Á coordenadora do Programa de Pós-graduação Profa. Dra. Raquel Assed Bezerra Segato pela direção embasada em valores éticos e humanos não deixando de lado o rigor científico e a excelência.

Aos Professores do Departamento de Clínica Infantil (Prof Adilson Thomazinho, Prof Dr. Al6erto Consolaro, Profa. Dra. Alexandra Mussolino de Queiroz, Profa. Dra. Andiara de Rossi Daldegan, Profa. Dra. Érika Calvano Kuchler, Prof. Dr. Fabio Lourenço Romano, Prof. Dr. Fabrício Kitazono de Carvalho, Prof. Dr. Francisco Wanderley de Paula Garcia e Silva, Profa Dra. Kranya Victória Diaz Serrano, Prof. Dr. Luis Carlos Pardini, Profa. Dra. Maria Bernadete Sasso Stuani, Profa. Dra. Maria Cristina Borsatto, Profa. Dra. Maria da Conceição Pereira Saraiva, Profa. Raquel Assed Bezerra Segato, Profa. Dra, Silmara Aparecida Milori Corona) pelos conhecimentos compartilhados, pela atenção e pela agradável convivência no dia-a-dia.

A Profa Dra. Aldevina Campos Freitas, por seu exemplo de dedicação e seu amor pela docência e pelas crianças.

Ao Prof. Dr. Paulo Nelson-Filho, um grande exemplo de mestre. Seu vasto conhecimento clínico e científico e suas observações sempre precisas e didáticas fazem com que seja um professor completo e admirável. 
Ao Prof. Dr. Rodrigo Gallo pela valiosa ajuda na análise estatística, pela paciência nos questionamentos e colaboração.

Ao Prof. Dr. José Tarcísio Lima Ferreira pela valiosa ajuda e orientações junto ao Comitê de Ética em Pesquisa da FORP/USP.

Ao Prof. Dr. Eustáquio Afonso Araújo, da Saint Louis University, meu primeiro mestre na Ortodontia. Como não lembrar do seu exemplo e das palavras elogiosas quando da minha entrada no Programa de Doutorado. O senhor formou toda uma geração de ortodontistas da qual me orgulfo em ter participado.

Ao Prof. Dr. Leandro Silva Marques, da Vniversidade Federal dos Vales do Jequitinhonha e Mucuri - MG, pela confiança em mim depositada na época da minha admissão ao Programa de Doutorado e pelo companheirismo quando formos contemporâneos em Belo Horizonte.

À Profa. Dra. Fabiana Sodré de Oliveira da Universidade Federal de Vberlândia-MMG. Por ter me indicado para o Programa de Doutorado confiando em minha capacidade e responsabilidade.

Á colega Karla O. Carpio Horta dos Reis por seu companheirismo e amizade em todos os momentos. Pela ajuda preciosa e valiosa quando da parte experimental desse trabalfo e por estar presente sempre disponível para ajudar. Meu sincero agradecimento.

À colega Raquel Fermanda B. Morelli por sua amizade e carinho. Pela valiosa ajuda no atendimento dos pacientes! Minha gratidão.

À colega Ana Zilda Nazar Bergamo que no longínquo ano de 2011 me apresentou o Programa de Doutorado na FORP e deu início a essa etapa que agora se encerra.

Aos pacientes e seus responsáveis que participaram dessa pesquisa. Por terem seguido à risca as recomendações e por terem, de fato, ajudado a realizar esse estudo.

À família de Renata Cardoso de Deus e seus pais Heleno Ribeiro de Deus e Maria Arminda Cardoso de Deus pela amizade e respeito para comigo e por ajudarem efetivamente na educação e na criação da minha filha Clara. 
Ao funcionário do Núcleo Integrado de Pesquisa de Biocompatibilidade de Materiais, Edson Volta por sua disponibilidade e ajuda na execução do ensaio de tração elástica.

À funcionária do Laboratório Heitor Panzeri, Rafaella Tonani, pela organização, atenção e cuidado durante a parte experimental desse trabalho. Muito obrigado.

Ao funcionário do Laboratório de Microscopia Eletrônica de Varredura, do Departamento de Química, Rodrigo Silva por sua atenção, cuidado e boa vontade ímpares que deixou o nosso convívio fraterno e agradável.

À secretária Rosemary Alves de Sá, por sua boa vontade em ajudar em todos os momentos, pela inestimável ajuda na formatação da tese e pelo convívio amigo durante esses 4 anos.

Aos funcionários do Departamento de Clínica Infantil, Micheli Cristina Leite Rovanholo, Matheus Morelli Zanela, Filomena Leli Palcciti, Carolina Paes Torres Mantovani, Marília Pacífico Lucisano, Benedita Viana Rodrigues e Fátima Aparecida Rizoli por sua boa vontade no dia-a-dia e sua atenção e respeito.

Às funcionárias da Seção de Pós-graduação da Faculdade de Odontologia de Ribeirão Preto: Isabel Cristina G. Solla e Mary Carmessano pela competência e atenção.

Aos funcionários das clínicas I, II e III da Faculdade de Odontologia de Ribeirão Preto no cumprimento diário de suas funções sem o qual esse trabalho não seria levado a termo.

Ás funcionárias da CLIN em Patos de Minas - MG, Luciana, Lorena, Lurdes e Glória, me cuidaram com responsabilidade e comprometimento dos pacientes e da clínica durante a minha ausência. 
Resumo 
Matos, L.G. Ligaduras ortodônticas elastoméricas estéticas: alteração de cor, ultraestrutura da superfície (MEV) e propriedade elástica após uso de dentifrício clareador (estudo in vivo). [Tese] Ribeirão Preto: Universidade de São Paulo, Faculdade de Odontologia de Ribeirão Preto, 2017. 106p.

O objetivo desse estudo foi comparar o desempenho de ligaduras ortodônticas estéticas de 4 marcas comerciais, após 30 dias na cavidade bucal, com o uso de dentifrício clareador e convencional para avaliar: alteração de cor por meio da espectrofotometria; a ultraestrutura da superfície por meio da Microscopia Eletrônica de Varredura (MEV); propriedade elástica por meio do teste de tração. Foram avaliadas as ligaduras seguintes marcas comerciais: American Orthodontics, 3M Unitek, Orthotechnology e Morelli Ortodontia. Foram selecionados, após o cálculo amostral, 20 pacientes que atenderam aos critérios de inclusão. Os pacientes receberam, de forma aleatória, com o auxílio do acessório Shooter (TP Orthodontics, La Porte, IN, EUA) ligaduras nos elementos 13, 23, 33 e 43; 32, 31, 41 e 42. No mesmo dia receberam dentifrício clareador Colgate Luminous White (Colgate-Palmolive Indústria e Comércio, São Bernardo do Campo, SP, Brasil) que foi usado por 30 dias (grupo experimental). Após esse período as ligaduras foram removidas, armazenadas (em saliva artificial) e, imediatamente submetidas aos testes. Os pacientes receberam, então, dentifrício convencional Colgate Máxima Proteção Anti-cáries (Colgate-Palmolive Indústria e Comércio, São Bernardo do Campo, SP, Brasil) (grupo controle). Após 30 dias, foram removidas, armazenadas e submetidas aos ensaios. As ligaduras inseridas nos bráquetes dos caninos foram avaliadas para alteração de cor pelo espectrofotômetro (Vita Easyshade Zahnfabrik, Bad Säckingen, Alemanha). Em seguida, as ligaduras, de cada marca, que apresentaram maior e menor variação de cor com o dentifrício clareador e convencional, bem como ligaduras novas, foram submetidas à avaliação qualitativa com a visualização pelo Microscópio Eletrônico de Varredura (EVO 50, Carl Zeiss, Cambridge, Inglaterra). As ligaduras que estavam inseridas nos bráquetes incisivos inferiores foram submetidas ao teste de tração pela Máquina de Ensaio Mecânico Universal (EMIC DL 2000, São José dos Pinhais, PR, Brasil). Os achados foram submetidos à análise estatística ANOVA e ao teste complementar de Duncan em um nível de significância de 5\%. Os resultados mostraram que o dentifrício clareador não conseguiu efetivamente manter a estabilidade de cor das ligaduras ortodônticas estéticas. $\mathrm{O}$ valor final para o $\Delta \mathrm{E}$ (variação total de cor) para todas as marcas foi $>3,3$ o que indica uma alteração clinicamente perceptível pelo olho humano e que sinaliza a reposição do material por razões estéticas. Em relação à MEV as imagens obtidas foram heterogêneas e não permitiram caracterizar um padrão para um ou outro dentifrício. No que se refere ao teste de tração, houve melhor desempenho para as marcas 3M Unitek e American Orthodontics. O tipo de dentifrício, clareador ou convencional, não alterou a propriedade elástica entre as marcas estudadas. Pode-se concluir, pela presente pesquisa, que o dentifrício clareador não foi capaz de alterar a estabilidade de cor nas 4 marcas avaliadas por um período de 30 dias. A avaliação qualitativa pela MEV não permitiu concluir se a abrasividade do dentifrício clareador trouxe danos ou injurias à superfície das ligaduras. Apesar disso, o seu uso não alterou a propriedade elástica das mesmas.

Palavras-chave: ligadura, espectrofotometria, tração, microscopia eletrônica de varredura. 
Abstract 
Matos, L. G. Esthetic orthodontic elastic ligatures: color change, ultra-structural surface (SEM) and elastic property after the use of whitening dentifrice (an in vivo study). [Thesis]. Ribeirão Preto: University of São Paulo, School of Dentistry of Ribeirão Preto, 2017. 106p.

The objective of this study was to compare the performance of aesthetic orthodontic ligatures/modules of 4 commercial brands, after 30 days in the oral cavity, with the use of conventional and whitening dentifrice to evaluate: color change by spectrophotometry; the ultrastructure of the surface by Scanning Electron Microscopy (SEM); elastic property by the tensile test. The following brands were evaluated: American Orthodontics, 3M Unitek, Orthotechnology and Morelli Orthodontics. Twenty patients who were included in the inclusion criteria were selected after sample calculation. Patients received, at random, with the aid of the Shooter accessory (TP Orthodontics, La Porte, IN, USA) ligatures on elements 13, 23, 33, 43, 32, 31, 41 e 42 and whitening dentifrice Colgate Luminous White (ColgatePalmolive Indústria e Comércio, São Bernardo do Campo, SP, Brazil), which was used for 30 days (test group). After this period, the ligatures were removed, stored (in artificial saliva) and immediately submitted to the tests. Patients were then given conventional toothpaste Colgate Maximum Anti-caries Protection (Colgate-Palmolive Indústria e Comércio, São Bernardo do Campo, SP, Brazil). This was the control group. Once again, after 30 days, the modules were removed, stored and submitted to assays. Ligatures inserted into the canine brackets were evaluated by the spectrophotometer (Vita Easyshade Zahnfabrik, Bad Säckingen, Germany) to evaluate the color change. After this step, the ligatures of each brand, which presented greater and lesser color variation, both with the whitening dentifrice as well as the conventional one, and new ligatures, were selected for qualitative evaluation with the visualization by the Scanning Electron Microscope (EVO 50, Carl Zeiss, Cambridge, England). The ligatures that were inserted in the lower incisor brackets were subjected to the tensile test by the Universal Mechanical Testing Machine (EMIC DL 2000, São José dos Pinhais, PR, Brazil). The findings were submitted to ANOVA statistical analysis and Duncan's complementary test at a significance level of 5\%. The results showed that the whitening dentifrice failed to effectively improve the color stability of aesthetic orthodontic ligatures. The final value for $\Delta \mathrm{E}$ (total color change) for all brands was $>3.3$ which indicates a change clinically perceptible by the human eye and signaling the replacement of the material for aesthetic reasons. In relation to the SEM the images obtained were heterogeneous and did not allow to characterize a standard for one or the other dentifrice. Regarding the tensile test, there was better performance for the brands $3 \mathrm{M}$ Unitek and American Orthodontics. The type of dentifrice, whitening or conventional did not alter the elastic property between the brands studied. It can be concluded from the present research that the whitening dentifrice was not able to change the color stability in the 4 brands evaluated for a period of 30 days. The qualitative evaluation by SEM did not allow the conclusion that the abrasiveness of the whitening dentifrice caused damage to the surface of the ligatures. Despite this, their use did not alter their elastic property.

Key words: ligature, spectrophotometry, tensile strength, scanning electron microscopy. 
Lista de Ilustrações 


\section{LISTA DE ILUSTRAÇÕES}

Figura 1 - Ilustração do sistema de cores da Commission Internationale L'Eclairage. (Moreira, 2011).

Figura 2 - Aspecto clínico do aparelho ortodôntico e ligaduras estéticas novas

Figura 3 - Aspecto clínico do aparelho ortodôntico e ligaduras estéticas após 30 dias com uso de dentifrício clareador.

Figura 4 - Aspecto clínico do aparelho e ligaduras estéticas após 30 dias com uso de dentifrício convencional

Figura 5 - Sequência clínica da colagem dos bráquetes: A: Profilaxia, B: condicionamento ácido do esmalte, $\mathbf{C}$ : aplicação do adesivo, D: posicionamento do bráquete, $\mathbf{E}$ : fotopolimerização.

Figura 6 - Ligaduras utilizadas no estudo: A: ligadura Orthotechnology, B: ligadura American Orthodontics, C: ligadura 3M Unitek, D: ligadura Morelli

Figura 7 - Esquema do posicionamento das ligaduras (letras diferentes simbolizam marcas comerciais diferentes).

Figura 8 - A: Shooter, B: ligadura posicionada no Shooter, C: ligadura distendida, D: posicionamento da ligadura no bráquete, E: ligadura inserida no bráquete

Figura 9 - Escova dental usada pelos articipantes.

Figura 10 - Remoção da ligadura

Figura 11 - Frascos identificados

Figura 12 - A: Espectrofotômetro, B: matriz acrílica, C: ligadura posicionada na matriz acrílica, D: ponteira do espectrofotômetro posicionada na matriz, E: espectrofotômetro acionado.

Figura 13 - Esquema com a distribuição da amostra das ligaduras avaliadas pela MEV.........

Figura 14 - A: equipamento de secagem e metalização Baltec SCD 50, B: microscópio eletrônico de varredura EVO 50, C: ligaduras metalizadas em ouro, D: visualização pela MEV em diferentes aumentos

Figura 15 - A: máquina de ensaio mecânico universal, B: ligadura posicionada nos ganchos, C: distensão da ligadura, D/E: exemplos de gráficos de leitura do teste de tração elástica.

Figura 16 - Fluxograma da metodologia empregada com o dentifrício clareador e convencional.

Figura 17 - Microscopia eletrônica de varredura - Ligadura Morelli nova. A: aumento de 150X; B: aumento de 500X; C: aumento de 2000X. 
Figura 18 - Microscopia eletrônica de varredura - Ligadura Morelli usada com dentifrício clareador com menor variação de cor. A: aumento de 150X; B: aumento de 500X; C: aumento de 2000X.

Figura 19 - Microscopia eletrônica de varredura - Ligadura Morelli usada com dentifrício clareador com maior variação de cor. A: aumento de 150X; B: aumento de 500X; C: aumento de 2000X.

Figura 20 - Microscopia eletrônica de varredura - Ligadura Morelli usada com dentifrício convencional com menor variação de cor. A: aumento de 150X; B: aumento de 500X; C: aumento de 2000X.

Figura 21 - Microscopia eletrônica de varredura - Ligadura Morelli usada com dentifrício convencional com maior variação de cor. A: aumento de 150X; B: aumento de 500X; C: aumento de 2000X.

Figura 22 - Microscopia eletrônica de varredura - Ligadura American Orthodontics nova. A: aumento de 150X; B: aumento de 500X; C: aumento de 2000X.

Figura 23 - Microscopia eletrônica de varredura - Ligadura American Orthodontics usada com dentifrício clareador com menor variação de cor. A: aumento de 150X; B: aumento de 500X; C: aumento de 2000X

Figura 24 - Microscopia eletrônica de varredura - Ligadura American Orthodontics usada com dentifrício clareador com maior variação de cor. A: aumento de 150X; B: aumento de 500X; C: aumento de 2000X

Figura 25 - Microscopia eletrônica de varredura - Ligadura American Orthodontics usada com dentifrício convencional com menor variação de cor. A: aumento de 150X; B: aumento de 500X; C: aumento de 2000X.

Figura 26 - Microscopia eletrônica de varredura - Ligadura American Orthodontics usada com dentifrício convencional com maior variação de cor. A: aumento de 150X; B: aumento de 500X; C: aumento de 2000X.

Figura 27 - Microscopia eletrônica de varredura - Ligadura 3M Unitek nova. A: aumento de 150X; B: aumento de 500X; C: aumento de 2000X.

Figura 28 - Microscopia eletrônica de varredura - Ligadura 3M Unitek usada com dentifrício clareador com menor variação de cor. A: aumento de 150X; B: aumento de 500X; C: aumento de 2000X

Figura 29 - Microscopia eletrônica de varredura - Ligadura 3M Unitek usada com dentifrício clareador com maior variação de cor. A: aumento de 150X; B: aumento de 500X; C: aumento de 2000X 
Figura 30 - Microscopia eletrônica de varredura - Ligadura 3M Unitek usada com dentifrício convencional com menor variação de cor. A: aumento de 150X; B: aumento de 500X; C: aumento de 2000X.

Figura 31 - Microscopia eletrônica de varredura - Ligadura 3M Unitek usada com dentifrício convencional com maior variação de cor. A: aumento de 150X; B: aumento de 500X; C: aumento de 2000X.

Figura 32 - Microscopia eletrônica de varredura - Ligadura Orthotechnology nova. A: aumento de 150X; B: aumento de 500X; C: aumento de 2000X.

Figura 33 - Microscopia eletrônica de varredura - Ligadura Orthotechnology usada com dentifrício clareador com menor variação de cor. A: aumento de 150X; B: aumento de 500X; C: aumento de 2000X.

Figura 34 - Microscopia eletrônica de varredura - Ligadura Orthotechnology usada com dentifrício clareador com maior variação de cor. A: aumento de 150X; B: aumento de 500X; C: aumento de 2000X

Figura 35 - Microscopia eletrônica de varredura - Ligadura Orthotechnology usada com dentifrício convencional com menor variação de cor. A: aumento de 150X; B: aumento de 500X; C: aumento de 2000X

Figura 36 - Microscopia eletrônica de varredura - Ligadura Orthotechnology usada com dentifrício clareador com maior variação de cor. A: aumento de 150X; B: aumento de 500X; C: aumento de 2000X. 


\section{Lista de Tabelas}




\section{LISTA DE TABELAS}

Tabela 1 - Dentifrícios utilizados no estudo e sua composição

Tabela 2 - Médias finais das leituras de cor marca Morelli com ambos dentifrícios (pacientes 1 ao 20)

Tabela 3 - Médias finais das leituras de cor marca American Orthodontics com ambos dentifrícios (pacientes 1 ao 20)

Tabela 4 - Médias finais das leituras de cor marca 3M Unitek com ambos dentifrícios (pacientes 1 ao 20)

Tabela 5 - Médias finais das leituras de cor marca Orthotechnology com ambos dentifrícios (pacientes 1 ao 20).

Tabela 6 - Resultados finais para a variável $\Delta \mathrm{E}$ (letras minúsculas diferentes indicam diferenças entre linhas, letras maiúsculas diferentes indicam diferenças entre colunas).

Tabela 7 - Resultados finais para a variável $\Delta \mathrm{L}$ (letras minúsculas diferentes indicam diferenças entre linhas, letras maiúsculas diferentes indicam diferenças entre colunas).

Tabela 8 - Resultados finais para a variável $\Delta$ a (letras minúsculas diferentes indicam diferenças entre linhas, letras maiúsculas diferentes indicam diferenças entre colunas)

Tabela 9 - $\quad$ Resultados finais para a variável $\Delta \mathrm{b}$ (letras minúsculas diferentes indicam diferenças entre linhas, letras maiúsculas diferentes indicam diferenças entre colunas)

Tabela 10 - Leituras do teste de tração marca Morelli (pacientes 1 ao 20)

Tabela 11 - Leituras do teste de tração marca American Orthodontics (pacientes 1 ao 20)..

Tabela 12 - Leituras do teste de tração marca 3M Unitek (pacientes 1 ao 20).

Tabela 13 - Leituras do teste de tração marca Orthotechnology (pacientes 1 ao 20).

Tabela 14 - Resultado do teste de tração elástica (letras minúsculas indicam semelhança estatística entre linhas, letras maiúsculas indicam semelhança estatística entre colunas) 


\section{Lista de Gráficos}




\section{LISTA DE GRÁFICOS}

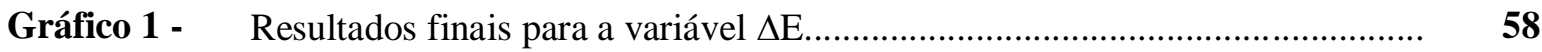

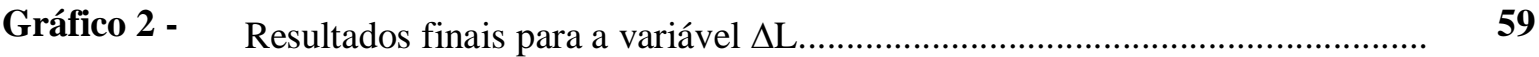

Gráfico 3 - $\quad$ Resultados finais para a variável $\Delta \mathrm{a}$................................................................... $\quad \mathbf{6 0}$

Gráfico 4 - $\quad$ Resultados finais para a variável $\Delta \mathrm{b}$..................................................................

Gráfico 5 - $\quad$ Resultado das forças máximas do teste de tração elástica $(\mathrm{N})$............................ $\quad 69$

Gráfico 6 - Resultado da deformação do teste de tração elástica $(\mathrm{mm})$................................. $\quad$ 69 


\section{Lista de Abreviaturas}




\section{LISTA DE ABREVIATURAS}

pH: potencial Hidrogeniônico

CIE: Commission Internationale L' Eclairage

“: polegadas

$\Delta \mathrm{E}$ : variação total de cor

$\Delta \mathrm{L}$ : variação total da coordenada $\mathrm{L}^{*}$

$\Delta \mathrm{a}$ : variação total da coordenada $\mathrm{a}^{*}$

$\Delta \mathrm{b}$ : variação total da coordenada $\mathrm{b}^{*}$

MEV: microscopia eletrônica de varredura

CO: dentifrício convencional

CL: dentifrício clareador

$\mathrm{CO}_{2}$ : dióxido de carbono

C: graus Celsius

g: gramas

ml: mililitros

mm: milímetros

$\mathrm{kV}$ : quilovolt

mBar: miliBar

$\mathrm{N}$ : Newtons

$\mathrm{X}$ : vezes 
Sumário 


\section{SUMÁRIO}

\section{RESUMO}

ABSTRACT

\section{LISTA DE ILUSTRAÇÕES}

\section{LISTA DE TABELAS}

\section{LISTA DE GRÁFICOS}

\section{LISTA DE ABREVIATURAS}

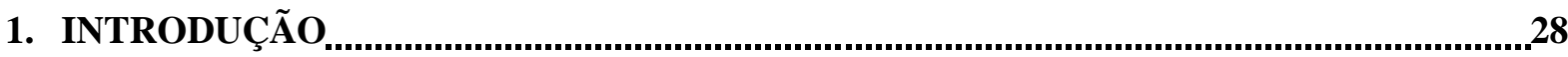

2. PROPOSIÇÃO

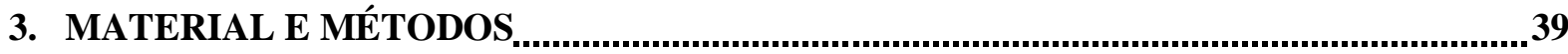

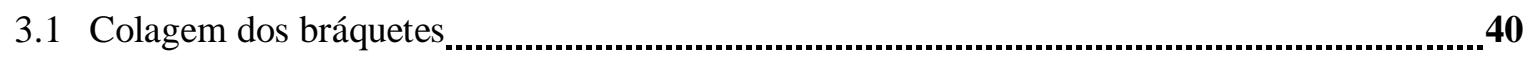

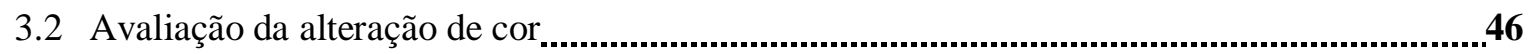

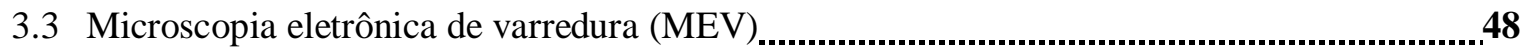

3.4 Avaliação da propriedade elástica ................................................................................51

4. RESULTADOS

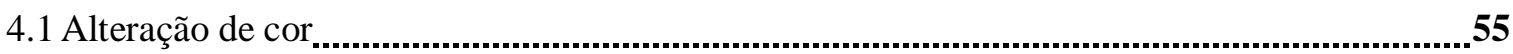

4.2 Ultraestrutura da superfície (MEV) ...........................................................................61

4.3 Tração elástica ..................................................................................................................6

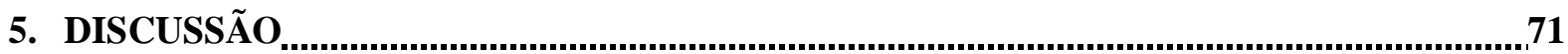

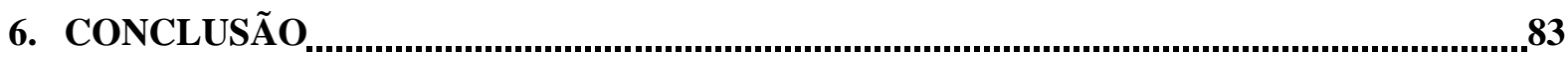

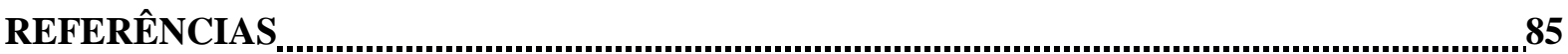

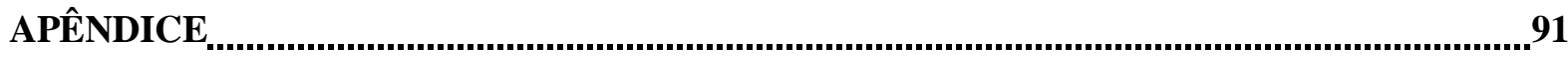

ANEXO 
1. Introdução 


\section{INTRODUÇÃO}

Nos dias atuais, o tratamento ortodôntico tem sido procurado por um número cada vez maior de pessoas, desde crianças, adolescentes e adultos. De fato, a Ortodontia tem indicações nas mais variadas idades. Nesse contexto, a alteração da aparência dos dentes e do sorriso durante a execução do tratamento tem considerável importância. Enquanto pacientes mais jovens tendem a gostar da visibilidade do aparelho ortodôntico com o uso de aparelhos metálicos e ligaduras coloridas, os adultos, com maior frequência, procuram por aparelhos mais discretos (Lew, 1990 e Capelli Jr et al., 2014).

De uma forma geral, há três componentes básicos de todos os aparelhos corretivos convencionais: o bráquete, o fio ortodôntico e o dispositivo que mantém o fio em posição junto ao slot ou canaleta do bráquete (Burstone et al., 2003).

Clinicamente, a fixação do arco ortodôntico ao bráquete pode ser feita por meio de ligaduras elastoméricas (coloridas ou incolores), fios ou amarrilhos de aço ou por meio de clipes, grampos, tampas ou dispositivos similares que caracterizam os bráquetes auto-ligados. As ligaduras elastoméricas são largamente utilizadas e tem como características: propriedade de memória elástica, fácil colocação e remoção, conforto, biocompatibilidade, facilidade de higienização, além de possuírem várias cores, o que pode contribuir para a motivação do paciente durante o tratamento (Martins et al., 2008).

De acordo com Forsberg et al. (1991), Pellegrini et al. (2009) e Garcez et al. (2011) apesar da maior praticidade, as ligaduras elastoméricas acumulam maior quantidade de biofilme quando comparadas às ligaduras metálicas ou aos bráquetes auto-ligados. No entanto, conforme Brêtas et al. (2005) e Condò et al. (2012), não houve diferença nas unidades formadoras de colônia (ufc) de $S$. mutans na saliva e no biofilme em pacientes portadores de bráquetes com ligaduras elastoméricas quando comparados àqueles com amarrilhos metálicos

O termo elastômero (no presente estudo, ligadura elastomérica) se refere, de uma forma geral, a materiais que retornam a sua configuração inicial após sofrerem uma deformação (Baty et al., 1994). O primeiro material elástico conhecido foi provavelmente a borracha natural obtida da árvore Hevea brasilienses. No entanto, a utilização dessas borrachas era limitada por serem muito sensíveis à absorção de água e instabilidade térmica. Com o advento da vulcanização por Charles Goodyear em 1839, as propriedades físicas do 
material foram melhoradas e suas possibilidades de uso aumentaram consideravelmente (Martins et al., 2008).

$\mathrm{Na}$ década de 1920 foram desenvolvidos os elásticos sintéticos que apresentavam propriedades físicas melhores, além de maior vida útil. Especificamente na Ortodontia, há relatos do uso de elásticos em 1893 por Calvin Case. Outro estudo foi publicado por Bertran em 1931 que empregou elásticos para produzir forças intermaxilares (Henriques et al., 2003). Elásticos sintéticos em corrente foram introduzidos na Ortodontia na década de 1960 e se tornaram acessórios de uso frequente na prática clínica, sendo empregados em retrações dentárias, correção de giroversões, fechamento de espaços entre outros (Baty et al., 1994).

Ambos os elásticos, naturais ou de borracha e sintéticos, são empregados na Ortodontia. Os elásticos naturais ou à base de látex são comumente usados em conjunto com aparelhos exta-orais ou como elásticos intermaxilares. Os elásticos sintéticos, por sua vez, são empregados para fixação dos arcos (ligaduras), módulos em cadeia, elásticos de separação dentária entre outros (Henriques et al., 2003 e Eliades et al., 2005).

Em relação aos elásticos sintéticos, entre os quais estão as ligaduras elastoméricas que são o objeto desse estudo, são considerados polímeros feitos de material poliuretano (cadeia de unidades orgânicas unidas por ligações uretânicas) obtidos através de transformações químicas do carvão, do petróleo e de alguns álcoois vegetais. Possuem fraca atração molecular formando um padrão geométrico de cadeias lineares dobradas em forma de espiral. Quando distendidas, essas cadeias poliméricas desdobram-se em uma estrutura linear ordenada com ligações cruzadas (Fernandes, 2012). O elastômero ideal seria aquele que após ser distendido aquém do seu limite elástico, retornaria a sua exata configuração inicial, todavia, isso não é possível pois as cadeias poliméricas distendidas deslizam de modo irreversível umas sobre as outras e obtém-se um novo arranjo espacial (Martins et al., 2008).

Apesar das melhorias nas propriedades dos elastômeros sintéticos o que lhes confere características tais como a praticidade e facilidade no manuseio, conforto, variedade de usos e cores, são relatadas algumas importantes desvantagens especialmente no que diz respeito ao acúmulo de biofilme, rápido decréscimo na elasticidade, pigmentação, alteração de cor e aumento do atrito (Masoud et al., 2016). Na verdade, a exposição desses materiais à luz solar, luz ultravioleta e especialmente às condições do meio bucal gera radicais livres que causam oxidação em sua superfície (Wong, 1976). Além disso, quando expostos à umidade, ocorre enfraquecimento das forças intermoleculares (Van der Waals, dipolo-dipolo ou pontes de hidrogênio) e consequente degradação química dessas ligações (Fernandes, 2012). 
A capacidade de aderir moléculas em sua superfície sólida quando em contato com um fluido é chamada de adsorção. Assim, no ambiente bucal, submetido a umidade, grandes variações de temperatura, atrito, variações de $\mathrm{pH}$ (especialmente $\mathrm{pH}$ baixos) além da presença de uma microflora complexa, a deterioração é ainda maior resultando em aumento de volume, mudança na coloração e uma deformação permanente e gradual ao longo do tempo (Fernandes, 2012).

A partir desse conhecimento, torna-se interessante e importante o estudo do comportamento dos elastômeros ou ligaduras ortodônticas, no presente estudo: as ligaduras estéticas. É relevante salientar que uma das principais motivações pela procura do tratamento ortodôntico, em especial pelos adultos, é a estética do aparelho a ser usado durante o tratamento, bem como o tempo de duração. Esses fatores estão diretamente relacionados à performance clínica das ligaduras (Capelli, Jr et al., 2014).

$\mathrm{Na}$ Odontologia, a cor tem grande relevância, uma vez que os dente e os materiais dentários estão expostos, diariamente, a uma grande variedade de substâncias e condições locais (Joiner, 2004). Muito se estuda sobre a estabilidade de cor do esmalte dentário, dos materiais restauradores e protéticos (especialmente nos casos de clareamento), porém a literatura é escassa quando se refere às ligaduras ortodônticas, notadamente estudos in vivo (Oliveira et al., 2015).

As cores são formadas basicamente por 3 componentes: o brilho que indica a quantidade de luz varia de 0 (totalmente escuro) até 100 (totalmente branco), saturação ou croma relacionados à pureza e o matiz caracterizado pelos diferentes comprimentos de onda que podem variar de 0 a $360^{\circ}$. Assim, 0 a $90^{\circ}$ representam o vermelho, laranja e o amarelo, $90^{\circ}$ a $180^{\circ}$ representam o amarelo, amarelo esverdeado e verde e $180^{\circ}$ a $270^{\circ}$ representam verde, ciano e azul, por fim, $270^{\circ}$ a $360^{\circ}$ representam azul roxo e magenta (Moreira, 2011).

A fim de definir um sistema de leitura e medição de cores compatível com o olho humano, a Commission Internationale L' Eclairage (CIE) elaborou o diagrama que pode ser visto na Figura 1. De acordo com esse sistema, $\mathrm{L}^{*}$ representa o eixo da claridade (pretobranco), $a^{*}$ representa o eixo verde-vermelho, $b^{*}$ determina o eixo azul-amarelo. Isso torna possível, através de uma fórmula especifica $\left(\Delta \mathrm{E}=\sqrt{ }\left(\Delta \mathrm{L}^{*}\right)^{2}+\left(\Delta \mathrm{a}^{*}\right)^{2}+\left(\Delta \mathrm{b}^{*}\right)^{2)}\right)^{2}$, o cálculo total da alteração de cor $(\Delta \mathrm{E})$, sendo denominado sistema CIE L* a* $\mathrm{b}^{*}$ (Moreira, 2011 e Knösel et al., 2012). 


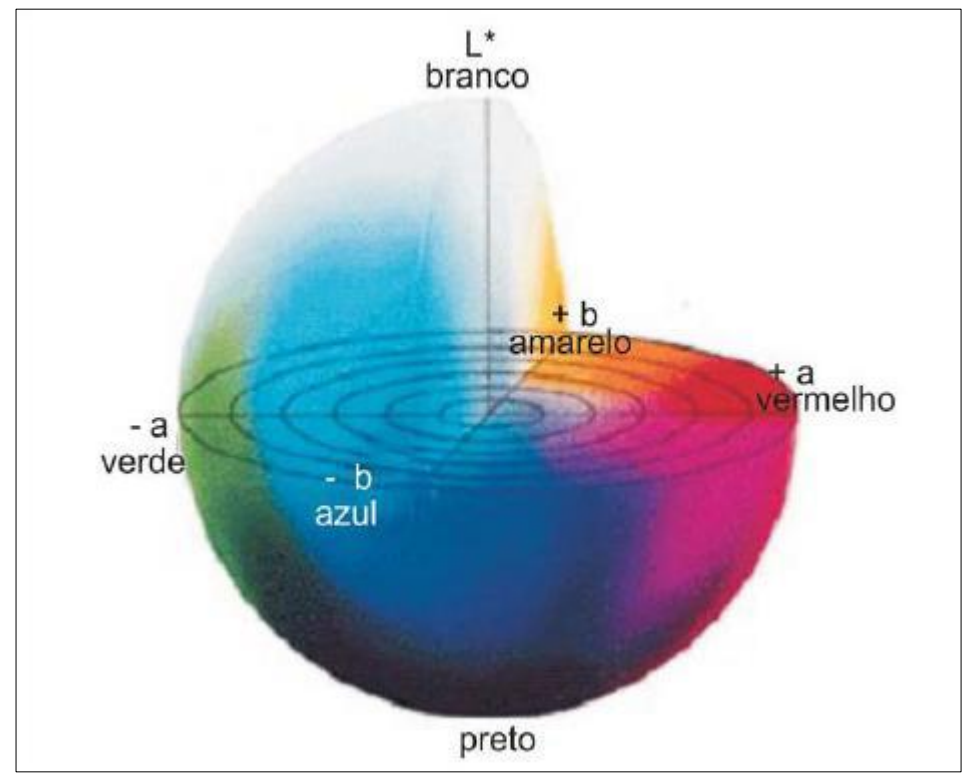

Figura 1- Ilustração do sistema de cores da Commission Internationale L'Eclairage. (Moreira, 2011).

Há vários métodos para a detecção, leitura e quantificação das alterações de cor do esmalte e dos materiais dentários. Podem ser usadas fotografias digitais anexadas a programas computadorizados específicos, colorímetros, avaliação visual associada a uma escala por examinadores calibrados e a espectrofotometria. Este último método é largamente utilizado devido a sua praticidade, confiabilidade e acurácia (Marson et al., 2008 e Kim e Lee, 2009).

Uma vez expostas ao meio bucal, as ligaduras ortodônticas sofrem influência direta dos mais variados fatores tais como: dieta, uso de enxagüatórios e dentifrícios, escovação, atrito, variações de temperatura e pH, ação da saliva e seus componentes, acúmulo de biofilme, tabagismo e até mesmo uso de cosméticos como batom e produtos para os lábios que podem promover a degradação química e física das mesmas (Talic e Almudhi, 2016).

Já no início da década de 1990, Lew (1990) relatou que um dos principais problemas enfrentados pelos pacientes que utilizam aparelhos ortodônticos estéticos refere-se à pigmentação das ligaduras usadas. Essa situação está diretamente relacionada aos hábitos alimentares. Esse autor estudou, in vivo, a alteração de cor de ligaduras estéticas após o uso de vários tipos de alimentos e concluiu que tanto bráquetes plásticos (policarbonato) quanto as ligaduras sofreram manchamento significativo após 72 horas.

Da mesma forma, Ardeshna e Vaidyanathan (2009) avaliaram in vitro, a estabilidade de cor de ligaduras incolores e coloridas de quatro marcas importantes no mercado americano (American Orthodontics, Ormco, TP e 3M Unitek) expostas a quatro tipos de alimentos: café, refrigerante à base de cola, chá preto e condimentos. As ligaduras permaneceram imersas por 
72 horas e foram afetadas com maior intensidade por chá e café, sendo que as ligaduras da companhia Ormco tiveram o pior desempenho enquanto as da marca American Orthodontics foram melhor avaliadas.

Na mesma linha de raciocínio, Soldati et al. (2013), avaliaram, in vitro, 4 marcas comerciais (incluindo duas marcas nacionais) expostas ao vinho tinto por 1 hora em intervalos de 7, 14, 21 e 28 dias. Todas as marcas comerciais sofreram pigmentação progressiva com o passar do tempo. As marcas Morelli e GAC mostraram os piores resultados enquanto as marcas 3M Unitek e American Orthodontics tiveram o melhor desempenho.

Recentemente, Talic e Almudhi (2016), avaliaram, in vitro, a resistência ao manchamento de 3 marcas comerciais usadas mundialmente (3M Unitek, Ormco e Dentaurum) frente a produtos consumidos com frequência na dieta moderna: café, chá preto, chocolate, bebida energética, ketchup e Coca-Cola. O café e o chá mostram os maiores potenciais para pigmentação e a marca 3M Unitek foi que mostrou pior resultado.

Outros autores se preocuparam em estudar a atratividade do sorriso influenciada pela pigmentação das ligaduras durante o tratamento ortodôntico. Assim, Ferraz et al. (2012), avaliaram esse aspecto através de fotografias clínicas. Fotos padronizadas faciais do sorriso e do sorriso aproximado de um paciente portando bráquetes de porcelana monocristalina e ligaduras estéticas de 5 marcas comerciais diferentes foram mostradas a ortodontistas e estudantes de Odontologia. Foram utilizadas ligaduras novas e ligaduras após pigmentação in vitro. Os melhores resultados foram encontrados para a marca American Orthodontics. Para os dois grupos avaliadores, a pigmentação das ligaduras influenciou negativamente no que consideraram um sorriso agradável, mesmo antes da finalização do tratamento propriamente dito.

A experiência clínica mostrou que o uso de um dentifrício indicado para clareamento dentário, pode, em muitos casos, manter a estabilidade de cor das ligaduras ortodônticas estéticas por mais tempo entre as consultas (figuras 2, 3 e 4). No entanto, essa era uma observação empírica sem nenhum embasamento científico. Em 2013, Pithon et al. estudaram, in vitro, o efeito de enxagüatórios com agentes clareadores sobre correntes elastoméricas sem encontrar influência na degradação de força. 


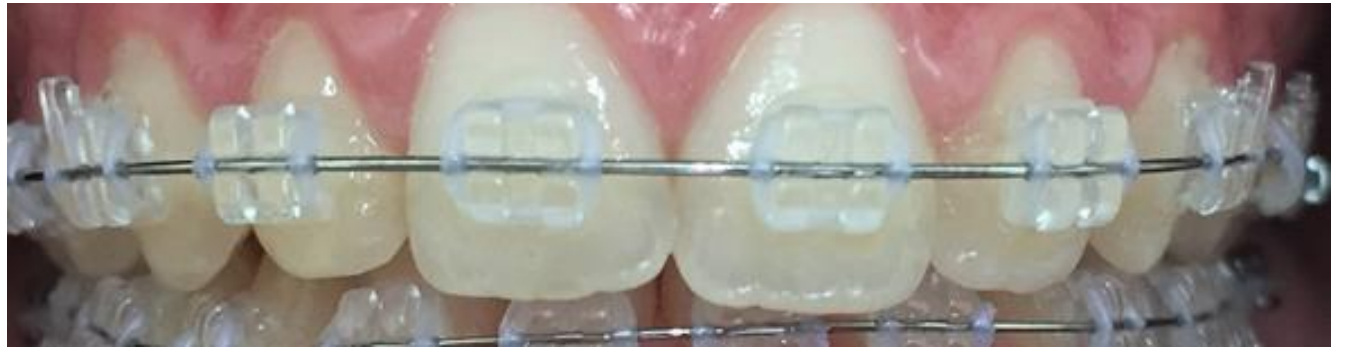

Figura 2 - Aspecto clínico do aparelho ortodôntico e ligaduras estéticas novas.

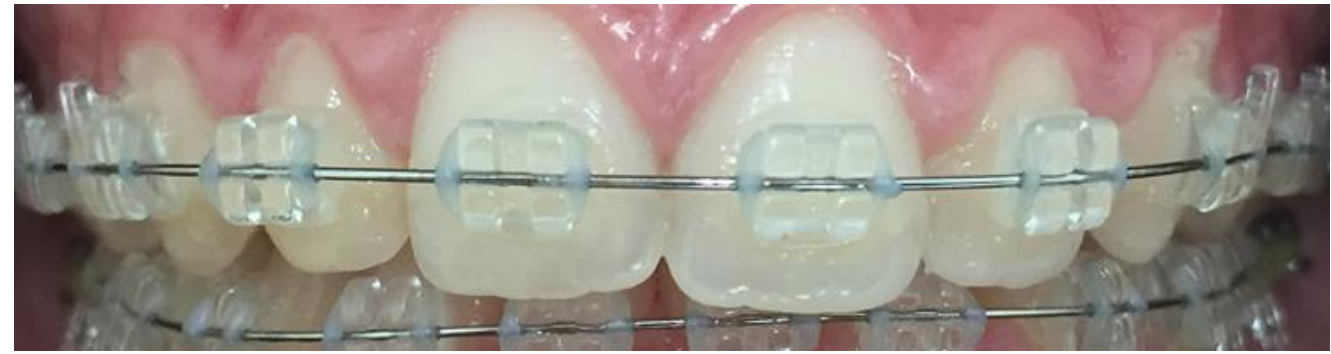

Figura 3 - Aspecto clínico do aparelho ortodôntico e ligaduras estéticas após 30 dias com uso dentifrício clareador.

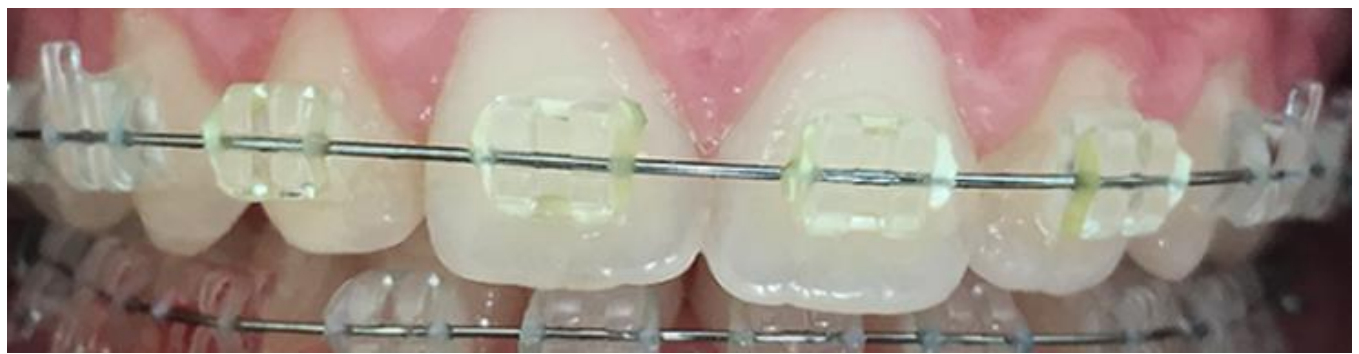

Figura 4 - Aspecto clínico do aparelho e ligaduras estéticas após 30 dias com uso de dentifrício convencional.

Em 2015, Oliveira et al. estudaram, pela primeira vez, in vitro, a influência do uso de uma dentifrício clareador na estabilidade de cor de ligaduras estéticas de duas marcas comerciais (uma importada, outra nacional). Nesse trabalho, as ligaduras das marcas Morelli e 3M Unitek foram expostas a vinho tinto por 1 hora, e avaliadas nos intervalos de 7, 14, 21 e 28 dias. Essas ligaduras foram posicionadas em bráquetes instalados em um artefato padronizado e escovadas manualmente (por um único operador), por um minuto, com dentifrício convencional e com dentifrício clareador contendo um pigmento azul. Os resultados mostraram que as ligaduras submetidas ao uso de dentifrício clareador não apresentaram maior estabilidade de cor, todavia o dentifrício clareador inibiu a coloração amarelada e melhorou a tonalidade azulada, o que, na opinião dos autores, foi clinicamente relevante, uma vez que a tonalidade azulada é bem aceita pelos pacientes e a perda estética menos severa. 
De acordo com Lopes Filho et al. (2012) e Talic e Almundhi (2016) o manchamento ou pigmentação das ligaduras constitui um problema clínico, já que, atualmente, os bráquetes e acessórios cerâmicos (mono ou poli cristalinos) possuem estabilidade dimensional e de cor ao contrário das ligaduras. Isso pode aumentar o número de visitas dos pacientes para trocas bem como o tempo de cadeira.

Além da questão da cor, as ligaduras elastoméricas ortodônticas também são afetadas pela intensidade e duração da força de distensão às quais são submetidas. Como componente básico do sistema de movimentação dentária induzida, a ligadura deve manter o fio ou arco ortodôntico inserido no slot ou canaleta do bráquete (Burstone et al., 2003).

De acordo com Taloumis et al. (1997) as ligaduras ortodônticas são manufaturadas de duas formas: pela injeção do material liquefeito em um molde ou pelo corte das unidades individuais feito em um tubo já processado. Sua composição exata é segredo comercial. A força exercida pela ligadura, depende da magnitude da força inicial aplicada, da duração dessa força e do enfraquecimento da ligadura. Esses autores avaliaram a diminuição da força, a deformação permanente, a dimensão da ligadura e a força por ela exercida. Foram estudadas 7 marcas comerciais tanto na temperatura e umidade ambiente quanto em um ambiente que simulava as condições intra-bucais. Todas as marcas foram afetadas pelo ambiente e pela temperatura e exibiram rápida perda da força inicial (até $60 \%$ nas primeiras 24 horas), além disso, sofreram deformação permanente após serem distendidas.

O estudo de Souza et al. (2008) avaliou, também in vitro, a marca mais comercializada no mercado nacional (Morelli), em relação ao percentual de degradação de forças. As ligaduras foram armazenadas em saliva artificial a $37^{\circ} \mathrm{C}$ e as medições foram feitas nos tempos de zero hora, 24 horas, 1 semana, 2 semanas, 3 semanas e 4 semanas em máquina universal de ensaios de tração. Do mesmo modo, o percentual de degradação de forças aumentou de forma acentuada nas primeiras 24 horas e depois gradualmente até o $28^{\circ}$ dia quando houve a perda completa da propriedade elástica.

Ahrari et al. (2010) enfatizaram que existem diferenças significativas das propriedades elásticas quando se considera diferentes marcas comerciais. Assim, é importante que o clínico considere essa informação na escolha dos produtos com os quais irá trabalhar no dia-a-dia

A degradação das ligaduras no ambiente bucal implica na necessidade de substituição periódica para manutenção da força adequada durante o tratamento ortodôntico. Guimarães et al. (2013), conduziram um estudo clínico prospectivo randomizado no qual estudaram (no intervalo de uma a 4 semanas) a degradação de ligaduras envelhecidas no 
ambiente bucal. Esses autores empregaram ensaio de tração e microscopia eletrônica de varredura (MEV). O grupo controle foi formado por ligaduras que não foram expostas ao meio bucal. Como em outros estudos, a força máxima de estiramento decresceu com o passar do tempo. A MEV evidenciou que, já na primeira semana, houve aumento na rugosidade superficial. Posteriormente, a superfície tornou-se gradativamente mais rugosa e após 4 semanas, estava completamente degradada com áreas de fraturas.

Conforme Masoud et al. (2016) o papel primário da ligadura ortodôntica é manter o fio atado aos bráquetes, porém fatores como alterações no $\mathrm{pH}$, temperatura e umidade podem prejudicar essa função. Estes autores compararam, após 8 semanas em saliva artificial, a degradação de força e as mudanças dimensionais em dois tipos de ligaduras: termoplásticas e um novo tipo chamado "thermoset". Os resultados mostraram a superioridade das ligaduras "thermoset" em relação às convencionais referente à menor perda das propriedades elásticas levando os autores a afirmarem que teriam maior indicação nas fases iniciais de alinhamento e nivelamento, bem como nos estágios finais do tratamento para uma melhor expressão dos torques.

Martínez-Colomer et al. (2016) avaliaram por meio da Microscopia Eletrônica de Varredura, entre outros, elásticos ortodônticos de látex e não-látex. O objetivo do trabalho foi avaliar a biocompatibilidade e a estrutura superficial. Ficou claro a presença de microesferas e porosidades na superfície dos elásticos especialmente naqueles à base de látex (em magnificações de 500 vezes). Essas irregularidades podem se tornar um importante nicho para o acúmulo de bactérias, vírus e fungos, bem como seus subprodutos.

De acordo com Roselino (2015), nos dentifrícios clareadores, os abrasivos são os principais responsáveis pela remoção do manchamento extrínseco. Atualmente, os abrasivos mais utilizados são a sílica hidratada, carbonato de cálcio, fosfato de cálcio e bicarbonato de sódio. Este autor avaliou a alteração de cor e a rugosidade do esmalte e de materiais restauradores após o uso dentifrício clareador. Foi encontrado que o uso desse dentifrício não promoveu maior estabilidade de cor no esmalte dentário nem nos compósitos restauradores estudados, bem como não promoveu aumento significativo na rugosidade dos substratos avaliados.

Ainda não há disponíveis na literatura, relatos sobre os efeitos que os dentifrícios clareadores exercem sobre as propriedades elásticas das ligaduras ortodônticas, bem como não existem evidências sobre possíveis danos a sua estrutura física e também não foram encontrados estudos que comprovem, in vivo, a estabilidade ou a alteração de cor frente ao uso desses dentifrícios. Diante do que foi exposto, justifica-se um aprofundamento no assunto, visto que a performance das ligaduras elastoméricas estéticas está diretamente inserida no contexto clínico do ortodontista. 
2. Proposição 


\section{PROPOSIÇÃO}

A proposta desse estudo foi comparar o desempenho de ligaduras ortodônticas estéticas de 4 marcas comerciais, após 30 dias na cavidade bucal, com o uso de dentifrício clareador (experimental) e convencional (controle) para avaliar:

1. A alteração de cor por meio da espectrofotometria.

2. A ultraestrutura da superfície por meio da microscopia eletrônica de varredura.

3. A propriedade elástica por meio do teste de tração.

A hipótese testada é que o uso do dentifrício clareador pode contribuir para maior estabilidade de cor das ligaduras estéticas sem deteriorar sua superfície e prejudicar significantemente sua propriedade elástica. 
3.Material e Métodos 


\section{MATERIAL E MÉTODOS}

Após a aprovação do Comitê de Ética em Pesquisa envolvendo seres humanos da Faculdade de Odontologia de Ribeirão Preto da Universidade de São Paulo (número CAAE: 56939916.0.0000.5419) foi obtido, impresso e assinado pelos pacientes e/ou responsáveis o Termo de Consentimento Livre e Esclarecido (Apêndice).

O cálculo amostral foi realizado pelo programa SPSS Sample Power (IBM Software - Statistical Package for the Social Science, Chicago, IL, EUA) que indicou que em uma amostra de 20 pacientes haveria $80 \%$ de probabilidade de ser evidenciado um efeito estatisticamente significativo. O cálculo foi baseado em cinco fatores: diferença das médias, dispersão dos escores, perda amostral, valor de alfa em 0,05 e considerando os dados que foram avaliados em uma análise bicaudal (Weyne, 2004).

Foram selecionados 20 pacientes com as seguintes características (critérios de inclusão):

- Idade entre 15 e 20 anos

- Ambos os gêneros

- Portadores de dentição permanente completa (exceto os terceiros molares)

- Portadores de boa saúde geral

- Sem restaurações metálicas

- Não faziam uso de nenhum enxagüatório bucal

- Não faziam uso de qualquer medicação sistêmica de uso contínuo

- Não estavam fazendo parte de nenhum outro estudo naquele momento

\subsection{Colagem dos bráquetes}

Para a colagem dos bráquetes ortodônticos foi realizada inicialmente a profilaxia com água e pedra-pomes de granulação fina sem flúor (SS White, Petrópolis, RJ, Brasil) com taça de borracha (KG Sorensen, Barueri, SP, Brasil) montada em contra-ângulo (Dabi Atlante, Ribeirão Preto, SP, Brasil) em baixa rotação. Posteriormente, os dentes foram lavados e secos por 10 segundos com jatos de ar comprimido livres de óleo e água. A seguir, foi feito o condicionamento do esmalte com ácido fosfórico a 37\% (Condac FGM, Joinville, SC, Brasil) por 20 segundos em cada dente. Foi, então, aplicada com aplicador descartável (Microbrush, Grafton, WI, EUA) uma fina camada do adesivo (Primer Transbond XT, Monrovia, CA, EUA). 
A seguir os bráquetes metálicos convencionais (Morelli, Sorocaba, SP, Brasil) foram colados em todos os dentes superiores e inferiores $1^{\circ}$ molar a $1^{\circ}$ molar seguindo a técnica Edgewise e utilizando compósito ortodôntico fotopolimerizável (Transbond XT, Monrovia, CA, EUA) de acordo com as instruções do fabricante. Para o correto posicionamento dos bráquetes foi utilizada pinça para colagem (Morelli, Sorocaba, SP Brasil) e a fotopolimerização do compósito foi realizada por 20 segundos (Ultralux Dabi Atlante, Ribeirão Preto, SP, Brasil) (figura 5).

Após a colagem, foi inserido um fio ortodôntico de níquel-titânio de 0.012" (GAC Dentsply, NY, EUA). No arco 0.018” de aço foram utilizadas para sua fixação, ligaduras de 4 marcas comerciais que são objeto deste estudo. Todas as ligaduras à base de poliuretano livres de látex e com aproximadamente o mesmo diâmetro ( $3 \mathrm{~mm}$ ou 0.115 ”) segundo os fabricantes e ilustradas na figura 6 sendo:

- Unistick Pearl - American Orthodontics (Sheboygan, WI, EUA)

- Power Sticks Pearl - Orthotechnology (Tampa, FL, EUA)

- Easy to tie Obscure - 3M Unitek (Monrovia, CA, EUA)

- Ligadura modular marfim código 60.06.120 (Morelli, Sorocaba, SP, Brasil)
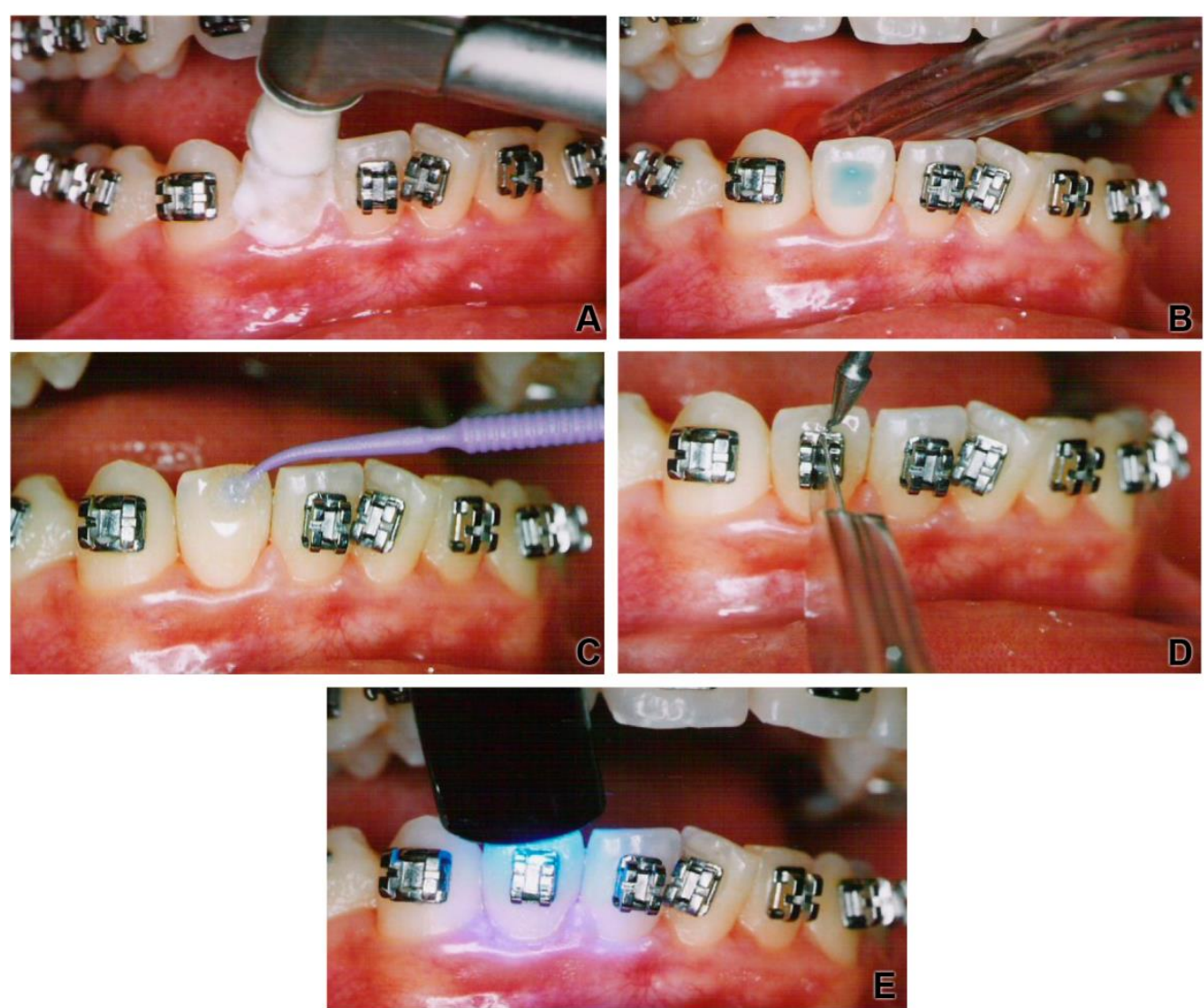

Figura 5 - Sequência clínica da colagem dos bráquetes: A: Profilaxia, B: condicionamento ácido do esmalte, C: aplicação do adesivo, D: posicionamento do bráquete, $\mathbf{E}$ : fotopolimerização. 

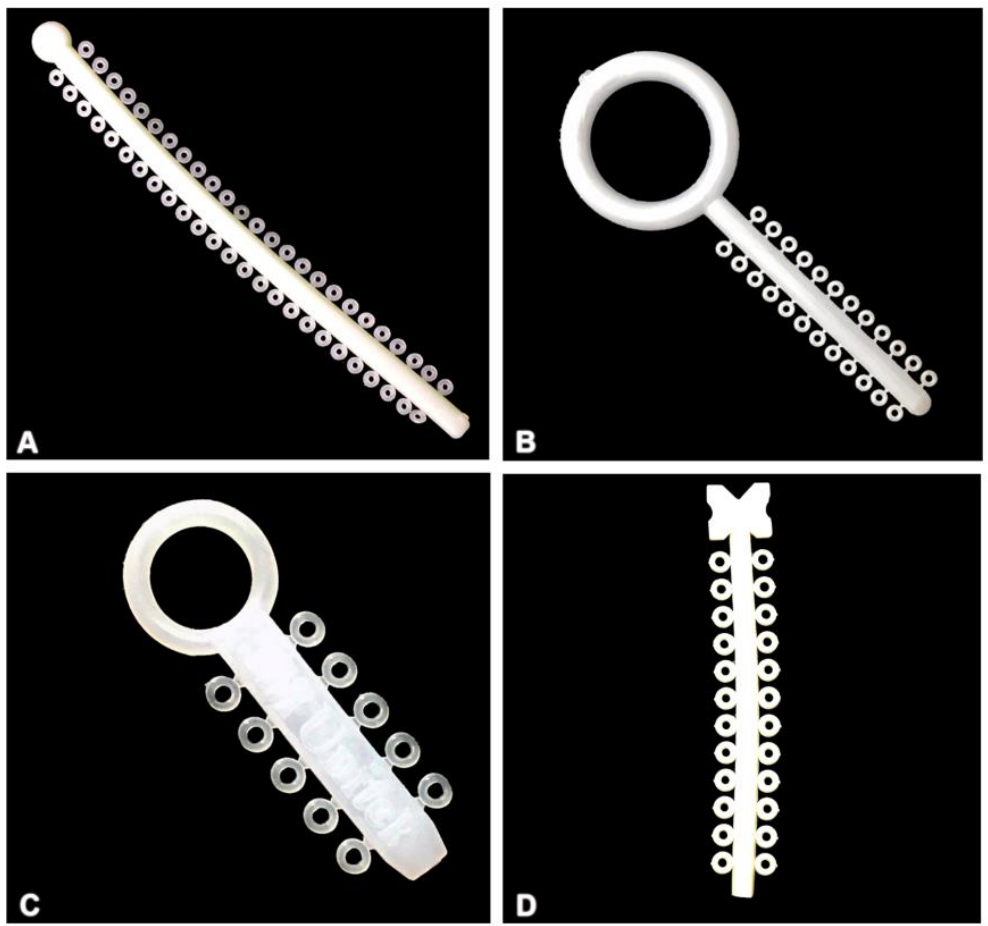

Figura 6 - Ligaduras utilizadas no estudo: A: ligadura Orthotechnology, B: ligadura American Orthodontics, C: ligadura 3M Unitek, D: ligadura Morelli.

As ligaduras das marcas citadas foram obtidas do mesmo lote, diretamente do fabricante e, até o início da fase experimental, foram estocadas em suas embalagens originais sob refrigeração e ao abrigo da luz. Para melhor padronização, foram escolhidas as tonalidades pérolas (pearl). Essa tonalidade difere da azul clara (light blue) e do transparente, também utilizadas com fins estéticos. No entanto, a tonalidade escolhida é a indicada pelos fabricantes para uso com bráquetes estéticos.

Cada paciente recebeu uma ligadura de marcas comerciais diferentes nos bráquetes dos caninos (elementos 13, 23, 33 e 43) e, da mesma forma, nos incisivos inferiores (elementos 32, 31, 41 e 42), conforme o esquema ilustrado na figura 7. As ligaduras foram colocadas de forma aleatória em sistema de rodízio seguindo o protocolo de forma cruzada para eliminar fatores de confusão. Este rodízio foi feito com o auxílio do programa SAS (Statistical Analysis System) for Windows, versão 9.1.3 (SAS Institute Inc., Cary, CA, EUA). Nos bráquetes dos demais dentes foram inseridas ligaduras Morelli para padronização e redução de custos. 


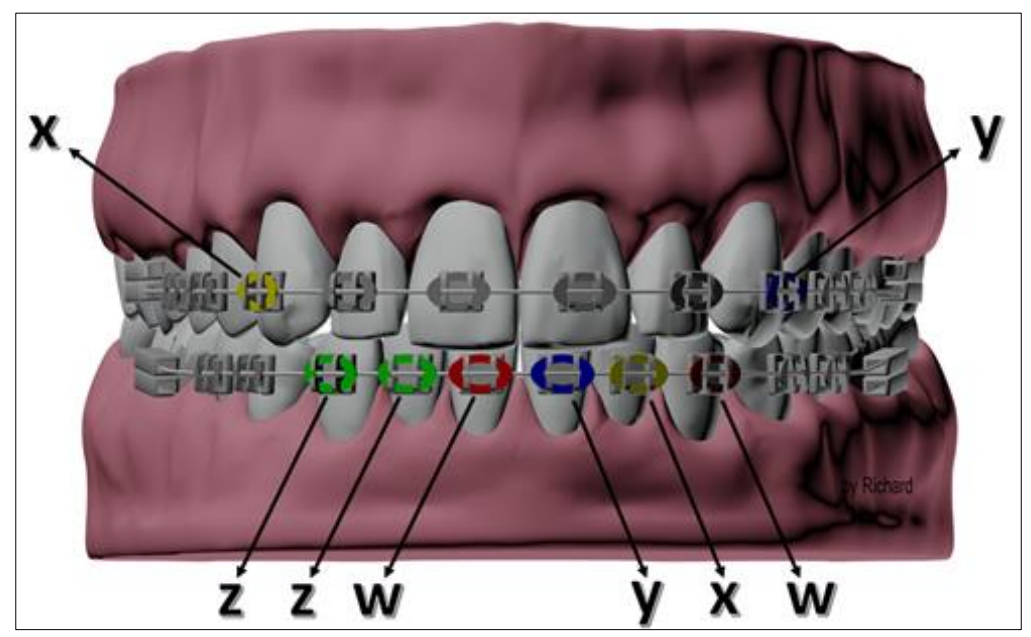

Figura 7 - Esquema do posicionamento das ligaduras (letras diferentes simbolizam marcas comerciais diferentes).

Com o objetivo de padronizar a colocação e distensão das ligaduras foi usado o acessório Shooter (TP Orthodontics, La Porte, IN, EUA) conforme as ilustrações da figura 8.

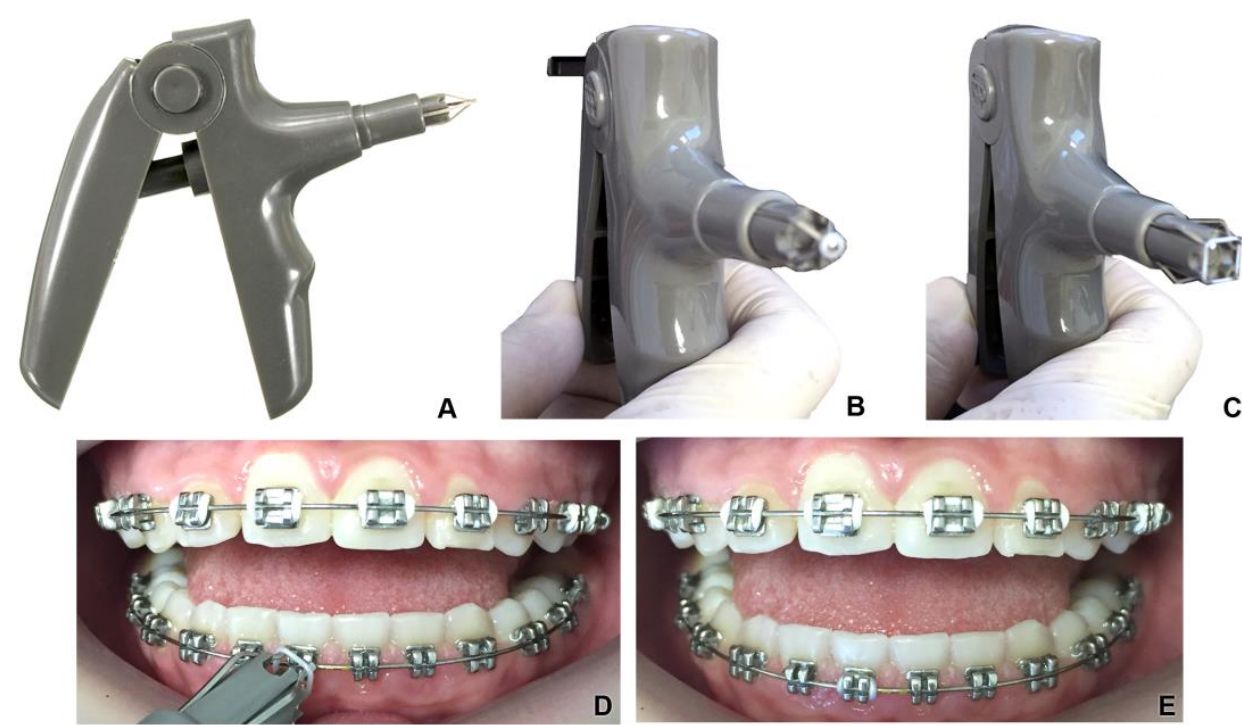

Figura 8 - A: Shooter, B: ligadura posicionada no Shooter, C: ligadura distendida, D: posicionamento da ligadura no bráquete, E: ligadura inserida no bráquete.

A seguir, os pacientes receberam instruções padronizadas de higiene bucal feitas por um único operador e receberam escovas dentais padronizadas (Twister ${ }^{\circledR}$ Colgate-Palmolive Indústria e Comércio, São Bernardo do Campo, SP, Brasil) (figura 9). 


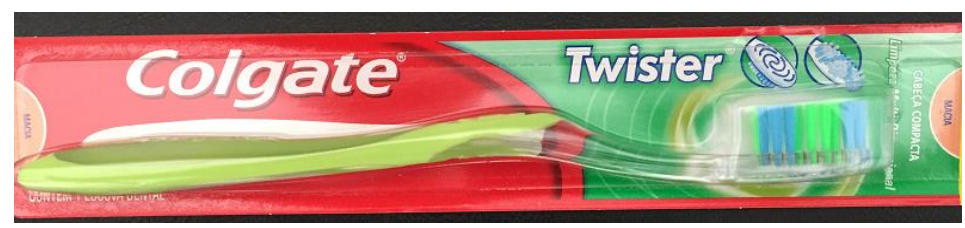

Figura 9- Escova dental usada pelos participantes.

Os pacientes receberam primeiramente o dentifrício clareador experimental Colgate Luminous White (Colgate-Palmolive Indústria e Comércio, São Bernardo do Campo, SP, Brasil) que foi usado por 30 dias. Após esse período, os pacientes retornaram e as ligaduras foram cuidadosamente removidas com instrumento próprio (código 375.01.002, Morelli, Sorocaba, SP, Brasil) (figura 10) lavadas em cuba ultrassônica (Odontobrás, Ribeirão Preto, SP, Brasil) por 1 minuto para remoção de resíduos e secas com papel absorvente (Yannikaki et al., 1998). Em seguida, seguindo o protocolo sugerido por Ahrari et al. (2010) e Oliveira et al. (2015) foram acondicionadas em frascos de vidro da cor âmbar, contendo $3 \mathrm{ml}$ de saliva artificial, pH 6,6 e mantidos ao abrigo da luz sob refrigeração por 24 horas, quando então foram submetidas aos ensaios de leitura de cor e tração elástica. Todos os frascos foram devidamente fechados e identificados com etiquetas adesivas que informavam o número do paciente, o dente em que estava a ligadura e sua marca comercial, além do dentifrício utilizado (figura11).

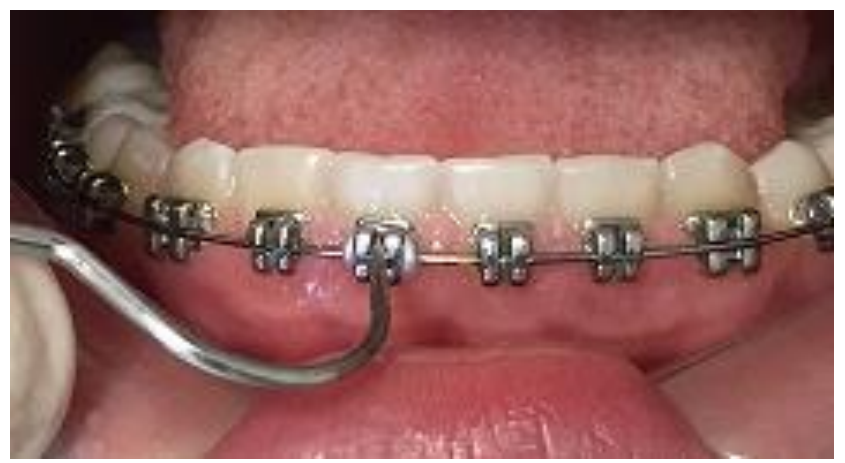

Figura 10 - Remoção da ligadura.

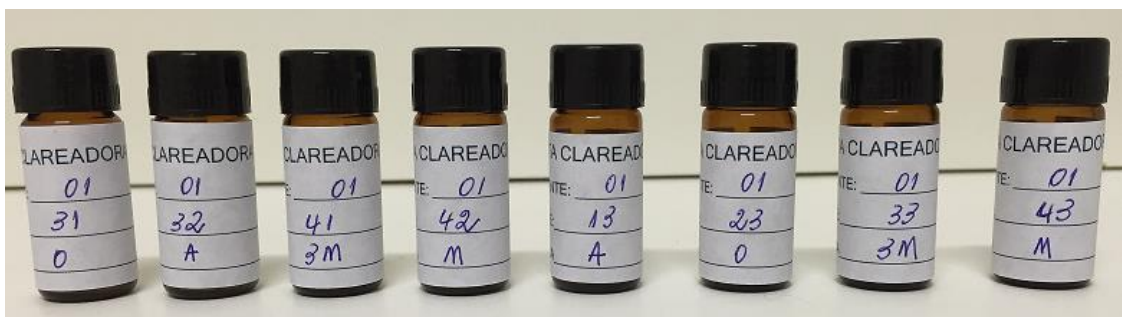

Figura 11- Frascos identificados. 
A identificação de cada ligadura, dos dentes correspondentes e do paciente foi devidamente anotada em formulário próprio (Apêndice) antes de serem inseridas nos bráquetes, removidas e analisadas. No mesmo dia em que as ligaduras submetidas ao dentifrício clareador foram removidas, os pacientes receberam novas ligaduras seguindo o mesmo rodízio e protocolo anterior.

Nesta nova etapa, as escovas foram recolhidas e os pacientes receberam novas escovas dentais iguais às primeiras, as mesmas instruções de higiene bucal e, desta vez, dentifrício convencional controle Colgate Máxima Proteção Anti-cáries (Colgate-Palmolive Indústria e Comércio, São Bernardo do Campo, SP, Brasil) que também foi utilizado por 30 dias. Decorrido esse período, as ligaduras foram removidas, estocadas e levadas aos ensaios seguindo exatamente o mesmo protocolo da etapa anterior. Em ambas as etapas, os pacientes usaram exclusivamente as pastas dentais e escovas fornecidas e foram orientados a não usar nenhum enxagüante bucal.

A seguir, a descrição das pastas utilizadas nesse estudo, bem como sua composição (Tabela 1).

Tabela 1- Dentifrícios utilizados no estudo e sua composição.

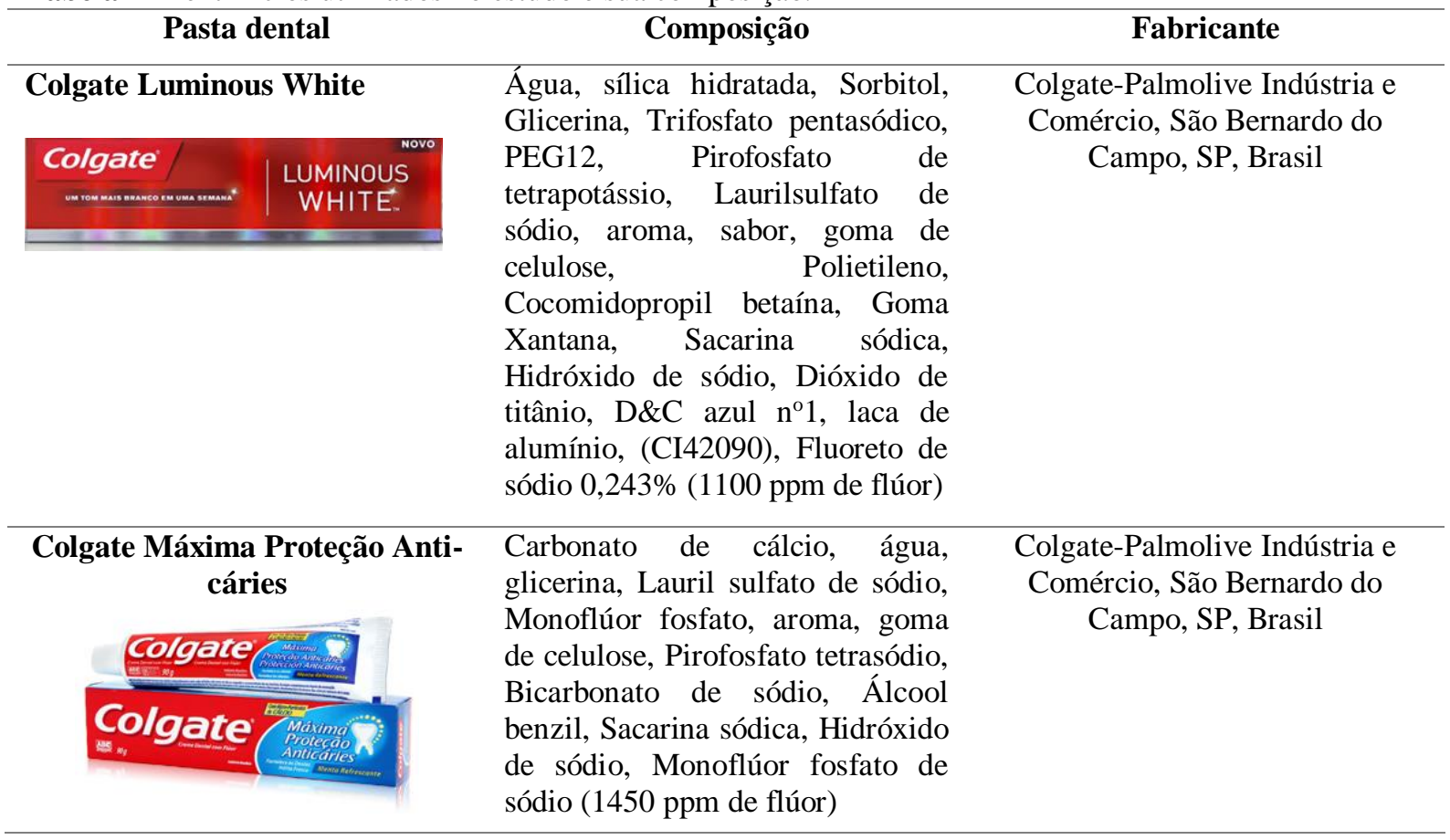




\subsection{Avaliação da alteração de cor}

Vinte e quatro horas após a remoção, em ambas as etapas, as ligaduras foram levadas ao Laboratório Heitor Panzeri do Departamento de Materiais Dentários e Prótese da Faculdade de Odontologia de Ribeirão Preto - USP. Todas as leituras foram feitas no mesmo ambiente, sob a mesma iluminação e temperatura e pelo mesmo operador, previamente calibrado. Individualmente, após a remoção dos recipientes onde estavam armazenadas, as ligaduras foram secas em papel absorvente branco e imediatamente submetidas ao teste.

Para a leitura das medidas relacionadas à cor, foi utilizado um espectrofotômetro digital portátil calibrado conforme as instruções do fabricante (Vita Easyshade Zahnfabrik, Bad Säckingen, Alemanha). A mensuração quantitativa deste aparelho é compatível com a escala Vita clássica (Vita, Zahnfabrik, Alemanha). As leituras foram realizadas sobre um fundo padrão branco para prevenir qualquer interferência na leitura de cor (Leibrock et al., 1997). Para padronizar o posicionamento da ligadura e da ponteira do equipamento, foi confeccionada uma matriz em resina acrílica transparente, na qual havia um encaixe central para acomodação da ligadura e um guia para a acoplagem da ponteira de leitura.

As ligaduras foram posicionadas na matriz acrílica com o auxílio de sonda periodontal (Trinity Odontologia, São Paulo, SP, Brasil) e, com o auxílio da matriz, o espectrofotômetro ficava sempre em uma posição padronizada perpendicular à ligadura executando a leitura na mesma posição. Essa sequência de procedimentos está ilustrada na figura 12 . 


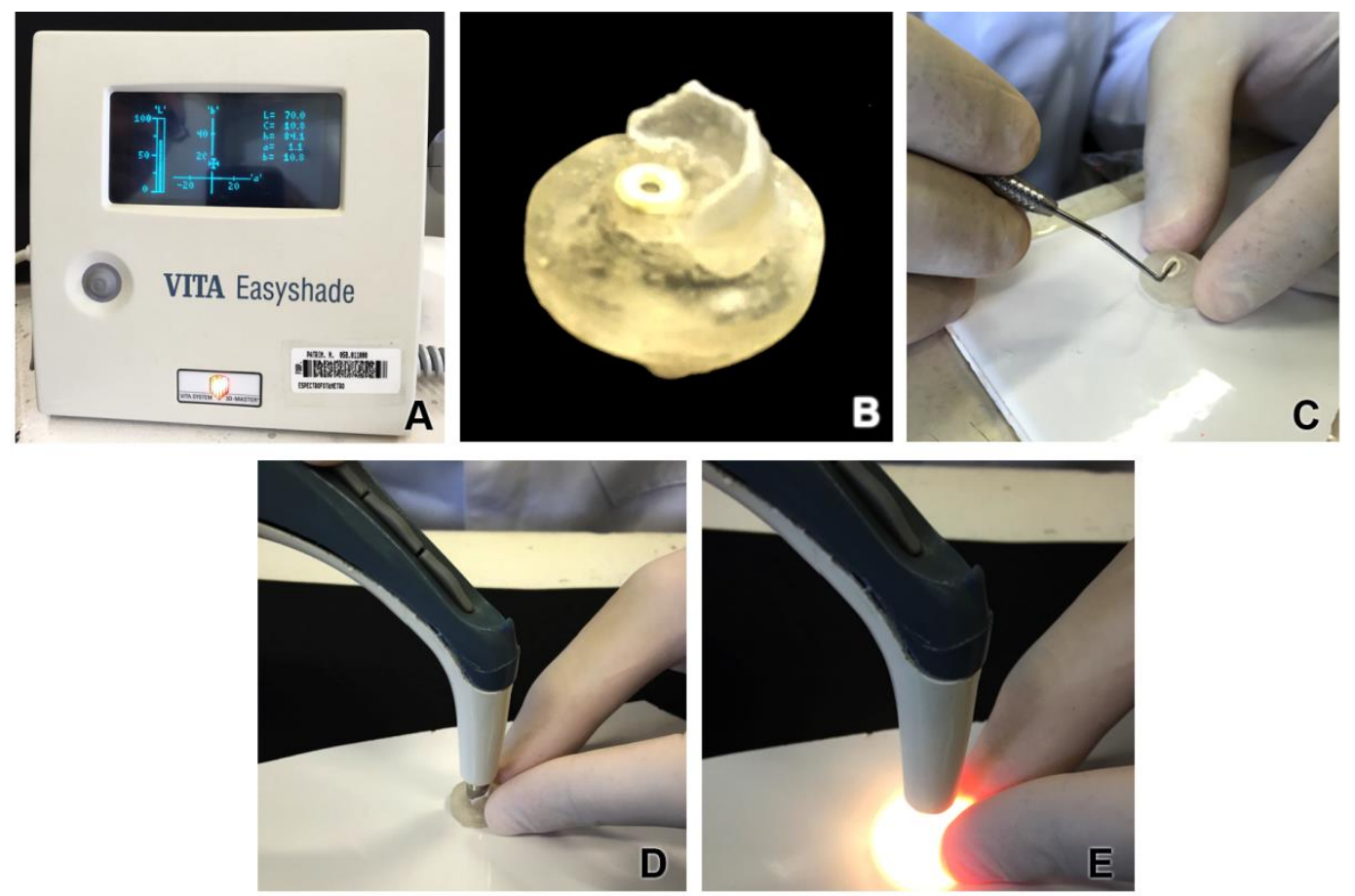

Figura 12 - A: Espectrofotômetro, B: matriz acrílica, C: ligadura posicionada na matriz acrílica, D: ponteira do espectrofotômetro posicionada na matriz, E: espectrofotômetro acionado.

Ligaduras novas, das 4 marcas estudadas, removidas diretamente das embalagens foram avaliadas quanto à leitura de cor, sendo essas consideradas como parâmetro inicial (baseline). As demais ligaduras avaliadas nesse ensaio foram aquelas que estavam inseridas nos elementos 13, 23, 33 e 43, num total de 80 ligaduras, ou seja, 4 ligaduras por paciente na amostra de 20 pacientes. Estes dentes foram escolhidos por se encontrarem em uma região média dos arcos, nem muito posteriormente onde poderiam sofrer menor efeito da luminosidade ambiente e dos fatores que potencialmente poderiam alterar a coloração e, da mesma forma, não estavam posicionados na região anterior onde poderiam estar submetidas mais fortemente aos mesmos fatores.

As ligaduras foram separadas em grupos de modo que o avaliador não estava ciente da marca comercial que estava sendo submetida à leitura. Para cada ligadura foram feitas 3 medidas de cada um dos parâmetros $\mathrm{L}^{*}, \mathrm{a}^{*} \mathrm{e} \mathrm{b}^{*} \mathrm{e}$ anotadas em formulário próprio (Apêndice) por um auxiliar.

As alterações de cor foram caracterizadas examinando as coordenadas $\mathrm{L}^{*} \mathrm{a}^{*}$ e $\mathrm{b}^{*}$ preconizadas pela Commission Internationale L' Eclairage (Sistema CIE L*a*b*). A alteração de cor foi calculada utilizando a média das 3 medidas feitas para cada variável que foram lançadas na seguinte fórmula: 


$$
\Delta E=\sqrt{ }\left(\Delta L^{*}\right)^{2}+\left(\Delta a^{*}\right)^{2}+(\Delta b *)^{2}
$$

Onde:

$\Delta \mathrm{E}:$ alteração total de cor

$\Delta \mathrm{L}$ : diferença na luminosidade ( $\left.\mathrm{L}^{*}\right)$ (claro-escuro)

$\Delta \mathrm{a}$ : diferença no eixo a* (eixo verde-vermelho)

$\Delta \mathrm{b}$ : diferença no eixo $\mathrm{b}^{*}$ (eixo azul-amarelo)

A direção da diferença de cor foi descrita pelas magnitudes e sinais algébricos dos componentes $\Delta \mathrm{L}, \Delta \mathrm{a}$ e $\Delta \mathrm{b}$ :

$\Delta \mathrm{L}=\mathrm{L}_{\mathrm{f}}-\mathrm{L}_{\mathrm{i}}$

$\Delta \mathrm{a}=\mathrm{a}_{\mathrm{f}}-\mathrm{a}_{\mathrm{i}}$

$\Delta \mathrm{b}=\mathrm{b}_{\mathrm{f}}-\mathrm{b}_{\mathrm{i}}$

No qual $\mathrm{L}^{*}{ }_{\mathrm{i}}, \mathrm{a}^{*}{ }_{\mathrm{i}}$ e $\mathrm{b}^{*}{ }_{\mathrm{i}}$ são referidos como medição inicial da cor (baseline ou ligadura nova) e $\mathrm{L}^{*} \mathrm{f}, \mathrm{a}_{\mathrm{f}} \mathrm{e} \mathrm{b}_{\mathrm{f}}$ como medição final da cor.

Todos esses dados foram compilados em uma planilha especificamente criada para esse estudo (Excel Microsoft, Redmond, WA, EUA) (Apêndice).

Nesse estudo foram considerados os seguintes parâmetros:

$\Delta \mathrm{E}<1$ - Alteração de cor não detectada pelo olho humano.

$\Delta \mathrm{E} \leq 3,3$ - Alteração detectada pelo olho humano, porém considerada aceitável.

$\Delta \mathrm{E}>3,3$ - Alteração de cor detectada pelo olho humano (considerada clinicamente inaceitável, indicada a substituição do material restaurador por motivos estéticos).

$\mathrm{O}$ valor de $\Delta \mathrm{E}$ é calculado com base nos parâmetros $\mathrm{L}^{*} \mathrm{a}^{*} \mathrm{~b}^{*}$ onde $\Delta \mathrm{L}$ representa a mudança de luminosidade indo do mais claro $\left(+\mathrm{L}^{*}\right)$ a mais escuro $\left(-\mathrm{L}^{*}\right) ; \Delta \mathrm{a}$, representa uma mudança de tonalidade ao longo da escala vermelho $\left(+\mathrm{a}^{*}\right) /$ verde $\left(-\mathrm{a}^{*}\right)$ e $\Delta$ b uma mudança na tonalidade ao longo do amarelo (+b*) /azul (-b*) (Alandia-Román, 2011).

\subsection{Microscopia Eletrônica de Varredura (MEV)}

Nessa etapa foram avaliadas as ligaduras de cada marca comercial que sofreram maior e menor variação de cor, após a leitura pelo Easyshade subsequente ao uso dos dentifrícios clareador e convencional. Uma ligadura nova, sem uso, de cada marca também foi avaliada. Como o procedimento de leitura de cor não é destrutivo, a ligadura continuou viável 
para que seu aspecto ultra estrutural fosse observado. A visualização pela MEV foi realizada aproximadamente 7 dias após a remoção das ligaduras, tempo necessário para seleção, preparo e metalização.

Dessa forma, um total de 20 ligaduras foram submetidas ao processamento e avaliação pela Microscopia Eletrônica de Varredura (MEV), conforme a figura 13.
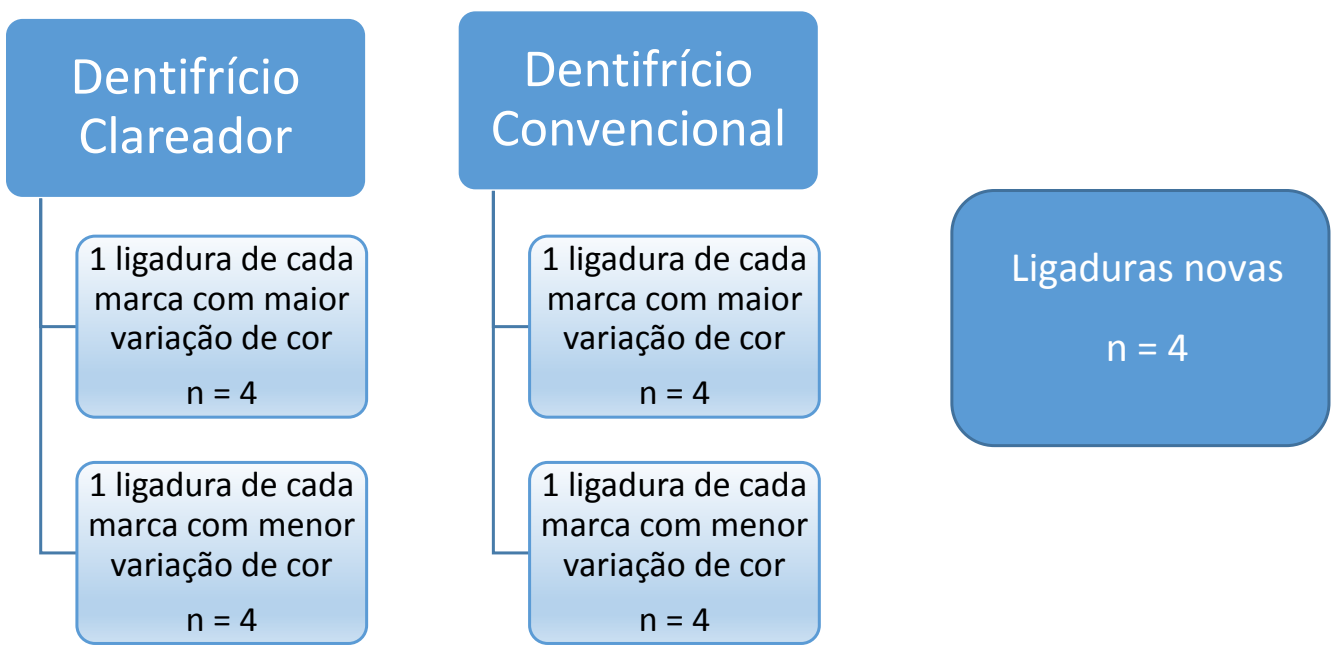

Figura 13 - Esquema com a distribuição da amostra das ligaduras avaliadas pela MEV.

Assim, a amostra foi levada ao Laboratório de Microscopia Eletrônica de Varredura e Microanálise Elementar do Departamento de Química da Faculdade de Filosofia Ciências e Letras da Universidade de São Paulo e processada seguindo a sequência proposta por Adriaens et al. (1985). Cada ligadura, foi cuidadosamente removida do recipiente de vidro âmbar onde estava armazenada com uma pinça apropriada (código 75.01.028, Morelli, Sorocaba, SP, Brasil) e colocada em recipientes de vidro esterilizados contendo $0,15 \mathrm{~g}$ de tripsina (tipo T7409 de 10g, Sigma-Aldrich, Saint Louis, MI, EUA), pesada em balança de alta precisão (Bioprecisa FA2104N, Curitiba, PR, Brasil) e diluída em 5,0 ml de água destilada obtendo-se uma concentração de $0,03 \mathrm{~g} / \mathrm{ml}$. Posteriormente as ligaduras foram lavadas em solução tampão de cacodilato $0,1 \mathrm{M}$ e colocadas em recipientes individualizados contendo solução de Karnovsky modificada (glutaraldeído a 8\%, paraformaldeído a 12\%, cacodilato de sódio $0,2 \mathrm{M}$, pH 7,2 - 7,4) para fixação por um período mínimo de 5 dias (Lessa et al., 2005 e Magno et al., 2008).

Após a fixação em glutaraldeído, as ligaduras foram lavadas em água destilada e colocadas em frascos contendo álcool em diferentes concentrações $(30 \%, 50 \%, 70 \%, 80 \%$, $90 \%$ e $100 \%$ ) sequencialmente por um período de 10 minutos em cada frasco. Foram, então, submetidas à secagem com $\mathrm{CO}_{2}$, no ponto crítico, no aparelho Baltec SCD50 (Fürstentun, 
Liechtenstein) e montadas em suportes metálicos (stubs) com adesivo de dupla face de carbono.

A seguir, as ligaduras foram submetidas ao processo de metalização em ouro sob vácuo (0,1 mbar) por um período de 120 segundos em aparelho Baltec SCD 50 (Fürstentun, Liechtenstein). A análise foi realizada em microscópio eletrônico (EVO 50, Carl Zeiss, Cambridge, Inglaterra) sob vácuo de 10 -15 torr e voltagem de aceleração do feixe de elétrons de $20 \mathrm{kV}$.

As magnificações utilizadas foram de 40,150, 500 e 2000 vezes. O objetivo dessa etapa foi fazer a avaliação topográfica da superfície das ligaduras para evidenciar a presença ou ausência de trincas, rachaduras, porosidades e falhas estruturais (Guimarães et al., 2013 e Fernandes et al., 2014). Procedimentos ilustrados na figura 14.
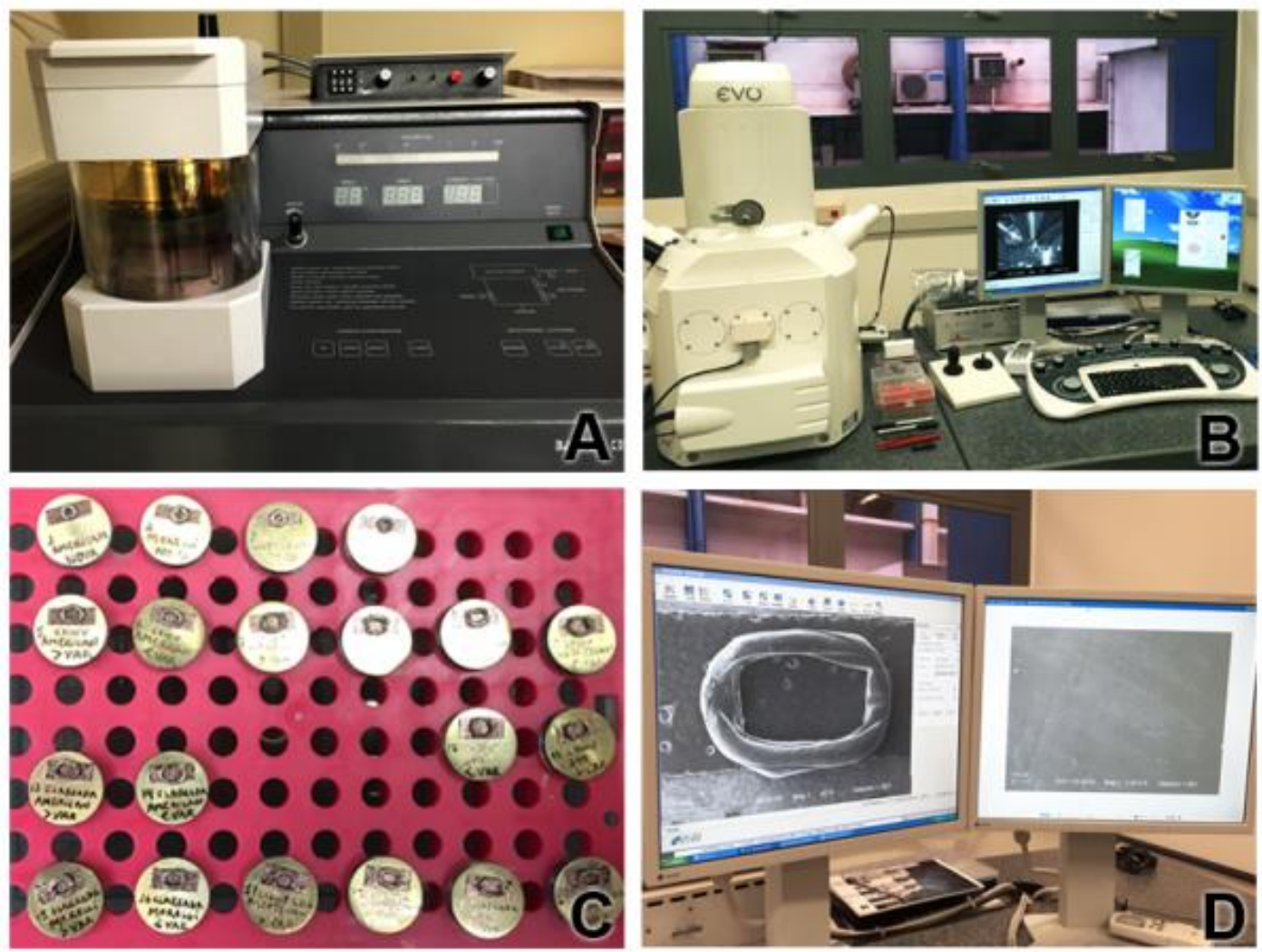

Figura 14 - A: equipamento de secagem e metalização Baltec SCD 50, B: microscópio eletrônico de varredura EVO 50, C: ligaduras metalizadas em ouro, D: visualização pela MEV em diferentes aumentos. 


\subsection{Avaliação da propriedade elástica}

Um ensaio de tração é aquele no qual um corpo de prova é submetido a um esforço que tende a alongá-lo na direção axial, normalmente até a ruptura, sendo, portanto, um teste destrutivo (Ahrari et al., 2010).

As ligaduras presentes nos incisivos inferiores $(31,32,41$ e 42$)$ e submetidas à ação do dentifrício clareador e convencional foram avaliadas neste ensaio, totalizando 80 ligaduras, ou seja, 4 por paciente na amostra de 20 pacientes. Os incisivos inferiores foram escolhidos pois neles são colados bráquetes que tem as mesmas dimensões. Desta forma, teoricamente, as ligaduras sofreram a mesma distensão inicial. Todas foram posicionadas com o acessório Shooter (TP Orthodontics, La Porte, IN, EUA) para padronizar a distensão. Ligaduras novas, removidas diretamente de suas embalagens originais também foram avaliadas.

Após 30 dias na cavidade bucal com uso de dentifrício clareador, as ligaduras dos incisivos foram cuidadosamente removidas com instrumento próprio (código 375.01.002, Morelli, Sorocaba, SP, Brasil) e armazenadas em frascos de cor âmbar contendo $3 \mathrm{ml}$ de saliva artificial, pH 6,6, sob refrigeração, ao abrigo da luz e devidamente identificados. Elas permaneceram guardadas por 48 horas quando foram então submetidas ao teste de tração elástica. O mesmo protocolo foi seguido para as ligaduras com o uso do dentifrício convencional.

O ensaio de tração foi realizado pela Máquina de Ensaio Mecânico Universal (EMIC DL 2000, São José dos Pinhais, PR, Brasil), conduzida por um único operador, em temperatura ambiente, no Núcleo Integrado de Pesquisa em Biomateriais do Departamento de Materiais Dentários e Prótese da Faculdade de Odontologia de Ribeirão Preto - USP.

As ligaduras foram removidas dos frascos, secas em papel absorvente branco, e cuidadosamente posicionadas em ganchos especiais seguindo o protocolo sugerido por Ahrari et al. 2010. Esses ganchos eram feitos de aço inoxidável e tinham a espessura e conformação tal para que não sofressem deformação durante o teste. As ligaduras foram distendidas a uma velocidade de $5 \mathrm{~mm} / \mathrm{min}$ até o limite de resistência, ou seja, até se romperem.

A máquina de ensaio universal foi conectada a um computador Itautec, processador Celeron R, CPU 2,53 GHz, 0,99 Ram (Itautec S/A, São Paulo, SP, Brasil). Os dados medidos foram:

- A força máxima de distensão em Newtons (N)

- A deformação em milímetros (mm) 
Os dados obtidos foram anotados numericamente e também representados na forma de gráficos no programa TESC versão 3.01 desenvolvido pelo próprio fabricante EMIC (São José dos Pinhais, PR, Brasil). Esta sequência de procedimentos está ilustrada na figura 15.
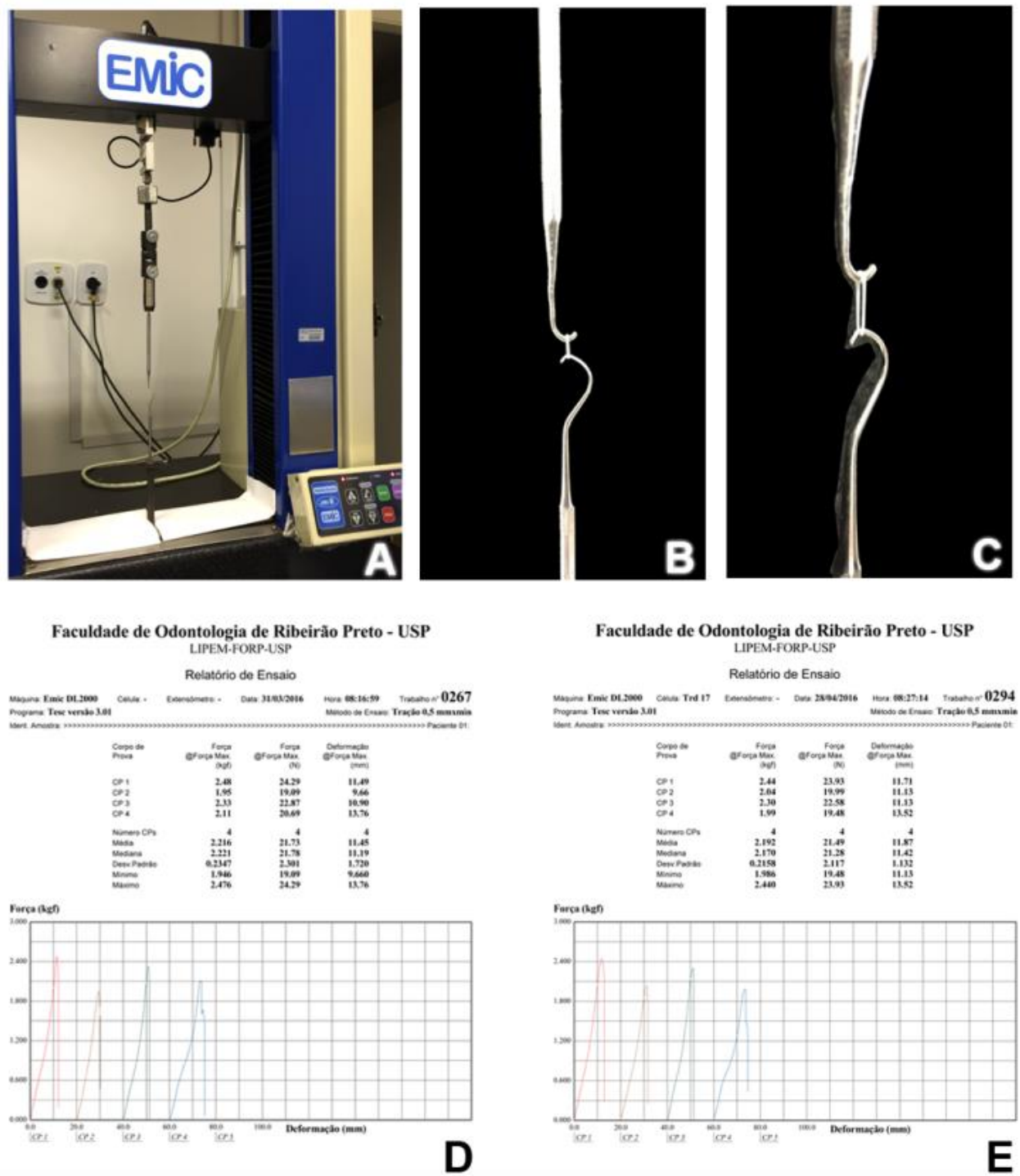

Figura 15- A: máquina de ensaio mecânico universal, B: ligadura posicionada nos ganchos, C: distensão da ligadura, D/E: exemplos de gráficos de leitura do teste de tração elástica. 
O fluxograma a seguir ilustra os principais procedimentos metodológicos desta etapa do estudo (figura 16).

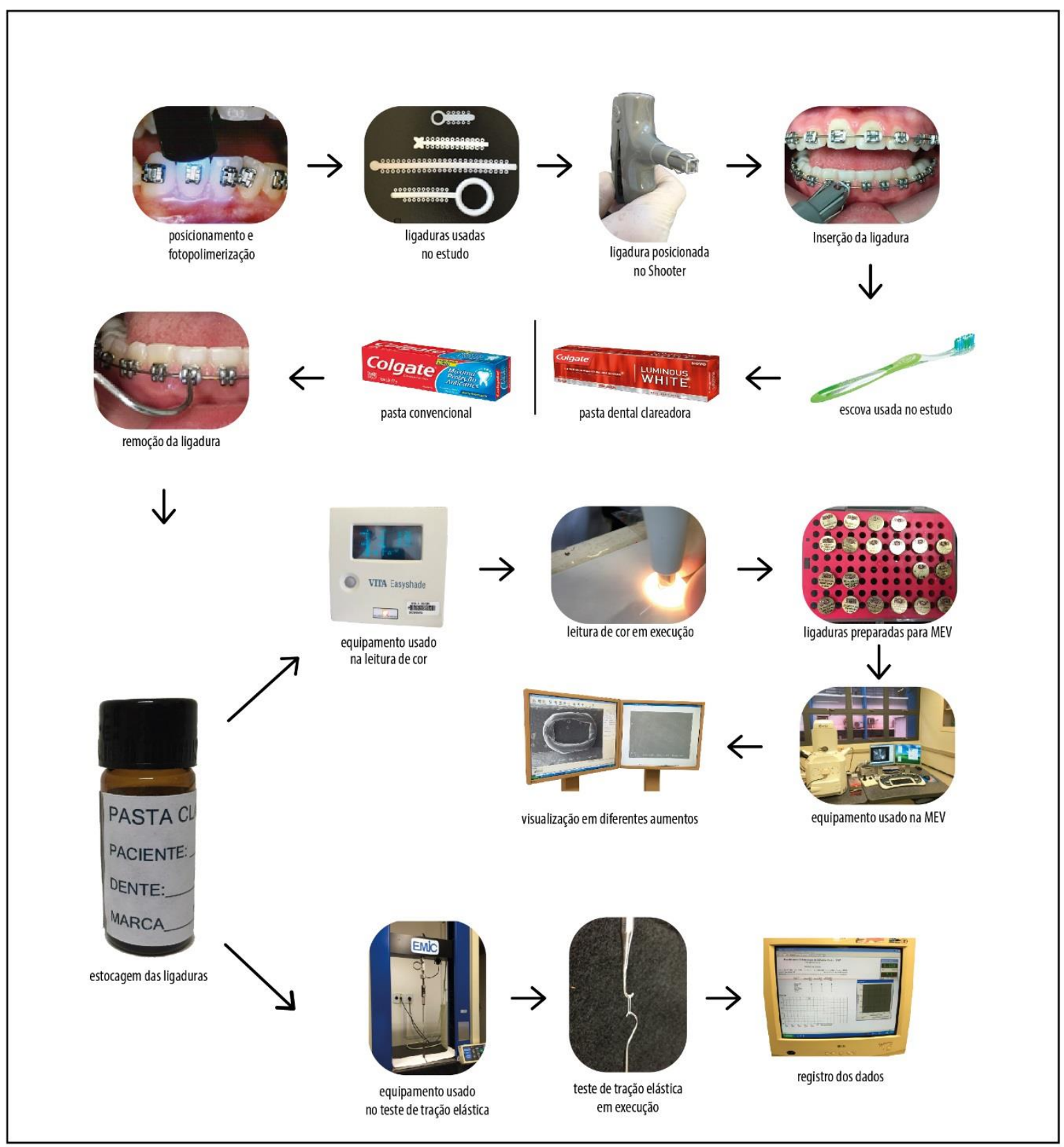

Figura 16 - Fluxograma da metodologia empregada com o dentifrício clareador e convencional. 
4.Resultados 


\section{RESULTADOS}

Primeiramente, foi realizado o teste estatístico para apurar se os dados apresentavam normalidade e/ou distribuição homogênea. Para tal foi utilizado o teste Kolmogorov-Smirnov quando foi concluído que a amostra se apresentava normal. Assim, optou-se pelo teste paramétrico de análise de variância - ANOVA e depois pelo teste complementar de Duncan em um nível de significância de 5\%.

Inicialmente, pode-se observar diferenças estatísticas entre as marcas estudadas e os dentifrícios (dentifrício convencional: $\mathrm{CO}$, dentifrício clareador: $\mathrm{CL}$ ). Entretanto, não houve interação entre os grupos estudados. Desta forma, foi realizado o teste complementar de Duncan para determinar se as marcas que foram diferentes entre si. Foi adotado o valor de $\mathrm{p}=$ 0,01 .

\subsection{Alteração de cor}

Para anotação dos resultados do teste de alteração de cor foram confeccionadas planilhas específicas de acordo com o dentifrício usado e as marcas comerciais. Para cada ligadura selecionada em cada paciente foram feitas 3 leituras das variáveis $L^{*}, a^{*}$ e $b^{*}$, bem como calculada a média destas 3 medidas e o desvio padrão (tabelas 15, 16, 17, 18, 19, 20, 21, e 22) que, por serem excessivamente extensas, foram incluídas na seção Apêndice. Foram avaliados 19 pacientes, uma vez que o paciente número 17 fez uso de solução evidenciadora de placa durante a pesquisa, sendo assim excluído da amostra.

As médias finais $(\Delta \mathrm{L}, \Delta \mathrm{a}, \Delta \mathrm{b}$ e $\Delta \mathrm{E})$ por marca, por dentifrício e por paciente estão nas tabelas 2, 3, 4 e 5 . 
Tabela 2 - Médias finais das leituras de cor da marca Morelli com ambos dentifrícios (pacientes 1 ao 20)

\begin{tabular}{|c|c|c|c|c|c|c|c|c|c|}
\hline \multirow{3}{*}{ MEAN } & \multirow{2}{*}{\multicolumn{3}{|c|}{ Leitura Final-Pasta Convenc-T1 }} & \multirow{3}{*}{$\Delta \mathrm{E}$} & \multirow{2}{*}{\multicolumn{4}{|c|}{ eitura Final-Pasta Clareadora-T }} & \multirow[b]{3}{*}{$\Delta \mathrm{E}$} \\
\hline & & & & & & & & & \\
\hline & $\Delta \mathrm{L}$ & $\Delta \mathrm{a}$ & $\Delta \mathrm{b}$ & & MEAN & $\Delta \mathrm{L}$ & $\Delta a$ & $\Delta \mathrm{b}$ & \\
\hline 1 & 8,27 & $-3,77$ & $-4,33$ & 10,17 & 1 & $-1,40$ & $-2,60$ & $-1,37$ & 3,78 \\
\hline 2 & 3,50 & $-4,27$ & $-1,10$ & 6,20 & 2 & $-9,70$ & $-2,10$ & 2,97 & 10,41 \\
\hline 3 & 1,60 & $-2,60$ & $-2,27$ & 4,10 & 3 & $-6,83$ & $-1,67$ & 2,20 & 7,53 \\
\hline 4 & 6,83 & $-4,43$ & $-2,33$ & 8,53 & 4 & 10,43 & $-3,60$ & $-1,17$ & 11,18 \\
\hline 5 & 10,13 & $-3,90$ & $-2,43$ & 11,17 & 5 & 5,43 & $-2,93$ & $-0,83$ & 6,61 \\
\hline 6 & 2,50 & $-3,70$ & $-2,60$ & 5,71 & 6 & $-6,63$ & $-1,67$ & 1,67 & 7,11 \\
\hline 7 & 11,73 & $-4,83$ & $-2,10$ & 12,91 & 7 & $-0,73$ & $-2,40$ & 2,70 & 4,00 \\
\hline 8 & 7,80 & $-3,03$ & $-1,30$ & 8,54 & 8 & $-12,10$ & $-1,33$ & 3,33 & 12,66 \\
\hline 9 & 46,87 & $-0,23$ & 14,07 & 48,94 & 9 & 3,47 & $-2,30$ & $-1,10$ & 4,46 \\
\hline 10 & 9,20 & $-3,93$ & $-3,87$ & 10,80 & 10 & $-7,13$ & $-2,10$ & 1,07 & 7,53 \\
\hline 11 & 5,27 & $-3,73$ & $-3,63$ & 7,57 & 11 & $-4,90$ & $-1,73$ & $-0,40$ & 5,31 \\
\hline 12 & 11,77 & $-2,73$ & $-3,13$ & 12,51 & 12 & 0,57 & $-1,60$ & 2,57 & 3,33 \\
\hline 13 & 11,63 & $-5,13$ & $-2,53$ & 13,01 & 13 & $-9,30$ & $-1,97$ & 0,87 & 9,62 \\
\hline 14 & 9,57 & $-3,67$ & $-1,63$ & 10,43 & 14 & $-4,67$ & $-2,17$ & 1,67 & 5,50 \\
\hline 15 & 4,70 & $-2,93$ & $-2,70$ & 6,29 & 15 & $-5,10$ & $-2,63$ & 1,27 & 6,01 \\
\hline 16 & 4,20 & $-4,97$ & $-3,63$ & 7,64 & 16 & $-19,43$ & $-2,07$ & 2,10 & 19,68 \\
\hline 17 & - & - & - & - & 17 & - & - & - & - \\
\hline 18 & 4,97 & $-3,90$ & $-2,40$ & 6,85 & 18 & 5,87 & $-3,60$ & $-2,20$ & 7,41 \\
\hline 19 & 1,20 & $-2,27$ & $-1,27$ & 3,11 & 19 & $-17,00$ & $-1,43$ & 2,00 & 17,20 \\
\hline 20 & 11,13 & $-3,80$ & 0,80 & 11,85 & 20 & $-9,27$ & $-2,33$ & 0,13 & 9,59 \\
\hline Mean (MEA^ & 8,64 & $-3,39$ & $-1,42$ & 10,32 & Mean (MEAN & $-4,42$ & $-2,11$ & 0,87 & 7,95 \\
\hline
\end{tabular}

Tabela 3 - Médias finais das leituras de cor da marca American Orthodontics com ambos dentifrícios (pacientes 1 ao 20)

\begin{tabular}{|c|c|c|c|c|c|c|c|c|c|}
\hline & Leitura Fir & Pasta C & iven-T1 & & & ura Fina & asta $\mathrm{Cla}$ & adora-T & \\
\hline MEAN & $\Delta \mathrm{L}$ & $\Delta \mathrm{a}$ & $\Delta \mathrm{b}$ & $\Delta \mathrm{E}$ & MEAN & $\Delta \mathrm{L}$ & $\Delta \mathrm{a}$ & $\Delta \mathrm{b}$ & $\Delta \mathrm{E}$ \\
\hline 1 & 0,33 & $-0,20$ & $-9,90$ & 9,98 & 1 & 2,23 & 1,50 & $-22,47$ & 22,67 \\
\hline 2 & 2,00 & $-2,10$ & $-15,37$ & 15,68 & 2 & $-2,60$ & $-1,03$ & $-11,97$ & 12,47 \\
\hline 3 & 1,77 & $-1,17$ & $-11,63$ & 11,90 & 3 & 3,73 & $-0,27$ & $-17,23$ & 17,65 \\
\hline 4 & 6,13 & $-3,73$ & $-18,33$ & 19,72 & 4 & 0,93 & $-2,07$ & 5,63 & 6,54 \\
\hline 5 & 2,70 & $-0,97$ & $-9,80$ & 10,25 & 5 & $-0,57$ & 0,50 & $-10,67$ & 10,77 \\
\hline 6 & 6,23 & $-0,77$ & $-12,43$ & 13,95 & 6 & 0,63 & 0,50 & $-10,27$ & 10,33 \\
\hline 7 & 6,23 & $-2,23$ & $-10,57$ & 12,49 & 7 & $-1,30$ & $-1,87$ & $-11,10$ & 11,38 \\
\hline 8 & 1,33 & $-0,63$ & $-9,57$ & 9,71 & 8 & $-0,27$ & $-0,17$ & $-9,20$ & 9,51 \\
\hline 9 & 58,07 & 0,63 & 5,63 & 58,35 & 9 & $-1,37$ & 0,23 & $-6,97$ & 7,23 \\
\hline 10 & 0,37 & $-0,20$ & $-14,10$ & 14,15 & 10 & $-7,80$ & 0,03 & $-6,07$ & 9,94 \\
\hline 11 & 4,10 & $-1,13$ & $-14,20$ & 14,87 & 11 & $-8,77$ & $-0,27$ & $-7,10$ & 11,33 \\
\hline 12 & 2,07 & 0,30 & $-15,67$ & 15,85 & 12 & $-1,73$ & - & $-7,07$ & 7,44 \\
\hline 13 & 2,17 & $-0,70$ & $-13,03$ & 13,29 & 13 & $-4,07$ & 0,13 & $-4,67$ & 6,36 \\
\hline 14 & 3,53 & $-1,37$ & $-14,63$ & 15,17 & 14 & $-2,20$ & $-0,10$ & $-9,23$ & 9,59 \\
\hline 15 & 7,10 & $-0,87$ & $-11,53$ & 13,59 & 15 & $-4,83$ & $-0,20$ & $-6,30$ & 7,97 \\
\hline 16 & 1,63 & $-2,63$ & $-15,80$ & 16,14 & 16 & $-4,60$ & $-3,20$ & $-8,77$ & 10,41 \\
\hline 17 & - & - & - & - & 17 & - & - & - & - \\
\hline 18 & 6,87 & $-1,30$ & $-15,67$ & 17,18 & 18 & 11,03 & $-2,50$ & $-16,23$ & 19,80 \\
\hline 19 & 5,40 & $-0,03$ & $-10,37$ & 11,74 & 19 & $-6,77$ & 0,47 & $-6,37$ & 9,33 \\
\hline 20 & 1,00 & $-0,60$ & $-8,13$ & 8,26 & 20 & $-0,47$ & 0,27 & $-14,13$ & 14,16 \\
\hline Mean (MEA^ & 5,95 & $-0,99$ & $-11,26$ & 15,11 & Mean (MEAN & $-1,44$ & $-0,40$ & $-9,01$ & 10,74 \\
\hline
\end{tabular}


Tabela 4 - Médias finais das leituras de cor da marca 3M Unitek com ambos dentifrícios (pacientes 1 ao 20).

\begin{tabular}{|c|c|c|c|c|c|c|c|c|c|}
\hline \multirow[b]{2}{*}{ MEAN } & \multicolumn{3}{|c|}{ Leitura Final-Pasta Convenc-T1 } & \multirow[b]{2}{*}{$\Delta \mathrm{E}$} & \multirow[b]{2}{*}{ MEAN } & \multicolumn{3}{|c|}{ itura Final-Pasta Clareadora-T } & \multirow[b]{2}{*}{$\Delta \mathrm{E}$} \\
\hline & $\Delta \mathrm{L}$ & $\Delta \mathrm{a}$ & $\Delta \mathrm{b}$ & & & $\Delta \mathrm{L}$ & $\Delta \mathrm{a}$ & $\Delta \mathrm{b}$ & \\
\hline 1 & 1,67 & 1,03 & $-8,93$ & 9,16 & 1 & $-0,53$ & 2,67 & $-10,63$ & 10,99 \\
\hline 2 & 3,63 & 0,23 & $-14,30$ & 14,76 & 2 & $-0,40$ & 0,90 & $-12,77$ & 12,81 \\
\hline 3 & 2,53 & 0,13 & $-10,63$ & 10,94 & 3 & $-1,70$ & 0,37 & $-17,03$ & 17,15 \\
\hline 4 & 6,87 & $-1,87$ & $-15,47$ & 17,03 & 4 & $-0,17$ & $-0,20$ & $-11,10$ & 11,24 \\
\hline 5 & 3,60 & 0,60 & $-7,30$ & 8,17 & 5 & 0,63 & 1,50 & $-8,13$ & 8,39 \\
\hline 6 & 3,60 & 1,17 & $-9,47$ & 10,20 & 6 & $-0,33$ & 2,20 & $-8,33$ & 8,65 \\
\hline 7 & 10,17 & $-1,33$ & $-13,13$ & 16,67 & 7 & 4,10 & $-0,30$ & $-11,93$ & 12,63 \\
\hline 8 & 6,37 & 0,17 & $-10,30$ & 12,12 & 8 & $-0,97$ & 1,23 & $-9,43$ & 9,58 \\
\hline 9 & 65,80 & 1,10 & 7,27 & 66,21 & 9 & $-0,80$ & 0,77 & $-6,37$ & 6,47 \\
\hline 10 & 1,47 & 0,70 & $-9,10$ & 9,26 & 10 & $-1,87$ & 0,50 & $-11,87$ & 12,11 \\
\hline 11 & 4,97 & 1,07 & $-16,57$ & 17,33 & 11 & $-1,17$ & 0,40 & $-5,50$ & 5,65 \\
\hline 12 & 10,63 & 1,10 & $-13,20$ & 16,99 & 12 & $-0,57$ & 0,70 & $-6,47$ & 6,54 \\
\hline 13 & 3,70 & $-0,00$ & $-8,97$ & 9,71 & 13 & $-0,80$ & 1,03 & 7,27 & 7,42 \\
\hline 14 & 5,43 & 1,07 & $-9,97$ & 11,42 & 14 & 3,83 & 1,43 & $-8,67$ & 9,60 \\
\hline 15 & 4,63 & 0,27 & $-6,30$ & 7,83 & 15 & $-2,27$ & 0,33 & $-4,87$ & 5,47 \\
\hline 16 & 7,77 & $-3,57$ & $-19,67$ & 21,45 & 16 & 9,10 & $-5,17$ & $-11,87$ & 15,83 \\
\hline 17 & - & - & - & - & 17 & - & - & - & - \\
\hline 18 & 6,30 & 0,40 & $-13,67$ & 15,06 & 18 & 2,10 & 0,93 & $-10,77$ & 11,02 \\
\hline 19 & 5,70 & 0,40 & $-7,20$ & 9,21 & 19 & $-0,30$ & 0,77 & $-4,30$ & 4,73 \\
\hline 20 & 7,47 & $-0,00$ & $-13,93$ & 15,81 & 20 & 2,27 & 1,00 & $-13,30$ & 13,53 \\
\hline Mean (MEA^ & 8,12 & 0,13 & $-10,04$ & 14,97 & Mean (MEAN & 0,51 & 0,55 & $-8,30$ & 9,49 \\
\hline
\end{tabular}

Tabela 5- Médias finais das leituras de cor marca Orthotechnology com ambos dentifrícios (pacientes 1 ao 20)

\begin{tabular}{|c|c|c|c|c|c|c|c|c|c|}
\hline \multirow[b]{2}{*}{ MEAN } & \multicolumn{3}{|c|}{ eitura Final-Pasta Convenc-T1 } & \multirow[b]{2}{*}{$\Delta \mathrm{E}$} & \multirow[b]{2}{*}{ MEAN } & \multicolumn{3}{|c|}{ tura Final-Pasta Clareadora-T } & \multirow[b]{2}{*}{$\Delta \mathrm{E}$} \\
\hline & $\Delta \mathrm{L}$ & $\Delta \mathrm{a}$ & $\Delta \mathrm{b}$ & & & $\Delta \mathrm{L}$ & $\Delta \mathrm{a}$ & $\Delta \mathrm{b}$ & \\
\hline 1 & 7,70 & $-0,73$ & $-13,37$ & 15,45 & 1 & 1,90 & $-0,23$ & $-11,50$ & 11,68 \\
\hline 2 & 5,73 & $-1,63$ & $-13,07$ & 14,37 & 2 & 5,50 & $-1,03$ & $-16,13$ & 17,08 \\
\hline 3 & 6,57 & $-0,40$ & $-12,33$ & 13,98 & 3 & $-1,23$ & $-0,40$ & 10,80 & 10,89 \\
\hline 4 & 10,17 & $-3,07$ & $-23,20$ & 25,53 & 4 & $-0,83$ & $-1,03$ & $-6,43$ & 6,60 \\
\hline 5 & 6,00 & $-1,87$ & $-8,03$ & 10,20 & 5 & 1,10 & $-0,37$ & $-5,93$ & 6,27 \\
\hline 6 & 5,53 & 0,57 & $-17,10$ & 17,99 & 6 & $-2,07$ & 2,00 & $-9,90$ & 10,37 \\
\hline 7 & 9,00 & $-1,17$ & $-13,80$ & 16,52 & 7 & 3,10 & $-0,37$ & $-15,00$ & 15,33 \\
\hline 8 & 7,33 & $-0,37$ & $-9,83$ & 12,28 & 8 & 1,40 & $-0,23$ & $-5,30$ & 5,50 \\
\hline 9 & 64,93 & $-0,57$ & 10,80 & 65,83 & 9 & 3,20 & 0,10 & $-19,10$ & 19,38 \\
\hline 10 & 4,77 & $-0,10$ & $-11,37$ & 12,35 & 10 & $-2,03$ & $-0,17$ & $-5,00$ & 5,42 \\
\hline 11 & 8,93 & $-1,23$ & $-18,57$ & 20,64 & 11 & 6,63 & $-0,60$ & $-14,53$ & 15,99 \\
\hline 12 & 11,43 & $-0,50$ & $-13,07$ & 17,38 & 12 & 3,23 & $-0,27$ & $-5,33$ & 6,26 \\
\hline 13 & 8,13 & $-2,77$ & $-16,33$ & 18,46 & 13 & 0,67 & $-0,73$ & $-3,70$ & 3,87 \\
\hline 14 & 5,83 & $-1,03$ & $-12,73$ & 14,05 & 14 & 5,23 & $-0,03$ & $-10,20$ & 11,48 \\
\hline 15 & 6,67 & $-0,80$ & $-10,57$ & 12,53 & 15 & 6,73 & $-1,87$ & $-9,93$ & 12,15 \\
\hline 16 & 11,37 & $-5,60$ & $-17,33$ & 21,48 & 16 & 6,57 & $-5,47$ & $-5,80$ & 10,33 \\
\hline 17 & - & - & - & - & 17 & - & - & - & - \\
\hline 18 & 9,23 & $-2,13$ & $-16,90$ & 19,38 & 18 & $-3,10$ & $-0,97$ & $-6,77$ & 7,52 \\
\hline 19 & 4,83 & $-0,57$ & $-7,07$ & 8,60 & 19 & 3,83 & 0,87 & $-8,63$ & 9,50 \\
\hline 20 & 8,07 & $-2,27$ & $-15,27$ & 17,42 & 20 & 1,07 & $-0,27$ & $-11,80$ & 11,86 \\
\hline Mean (MEA^ & 10,11 & $-1,31$ & $-11,96$ & 17,72 & Mean (MEAN & 2,05 & $-0,55$ & $-8,01$ & 9,87 \\
\hline
\end{tabular}


A comparação das médias realizadas pelo teste estatístico paramétrico de análise de variância ANOVA e pelo teste complementar de Duncan para análise da variação total de cor, $\Delta \mathrm{E}$, está expresso na tabela 6 e no gráfico 1. Aqui, pode-se constatar que as marcas que mostraram diferenças entre dentifrício convencional (CO) e clareador (CL) foram Morelli e Orthotechnology, evidenciado pela diferença entre as letras minúsculas. Em relação às marcas, não houve diferenças (avaliação das colunas com letras maiúsculas iguais). Todas as ligaduras com dentifrício convencional e clareador apresentaram alteração de cor considerada clinicamente inaceitável $(\Delta \mathrm{E}>3,3)$. Apesar disso, as ligaduras Morelli apresentaram a menor alteração de cor quando utilizado o dentifrício clareador.

Tabela 6 - Resultados finais para a variável $\Delta \mathrm{E}$ (letras minúsculas diferentes indicam diferenças entre linhas, letras maiúsculas diferentes indicam diferenças entre colunas).

\begin{tabular}{ccccc}
\cline { 2 - 5 } Delta E & Morelli & American & Grupos & Orthotechnology \\
\hline CO convencional & $10,32 \pm 6,45^{\mathrm{aA}}$ & $15,11 \pm 10,97^{\mathrm{aA}}$ & $14,96 \pm 12,96^{\mathrm{aA}}$ & $17,72 \pm 12,53^{\mathrm{aA}}$ \\
CL clareador & $7,94 \pm 4,68^{\mathrm{bA}}$ & $10,74 \pm 5,00^{\mathrm{aA}}$ & $9,49 \pm 4,09^{\mathrm{aA}}$ & $9,87 \pm 4,81^{\mathrm{bA}}$ \\
\hline
\end{tabular}

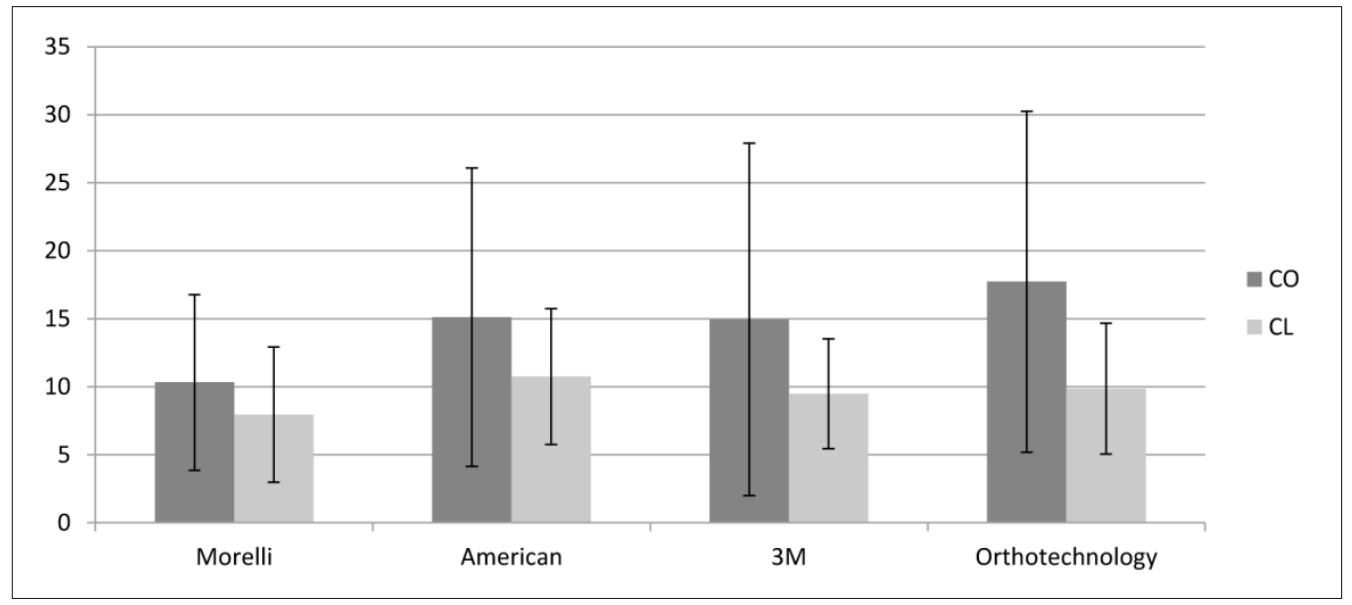

Gráfico 1 - Resultados finais para a variável $\Delta \mathrm{E}$.

Ao se avaliar o $\Delta \mathrm{L}$, que está relacionado à luminosidade do material (claro - escuro) ou seja, que indica quanto preto/branco o material apresenta pode-se verificar que, quando analisado o efeito do dentifrício, houve diferença estatisticamente significante em relação a todas as marcas de ligaduras estudadas. Na tabela 7 é possível visualizar diferença estatística quando são comparadas as linhas (letras minúsculas diferentes indicam diferenças entre as linhas). Verificou-se que houve aumento significante da luminosidade (mais claro) das ligaduras 3M Unitek e Orthotechnology após o uso do dentifrício clareador, mas diminuição da luminosidade (mais escuro) quando analisadas as ligaduras Morelli e American Orthodontics que apresentaram valores negativos do $\Delta \mathrm{L}$. 
Quando são comparadas as colunas, ou seja, cada marca dentro da mesma condição a que foi submetida, verifica-se que para o dentifrício convencional (CO) não provocou diferenças de luminosidade entre os grupos (letras maiúsculas indicam diferenças entre as colunas).

No entanto, para o dentifrício clareador (CL) a marca Morelli foi estatisticamente igual à American Orthodontics que por sua vez, apresentou valores similares à 3M Unitek. Entretanto, a 3M Unitek foi diferente da marca Morelli que apresentou menor luminosidade. A marca Orthotechnology, foi similar à marca 3M Unitek e diferente das demais. Com o dentifrício clareador houve diminuição da luminosidade, ou seja, escurecimento das ligaduras sobretudo nas marcas Morelli e American Orthodontics (Tabela 7, gráfico 2).

Tabela 7 - Resultados finais para a variável $\Delta \mathrm{L}$ (letras minúsculas diferentes indicam diferenças entre linhas, letras maiúsculas diferentes indicam diferenças entre colunas).

\begin{tabular}{ccccc} 
& \multicolumn{3}{c}{ Grupos } \\
\hline Delta L & Morelli & American & $\mathbf{3 M}$ & Orthotechnology \\
\hline CO convencional & $8,64 \pm 9,75^{\mathrm{aA}}$ & $5,95 \pm 12,49^{\mathrm{aA}}$ & $8,11 \pm 13,85^{\mathrm{aA}}$ & $10,11 \pm 13,16^{\mathrm{aA}}$ \\
CL clareador & $-4,42 \pm 7,57^{\mathrm{bA}}$ & $-1,44 \pm 4,37^{\mathrm{bAB}}$ & $0,50 \pm 2,66^{\mathrm{bBC}}$ & $2,04 \pm 3,07^{\mathrm{bC}}$ \\
\hline
\end{tabular}

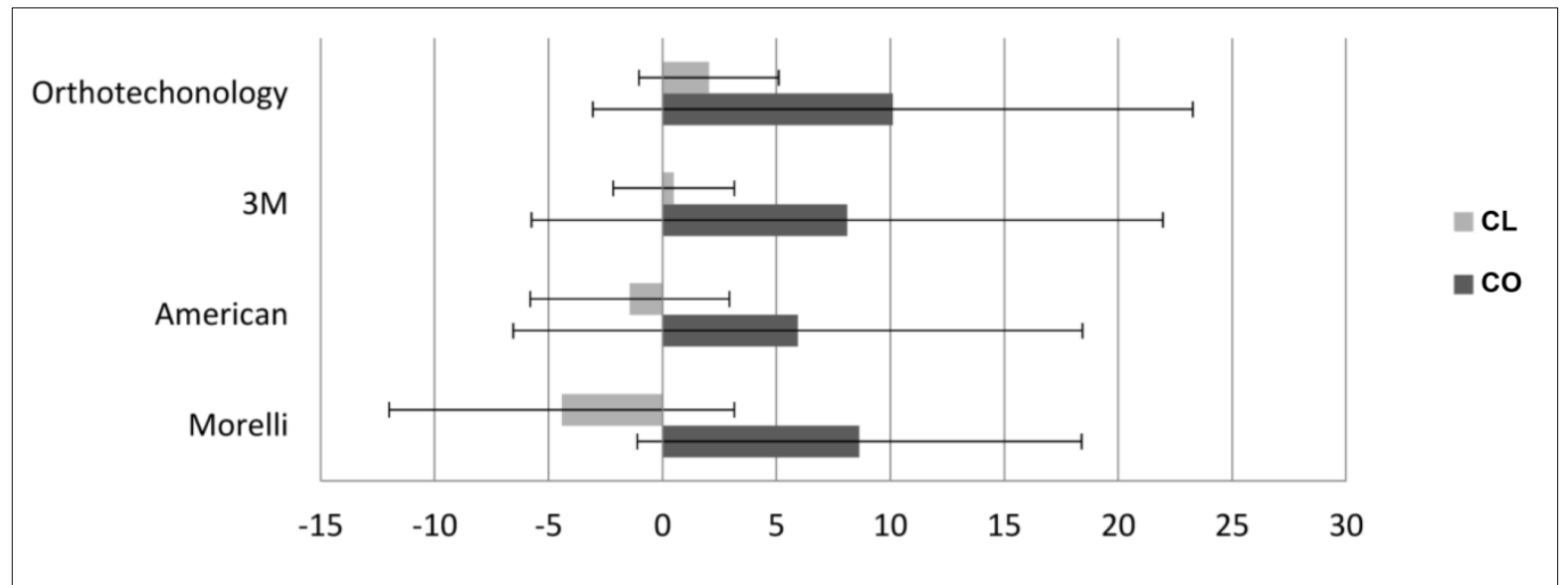

Gráfico 2 - Resultados finais para a variável $\Delta \mathrm{L}$.

Quando se analisa a variável $\Delta \mathrm{a}$ (eixo verde - vermelho), observa-se que somente a marca Morelli, apresentou diferença estatisticamente significante quando comparados os dentifrícios conforme a tabela 8 que mostra letras minúsculas diferentes entre as linhas somente para a marca citada.

Todas as demais marcas de ligaduras não apresentaram influência do dentifrício na alteração da coordenada. As ligaduras Morelli e American Orthodontics apresentaram valores de $\Delta$ a negativos, quando utilizados ambos dentifrícios, demonstrando que houve uma diminuição da saturação do croma vermelho, o mesmo ocorrendo para a ligadura 
Orthotechnology, quando utilizado o dentifrício convencional. A ligadura 3M Unitek apresentou pequenas alterações da coordenada $a^{*}$ com ambos dentifrícios, o mesmo resultado que a Orthotechnology, com o dentifrício clareador.

Comparando o desempenho das ligaduras com o mesmo dentifrício utilizado, verifica-se que as maiores alterações ocorreram na ligadura Morelli, com diminuição da saturação do croma vermelho e tendência ao croma verde com ambos dentifrícios, resultados diferentes estatisticamente de todas as demais ligaduras. As ligaduras American Orthodontics apresentaram valores similares à Orthotechnology e ambas foram diferentes da ligadura 3M Unitek, independente do dentifrício utilizado (Tabela 8, gráfico 3).

Tabela 8 - Resultados finais para a variável $\Delta$ a (letras minúsculas diferentes indicam diferenças entre linhas, letras maiúsculas diferentes indicam diferenças entre colunas).

\begin{tabular}{ccccc} 
& \multicolumn{3}{c}{ Grupos } \\
\cline { 2 - 5 } Delta a & Morelli & American & 3M & Orthotechnology \\
\hline CO convencional & $-3,39 \pm 1,35^{\mathrm{aA}}$ & $-0,98 \pm 1,05^{\mathrm{aB}}$ & $0,13 \pm 1,17^{\mathrm{aC}}$ & $-1,31 \pm 1,38^{\mathrm{aB}}$ \\
CL clareador & $-2,11 \pm 0,79^{\mathrm{bA}}$ & $-0,40 \pm 1,15^{\mathrm{aB}}$ & $0,55 \pm 1,53^{\mathrm{aC}}$ & $0,55 \pm 1,39^{\mathrm{aB}}$ \\
\hline
\end{tabular}

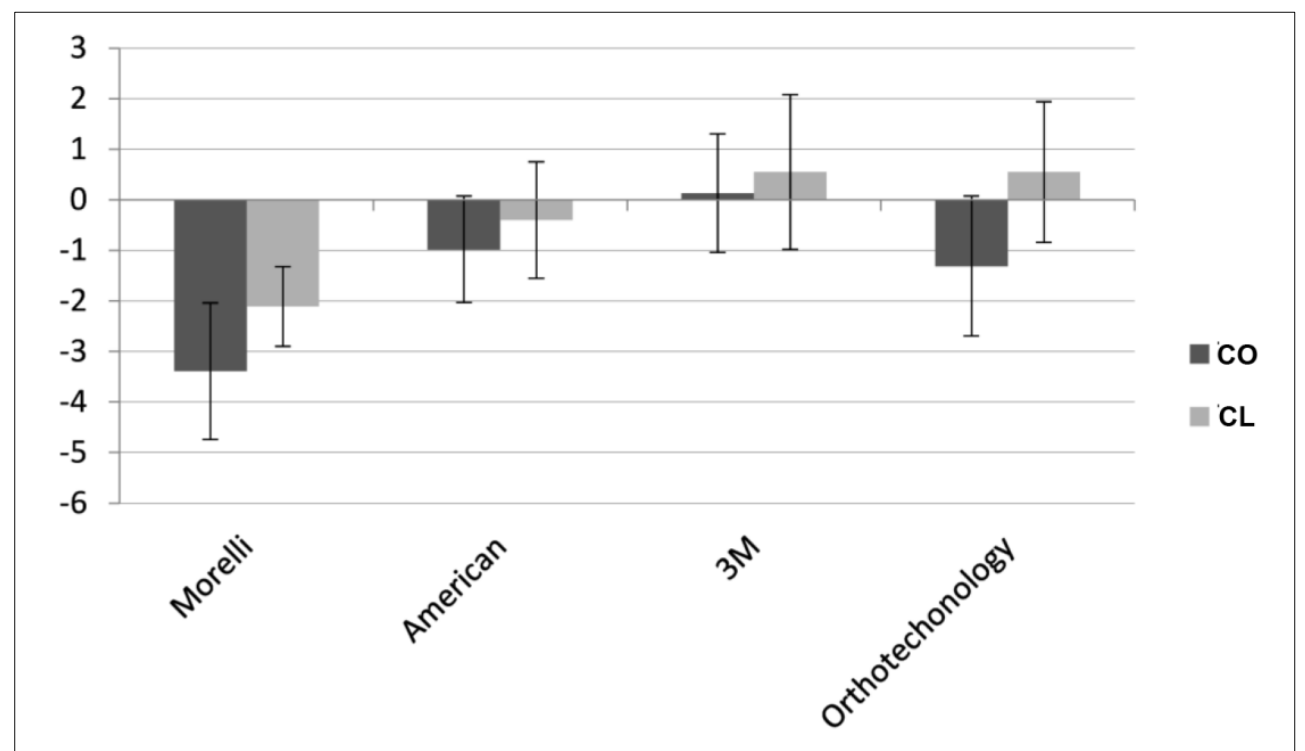

Gráfico 3 - Resultados finais para a variável $\Delta \mathrm{a}$.

No que diz respeito à variável $\Delta \mathrm{b}$ (eixo azul - amarelo), a tabela 9 mostra que apenas a marca Morelli apresentou diferença entre dentifrício convencional (CO) e clareador (CL), expressada pelas letras minúsculas diferentes entre linhas somente nesta marca. Com o dentifrício convencional, a citada ligadura apresentou uma diminuição do croma amarelo, com tendência ao croma azul, enquanto que com o dentifrício clareador, houve pequena alteração da coordenada, com tendência de manutenção do croma original. Todas as demais 
ligaduras não apresentaram diferença estatisticamente significante entre os dentifrícios utilizados.

Quando as colunas são comparadas, observou-se, novamente, que a menor alteração da coordenada $b^{*}$ ocorreu para a ligadura Morelli, resultados diferentes estatisticamente em relação às demais ligaduras estudadas, que não apresentaram diferença estatisticamente significante entre si. Estas ligaduras apresentaram variações altas de $\Delta b$, com valores negativos, indicando que houve grande diminuição do croma amarelo com tendência ao croma azul, independentemente do tipo de dentifrício utilizado (tabela 9 e gráfico 4).

Tabela 9 - Resultados finais para a variável $\Delta \mathrm{b}$ (letras minúsculas diferentes indicam diferenças entre linhas, letras maiúsculas diferentes indicam diferenças entre colunas).

\begin{tabular}{ccccc} 
& \multicolumn{4}{c}{ Grupos } \\
\hline Delta b & Morelli & American & $3 \mathrm{M}$ & Orthotechnology \\
\hline COconvencional & $-1,41 \pm 3,85^{\mathrm{aA}}$ & $-11,25 \pm 5,56^{\mathrm{aB}}$ & $-10,04 \pm 5,91^{\mathrm{aB}}$ & $-11,95 \pm 7,23^{\mathrm{aB}}$ \\
CL clareadora & $0,87 \pm 1,63^{\mathrm{bA}}$ & $-9,00 \pm 6,04^{\mathrm{aB}}$ & $-8,30 \pm 5,30^{\mathrm{aB}}$ & $-8,00 \pm 6,45^{\mathrm{aB}}$ \\
\hline
\end{tabular}

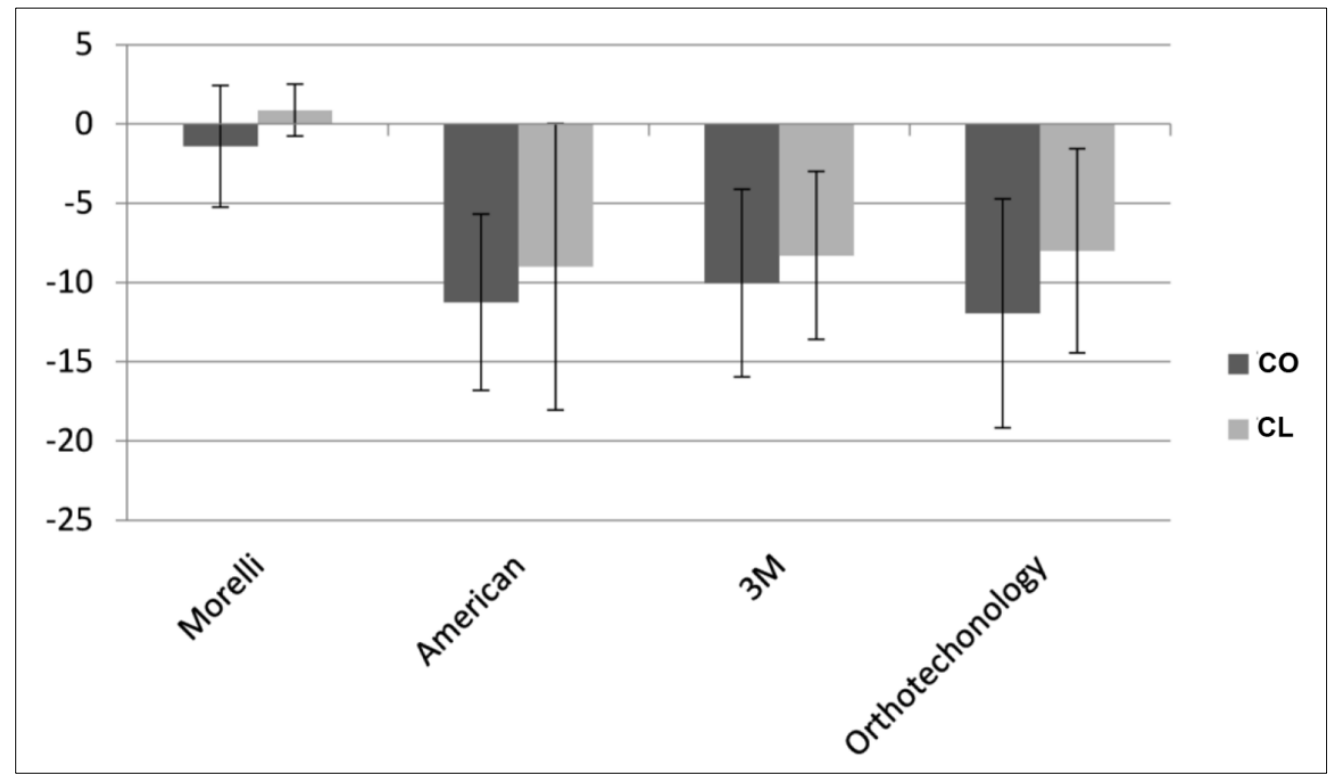

Gráfico 4 - Resultados finais para a variável $\Delta \mathrm{b}$.

\subsection{Ultraestrutura da superfície (MEV)}

Após a análise da alteração de cor, foram avaliadas qualitativamente pela Microscopia Eletrônica de Varredura (MEV), uma ligadura nova de cada marca, bem como aquela que mostrou a maior e menor variação de cor de cada marca, após o uso do dentifrício convencional e clareador, totalizando 20 ligaduras. Essas ligaduras foram observadas nos aumentos de 150, 500 e 2000 vezes. 


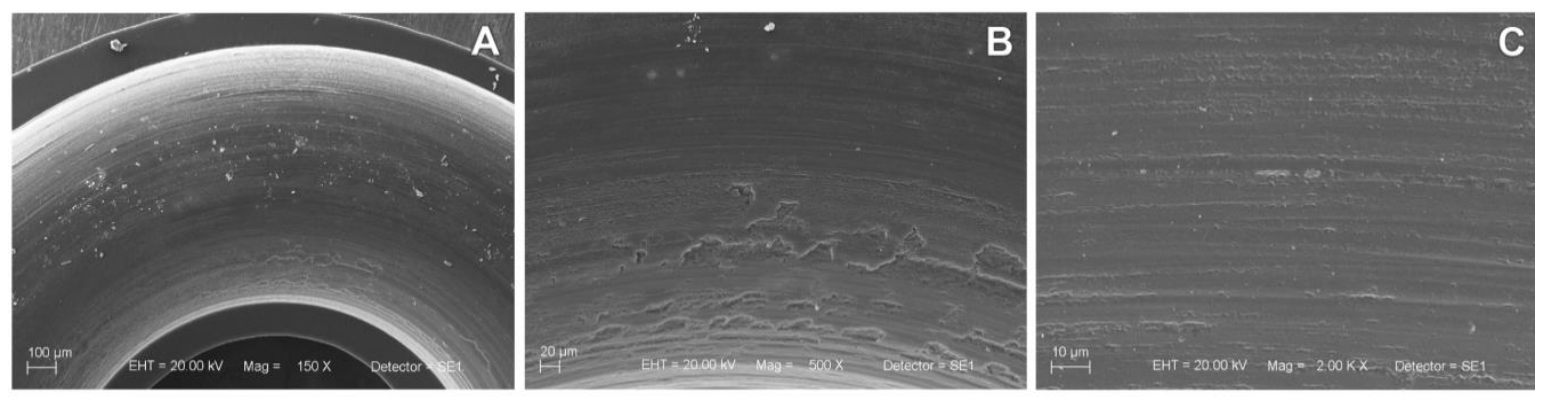

Figura 17 - Microscopia eletrônica de varredura - Ligadura Morelli nova. A: aumento de 150X; B: aumento de 500X; C: aumento de 2000X.

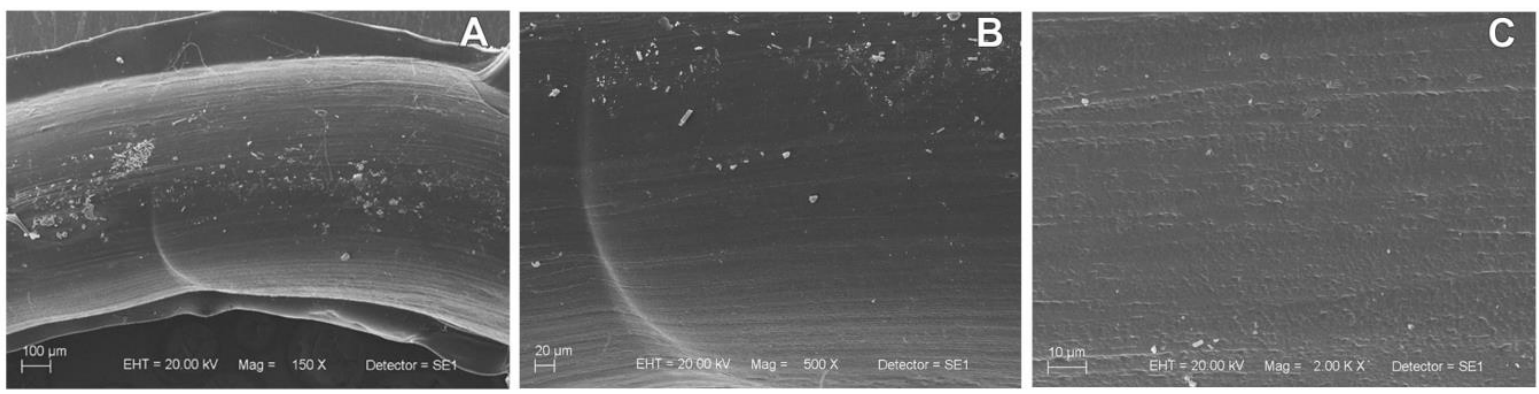

Figura 18 - Microscopia eletrônica de varredura - Ligadura Morelli usada com dentifrício clareador com menor variação de cor. A: aumento de 150X; B: aumento de 500X; C: aumento de 2000X.

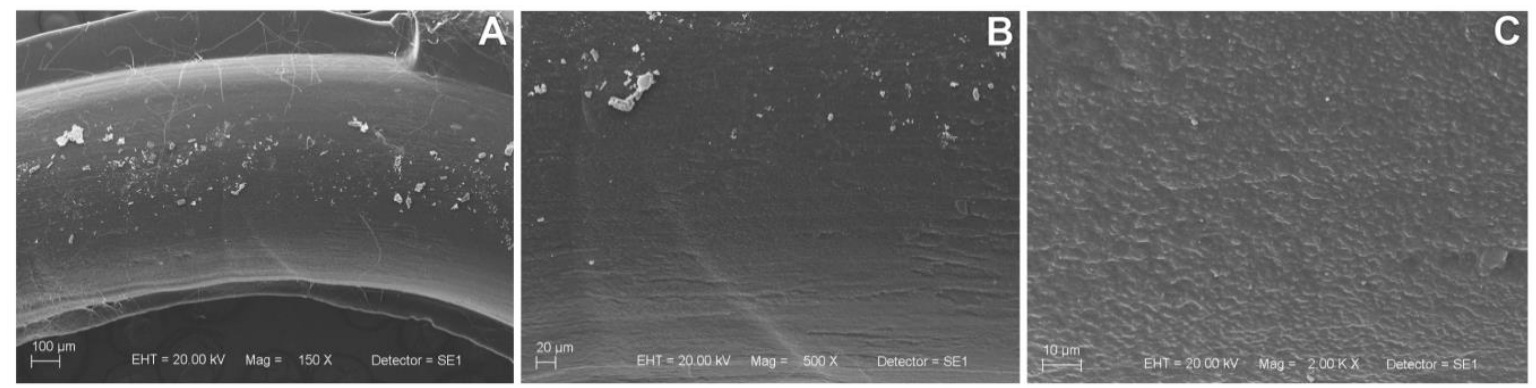

Figura 19 - Microscopia eletrônica de varredura - Ligadura Morelli usada com dentifrício clareador com maior variação de cor. A: aumento de 150X; B: aumento de 500X; C: aumento de 2000X.
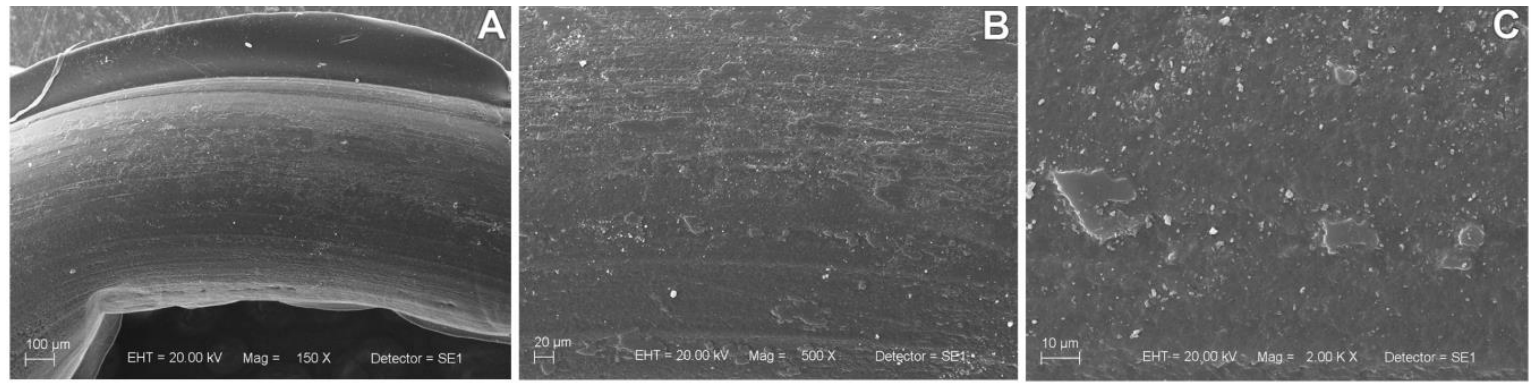

Figura 20 - Microscopia eletrônica de varredura - Ligadura Morelli usada com dentifrício convencional com menor variação de cor. A: aumento de 150X; B: aumento de 500X; C: aumento de 2000X.

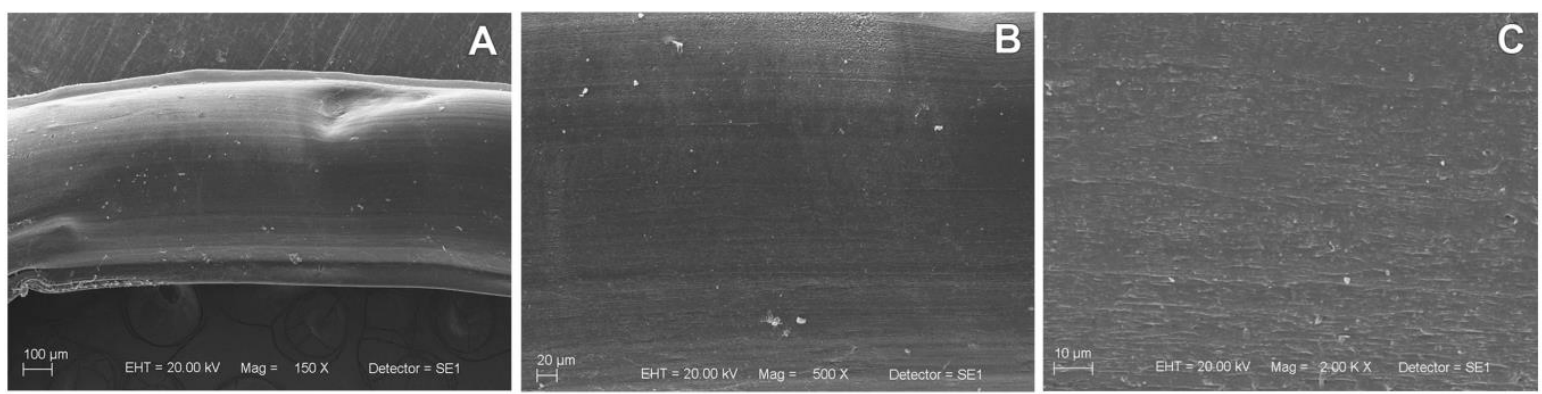

Figura 21-Microscopia eletrônica de varredura - Ligadura Morelli usada com dentifrício convencional com maior variação de cor. A: aumento de 150X; B: aumento de 500X; C: aumento de 2000X. 

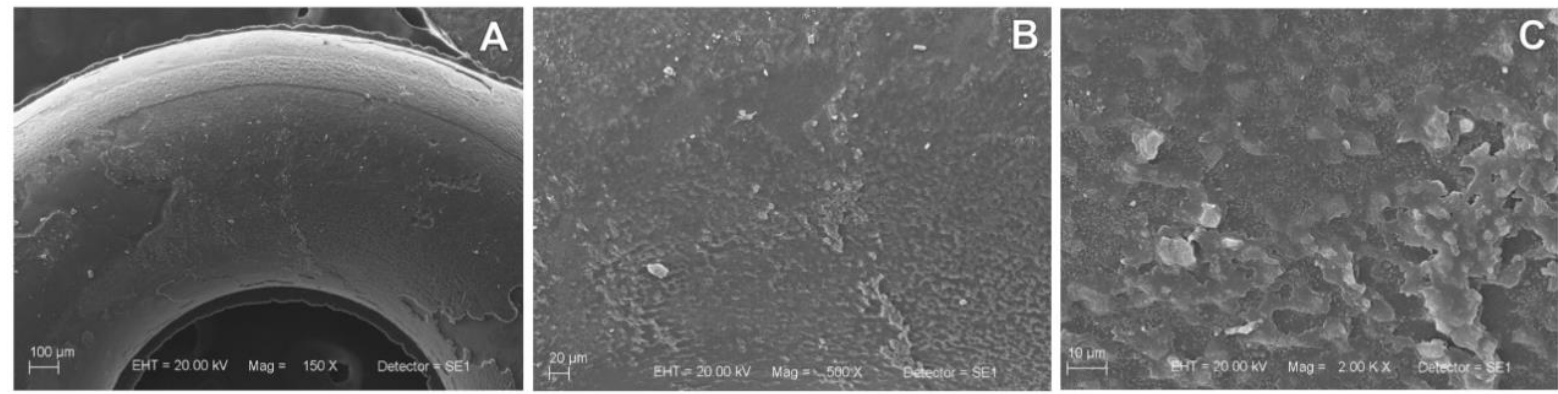

Figura 22 - Microscopia eletrônica de varredura - Ligadura American Orthodontics nova. A: aumento de 150X; B: aumento de 500X; C: aumento de 2000X.
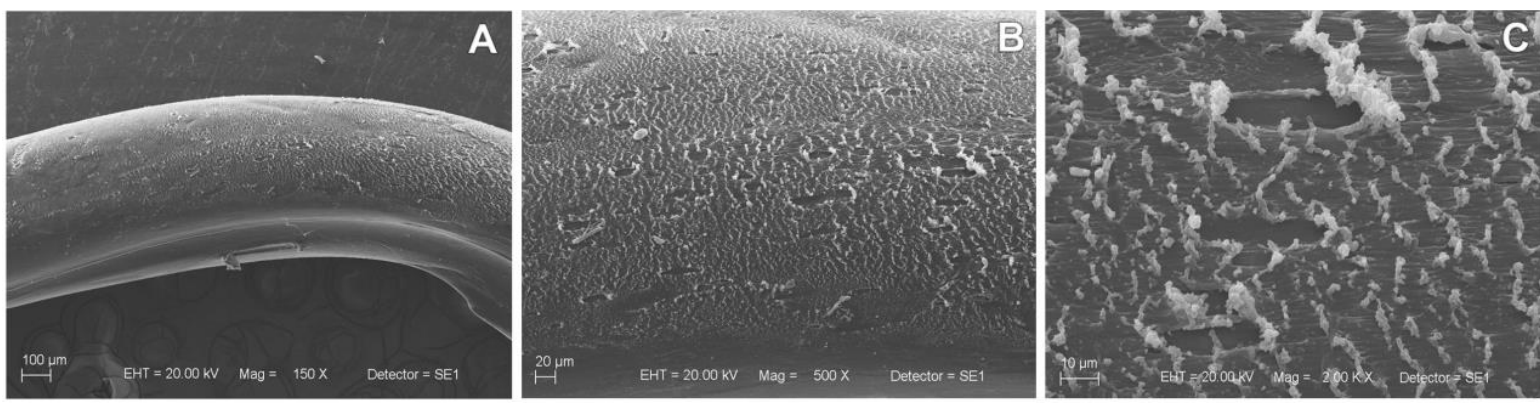

Figura 23 - Microscopia eletrônica de varredura - Ligadura American Orthodontics usada com dentifrício clareador com menor variação de cor. A: aumento de 150X; B: aumento de 500X; C: aumento de 2000X.
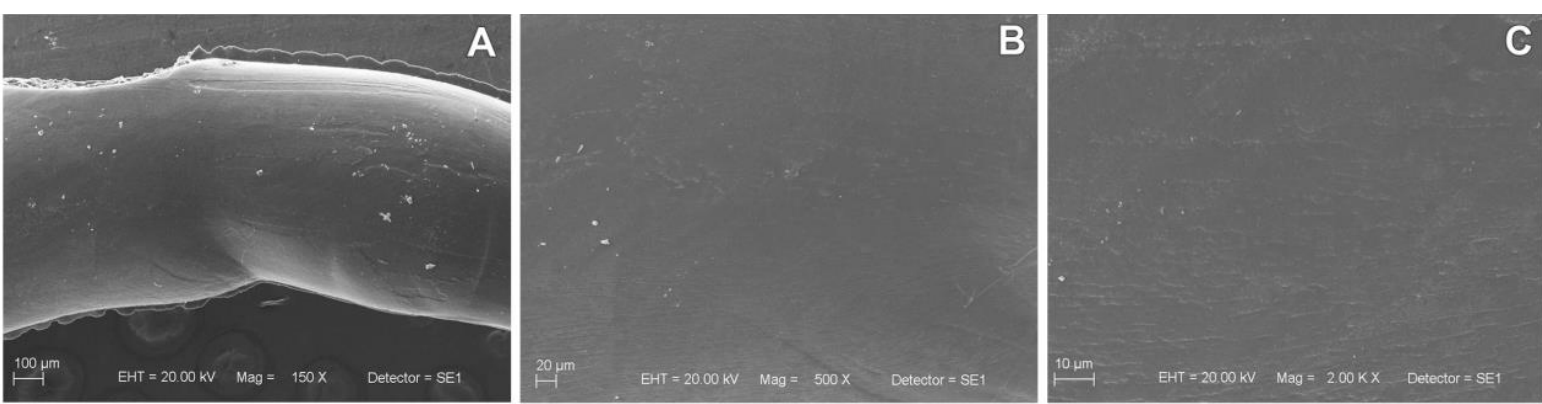

Figura 24 - Microscopia eletrônica de varredura - Ligadura American Orthodontics usada com dentifrício clareador com maior variação de cor. A: aumento de 150X; B: aumento de 500X; C: aumento de 2000X.
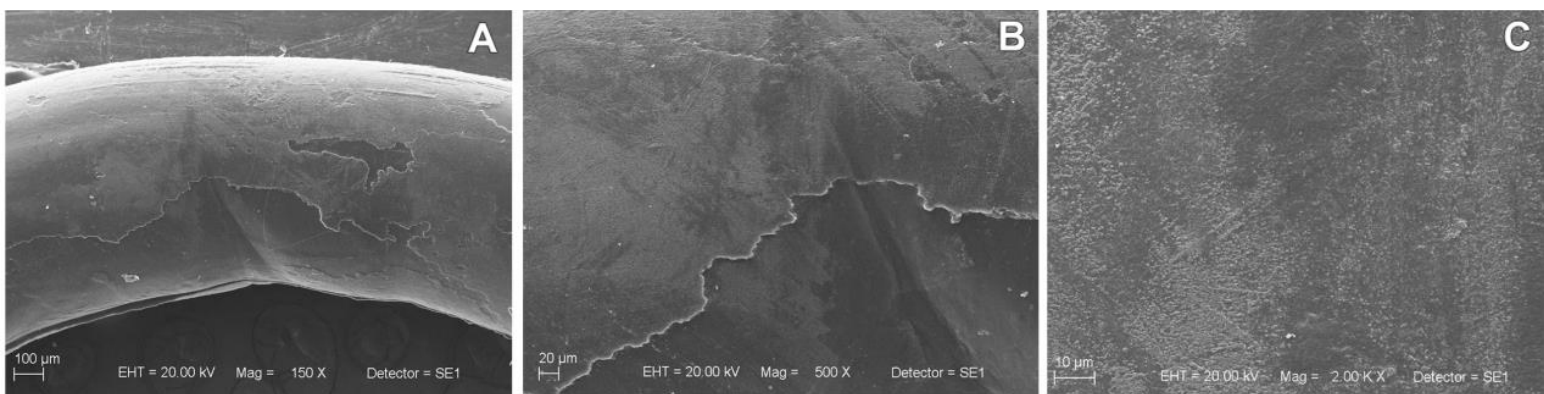

Figura 25 - Microscopia eletrônica de varredura - Ligadura American Orthodontics usada com dentifrício convencional com menor variação de cor. A: aumento de 150X; B: aumento de 500X; C: aumento de 2000X.

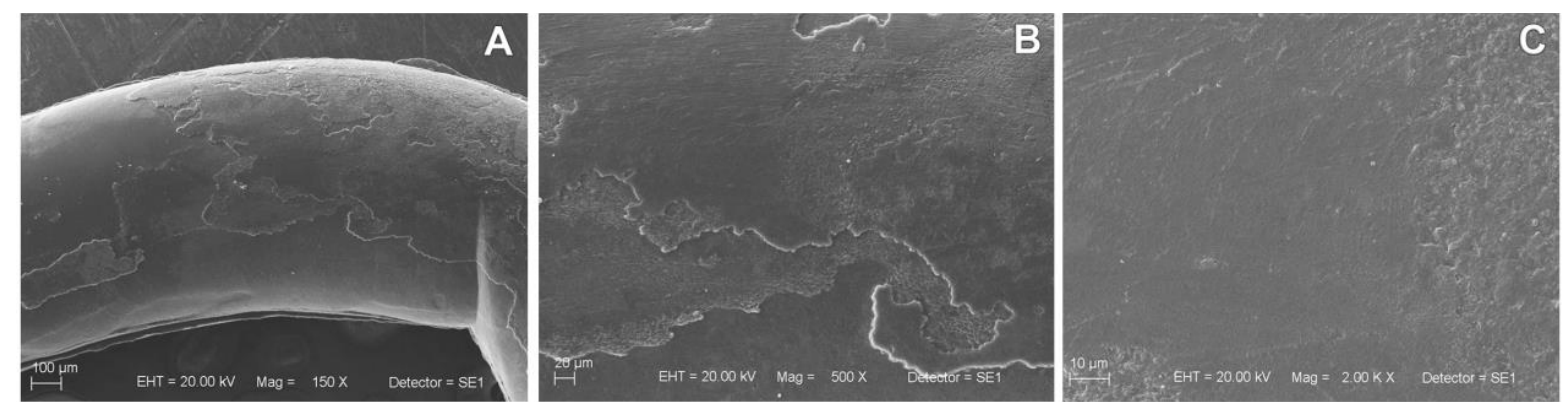

Figura 26 - Microscopia eletrônica de varredura - Ligadura American Orthodontics usada com dentifrício convencional com maior variação de cor. A: aumento de 150X; B: aumento de 500X; C: aumento de 2000X. 

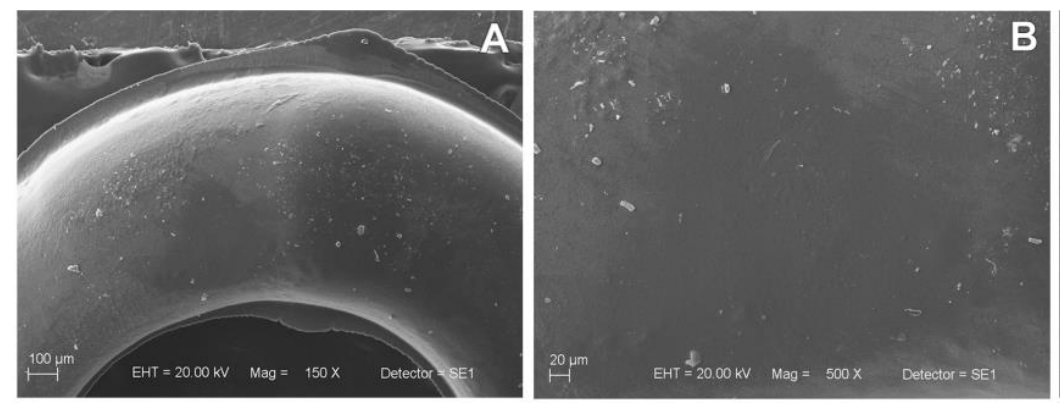

Figura 27 - Microscopia eletrônica de varredura - Ligadura 3M Unitek nova. A: aumento de 150X; B: aumento de 500X; C: aumento de 2000X.
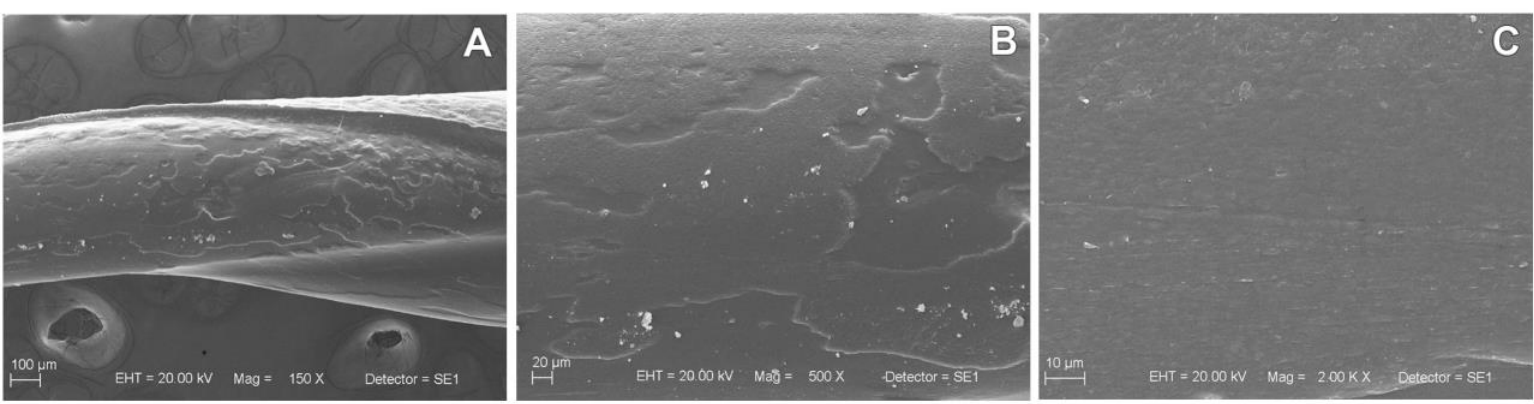

Figura 28 - Microscopia eletrônica de varredura - Ligadura 3M Unitek usada com dentifrício clareador com menor variação de cor. A: aumento de 150X; B: aumento de 500X; C: aumento de 2000X.

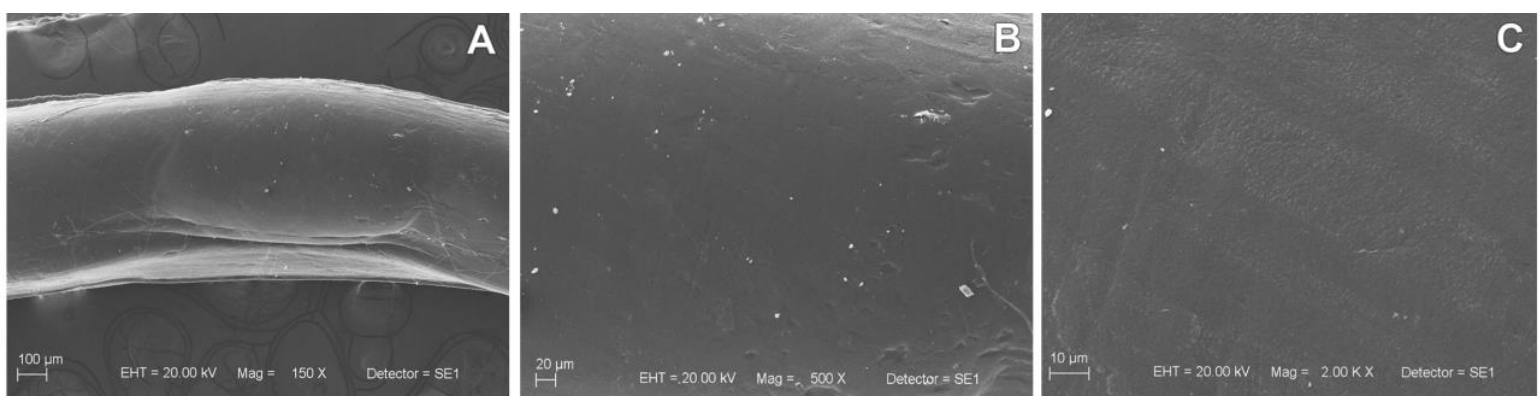

Figura 29 - Microscopia eletrônica de varredura - Ligadura 3M Unitek usada com dentifrício clareador com maior variação de cor. A: aumento de 150X; B: aumento de 500X; C: aumento de 2000X.
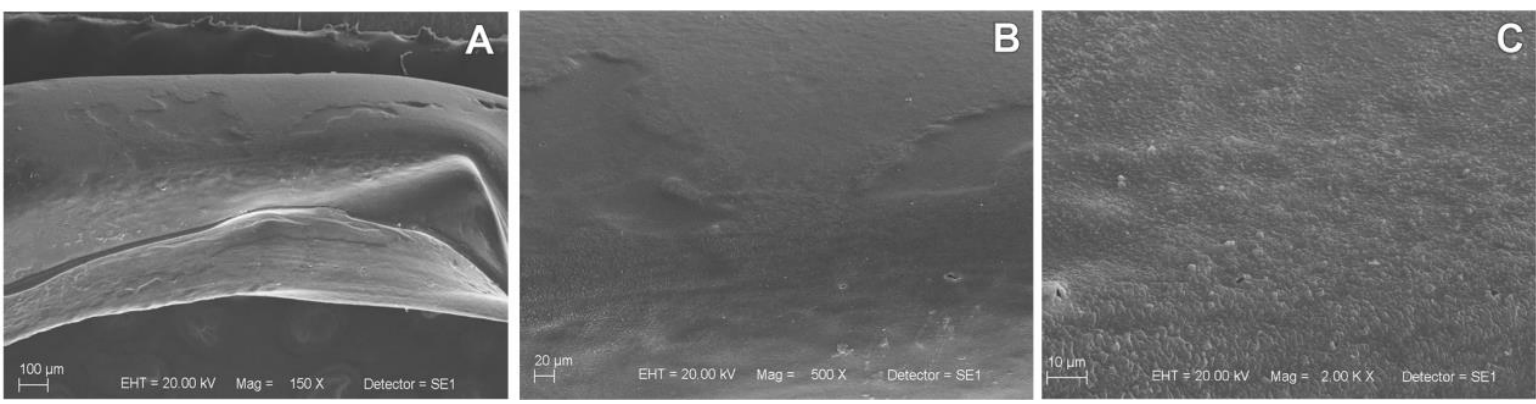

Figura 30 - Microscopia eletrônica de varredura - Ligadura 3M Unitek usada com dentifrício convencional com menor variação de cor. A: aumento de 150X; B: aumento de 500X; C: aumento de 2000X.

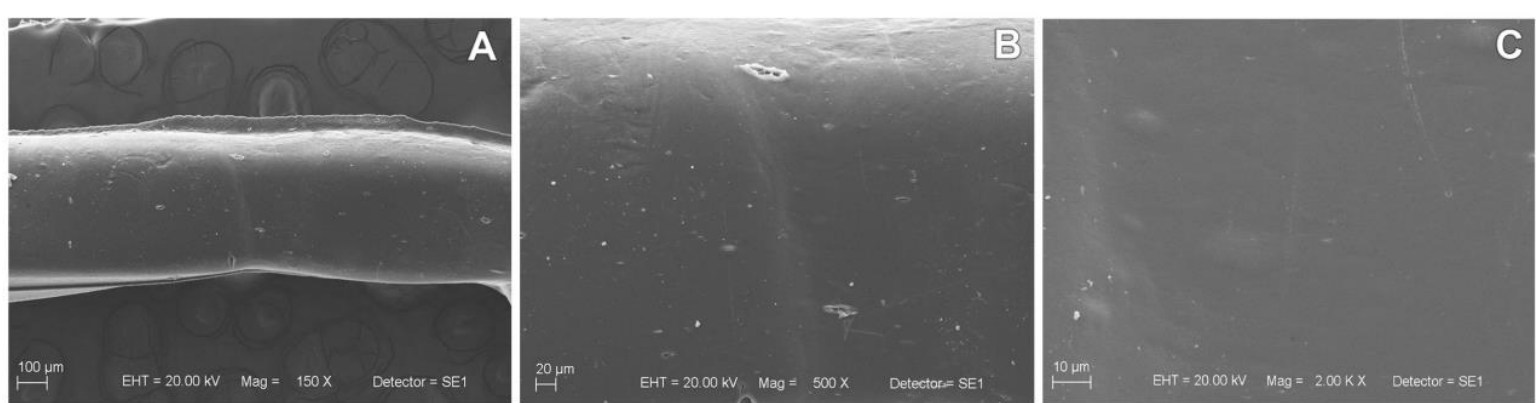

Figura 31 - Microscopia eletrônica de varredura - Ligadura 3M Unitek usada com dentifrício convencional com maior variação de cor. A: aumento de 150X; B: aumento de 500X; C: aumento de 2000X. 


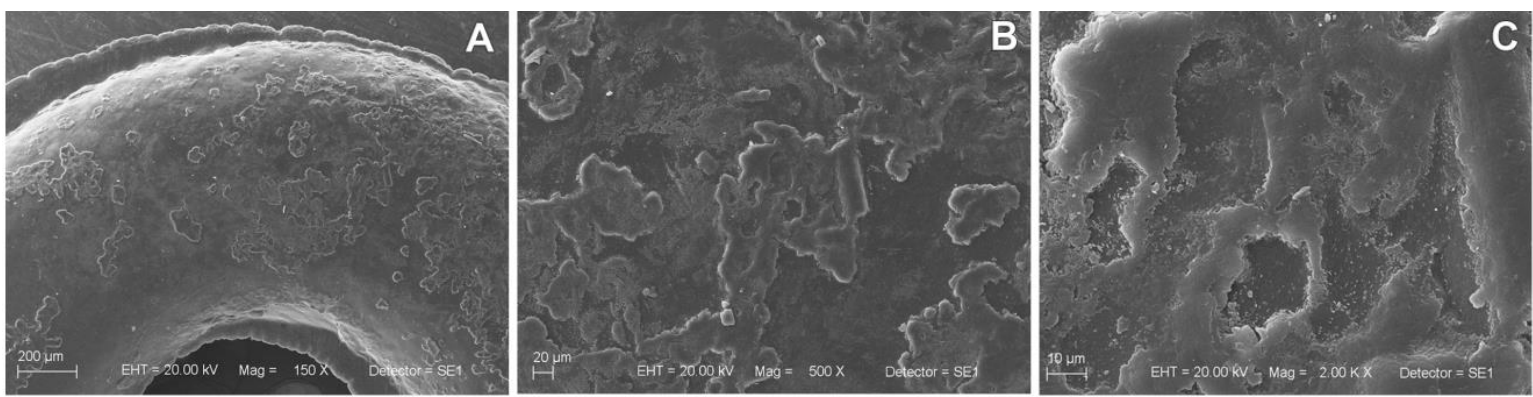

Figura 32 - Microscopia eletrônica de varredura - Ligadura Orthotechnology nova. A: aumento de 150X; B: aumento de 500X; C: aumento de 2000X.
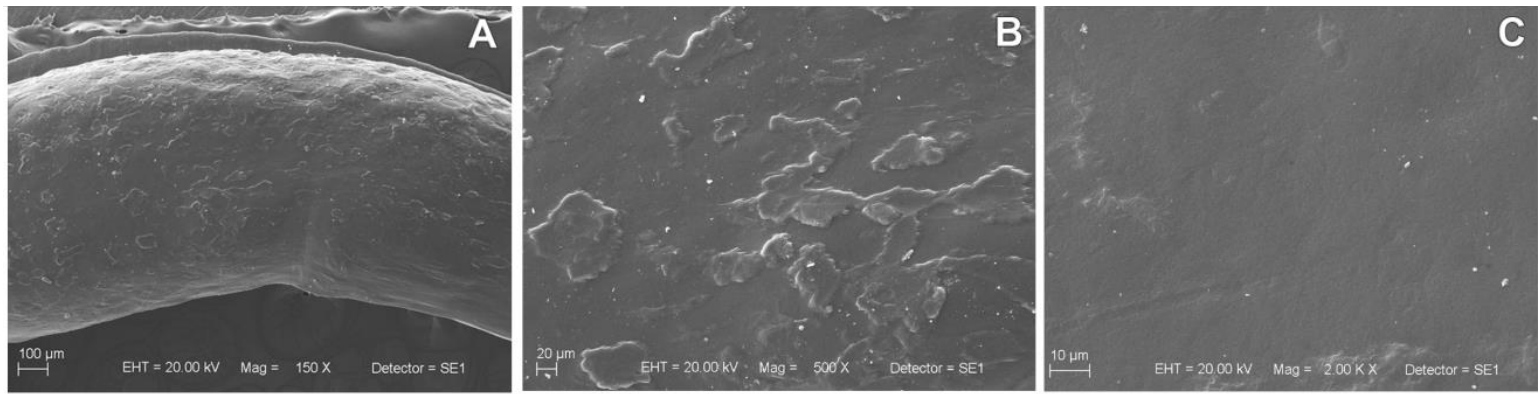

Figura 33 - Microscopia eletrônica de varredura - Ligadura Orthotechnology usada com dentifrício clareador com menor variação de cor. A: aumento de 150X; B: aumento de 500X; C: aumento de 2000X.

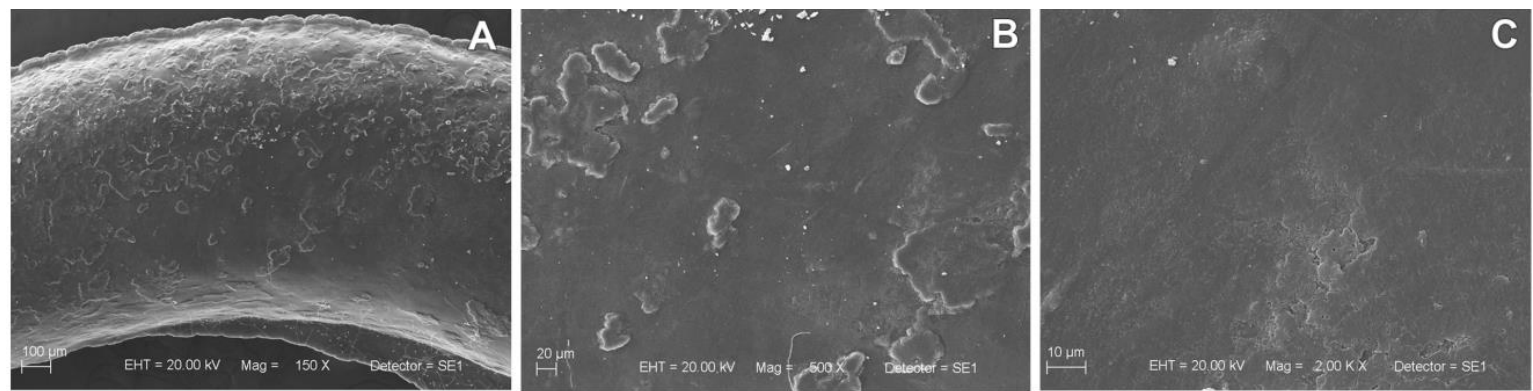

Figura 34 - Microscopia eletrônica de varredura - Ligadura Orthotechnology usada com dentifrício clareador com maior variação de cor. A: aumento de 150X; B: aumento de 500X; C: aumento de 2000X.
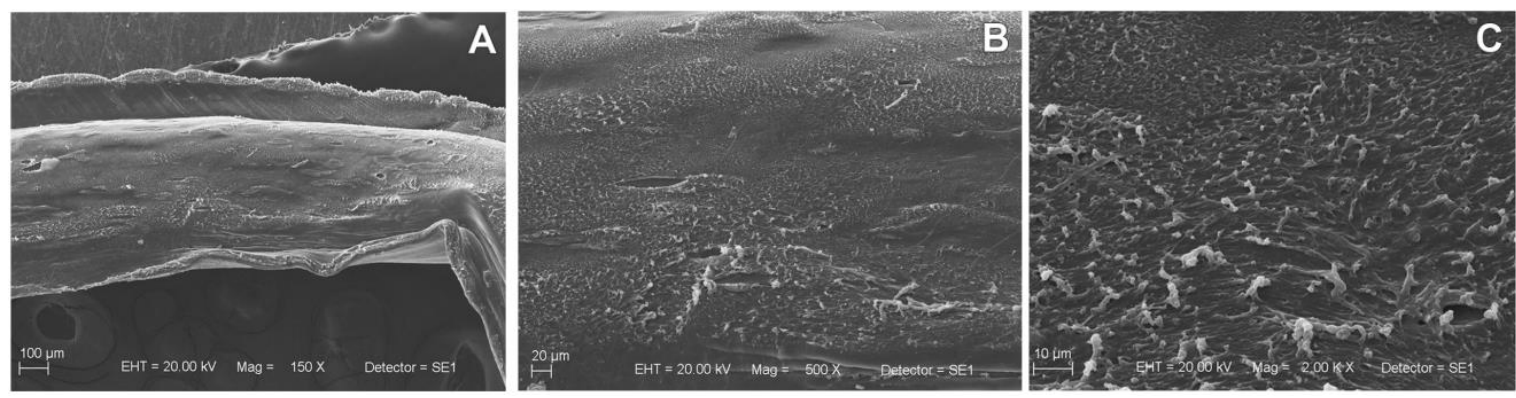

Figura 35 - Microscopia eletrônica de varredura - Ligadura Orthotechnology usada com dentifrício convencional com menor variação de cor. A: aumento de 150X; B: aumento de 500X; C: aumento de 2000X.

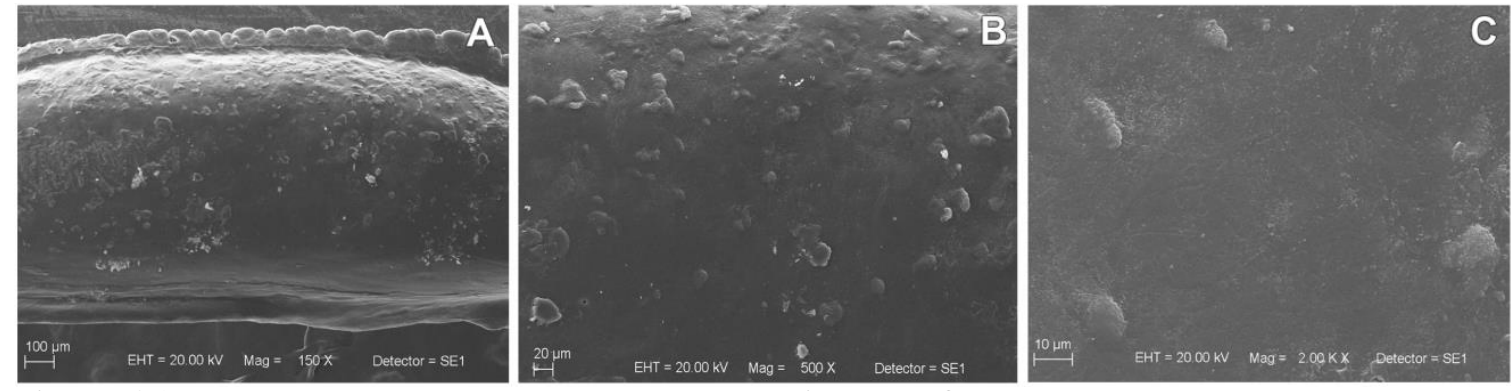

Figura 36 - Microscopia eletrônica de varredura - Ligadura Orthotechnology usada com dentifrício clareador com maior variação de cor. A: aumento de 150X; B: aumento de 500X; C: aumento de 2000X. 
A avaliação das imagens das ligaduras novas, sem uso, mostrou que as que apresentaram a superfície mais lisa, homogênea e sem porosidades foram as das marcas $3 \mathrm{M}$ Unitek e Morelli, sendo evidenciado desde as magnificações 150X até 2000X. A ligadura American Orthodontics apresentou superfície irregular, que parece ser uma película ou revestimento na magnificação $150 \mathrm{X}$, confirmado nos aumentos maiores. A pior qualidade foi indicada pela Orthotechnology, com superfície bastante irregular e acidentada com muitas porosidades, também evidentes nas magnificações maiores.

A comparação das imagens das ligaduras usadas com o dentifrício clareador e convencional permitiu a constatação de que a ligadura Morelli mostrou superfícies bem mais lisas que as demais, sendo evidenciado apenas com a magnificação de 2000 vezes, superfície pouco irregular tanto no uso do dentifrício clareador como convencional, enquanto que na marca 3M Unitek as irregularidades na superfície foram encontradas apenas nas ligaduras com menor alteração de cor e associadas ao dentifrício clareador. A marca Orthotechnology apresentou em todas as situações, superfícies bastante deterioradas e irregulares, sendo visíveis em todos os aumentos. Por sua vez, as ligaduras American Orthodontics apresentaram superfície lisa apenas nas ligaduras com maior alteração de cor e associadas com dentifrício clareador, nas demais observou-se evidente deterioração na película que a recobre, com perda da película superficial.

\subsection{Tração elástica}

Para o teste de tração elástica também foi confeccionada uma planilha específica onde foram incluídos os pacientes numerados de 1 a 20. Foram excluídos os pacientes número 9 e 17 por não terem seguido corretamente as recomendações durante o período experimental (Tabelas 10, 11, 12 e 13). 
Tabela 10 - Leituras do teste de tracão da marca Morelli (nacientes 1 ao 20).

\begin{tabular}{|c|c|c|c|c|c|c|c|c|c|}
\hline & \multicolumn{9}{|c|}{ Morelli } \\
\hline \multirow[b]{2}{*}{ Pacientes } & \multicolumn{3}{|c|}{ Leitura Inicial-Baseline-To } & \multicolumn{3}{|c|}{ Leitura Final-Pasta Convenc-T1 } & \multicolumn{3}{|c|}{ Leitura Final-Pasta Clareadora-T2 } \\
\hline & Força Max (kgf) & Força Max (N) & Deformação (mm) & Força Max (kgf) & Força Max (N) & \begin{tabular}{|l|} 
Deformação (mm) \\
\end{tabular} & Força Max (kgf) & Força Max (N) & Deformação (mm) \\
\hline 1 & 2,21 & 21,53 & 14,92 & 1,99 & 19,48 & 13,52 & 2,11 & 20,69 & 13,76 \\
\hline 2 & 2,21 & 21,53 & 14,92 & 2,13 & 20,85 & 14,46 & 2,14 & 21,01 & 14,45 \\
\hline 3 & 2,21 & 21,53 & 14,92 & 2,19 & 21,43 & 14,02 & 2,21 & 21,71 & 13,32 \\
\hline 4 & 2,21 & 21,53 & 14,92 & 2,09 & 20,52 & 14,29 & 2,06 & 20,24 & 13,35 \\
\hline 5 & 2,21 & 21,53 & 14,92 & 1,95 & 19,11 & 13,29 & 1,86 & 18,28 & 13,65 \\
\hline 6 & 2,21 & 21,53 & 14,92 & 2,12 & 20,84 & 13,86 & 2,07 & 20,33 & 12,73 \\
\hline 7 & 2,21 & 21,53 & 14,92 & 1,82 & 17,81 & 13,37 & 2,31 & 22,61 & 13,1 \\
\hline 8 & 2,21 & 21,53 & 14,92 & 2 & 19,57 & 14,68 & 1,91 & 18,7 & 14,27 \\
\hline \multicolumn{10}{|l|}{9} \\
\hline 10 & 2,21 & 21,53 & 14,92 & 1,9 & 18,63 & 13,15 & 1,98 & 19,39 & 13,2 \\
\hline 11 & 2,21 & 21,53 & 14,92 & 1,91 & 18,68 & 13,59 & 1,98 & 19,45 & 14,72 \\
\hline 12 & 2,21 & 21,53 & 14,92 & 1,87 & 18,37 & 13,43 & 1,99 & 19,51 & 14,68 \\
\hline 13 & 2,21 & 21,53 & 14,92 & 2,07 & 20,31 & 13,93 & 1,96 & 19,22 & 15 \\
\hline 14 & 2,21 & 21,53 & 14,92 & 2,05 & 20,06 & 14,2 & 2,01 & 19,74 & 13,56 \\
\hline 15 & 2,21 & 21,53 & 14,92 & 2,05 & 20,1 & 13,32 & 1,82 & 17,89 & 13,79 \\
\hline 16 & 2,21 & 21,53 & 14,92 & 2,15 & 21,08 & 13,38 & 1,89 & 18,55 & 13,88 \\
\hline \multicolumn{10}{|l|}{17} \\
\hline 18 & 2,21 & 21,53 & 14,92 & 2,06 & 20,16 & 13,75 & 1,98 & 19,44 & 14,02 \\
\hline 19 & 2,21 & 21,53 & 14,92 & 1,83 & 17,91 & 12,45 & 1,54 & 15,11 & 10,56 \\
\hline 20 & 2,21 & 21,53 & 14,92 & 1,56 & 15,31 & 12,27 & 1,8 & 17,65 & 12,45 \\
\hline
\end{tabular}

Tabela 11 - Leituras do teste de tração da marca American Orthodontics (pacientes 1 ao 20).

\begin{tabular}{|c|c|c|c|c|c|c|c|c|}
\hline \multicolumn{9}{|c|}{ American } \\
\hline \multicolumn{3}{|c|}{ Leitura Inicial-Baseline-To } & \multicolumn{3}{|c|}{ Leitura Final-Pasta Convenc-T1 } & \multicolumn{3}{|c|}{ Leitura Final-Pasta Clareadora-T2 } \\
\hline Força Max (kgf) & Força Max (N) & Deformação (mm) & Força Max (kgf) & Força Max (N) & Deformação (mm) & Força Max (kgf) & Força Max (N) & Deformação (mm) \\
\hline 2,62 & 25,71 & 12,19 & 2,44 & 23,93 & 11,71 & 2,48 & 24,29 & 11,49 \\
\hline 2,62 & 25,71 & 12,19 & 2,11 & 20,74 & 11,22 & 2,01 & 19,73 & 10,88 \\
\hline 2,62 & 25,71 & 12,19 & 2,34 & 22,97 & 11,51 & 2,08 & 20,42 & 11,09 \\
\hline 2,62 & 25,71 & 12,19 & 2,66 & 26,09 & 12,79 & 2,41 & 23,64 & 12,28 \\
\hline 2,62 & 25,71 & 12,19 & 2,17 & 21,31 & 11,92 & 2,53 & 24,81 & 12,32 \\
\hline 2,62 & 25,71 & 12,19 & 2,14 & 21,01 & 11,85 & 2,01 & 19,64 & 11,52 \\
\hline 2,62 & 25,71 & 12,19 & 2,23 & 21,89 & 11,07 & 2,33 & 22,88 & 11,39 \\
\hline 2,62 & 25,71 & 12,19 & 2,34 & 22,98 & 11,92 & 2,35 & 23,04 & 12,37 \\
\hline & & & & & & & & \\
\hline 2,62 & 25,71 & 12,19 & 2,52 & 24,72 & 12,07 & 2,23 & 21,89 & 11,37 \\
\hline 2,62 & 25,71 & 12,19 & 2,31 & 22,65 & 11,8 & 2,45 & 24,01 & 12,87 \\
\hline 2,62 & 25,71 & 12,19 & 2,29 & 22,47 & 12,13 & 2,1 & 20,57 & 11,9 \\
\hline 2,62 & 25,71 & 12,19 & 2,4 & 23,51 & 12,15 & 1,97 & 19,31 & 11,69 \\
\hline 2,62 & 25,71 & 12,19 & 1,74 & 17,11 & 11,01 & 2,25 & 22,09 & 12,88 \\
\hline 2,62 & 25,71 & 12,19 & 2,16 & 21,17 & 11,54 & 2,39 & 23,39 & 11,87 \\
\hline 2,62 & 25,71 & 12,19 & 2,55 & 25 & 12,13 & 1,99 & 19,56 & 11,19 \\
\hline & & & & & & & & \\
\hline 2,62 & 25,71 & 12,19 & 2,39 & 23,47 & 12,33 & 1,87 & 18,31 & 11,84 \\
\hline 2,62 & 25,71 & 12,19 & 2,42 & 23,78 & 12,19 & 2,31 & 22,69 & 11,82 \\
\hline 2,62 & 25,71 & 12,19 & 2,29 & 22,42 & 11,88 & 2,32 & 22,75 & 11,83 \\
\hline
\end{tabular}

Tabela 12 - Leituras do teste de tração da marca 3M Unitek (pacientes 1 ao 20).

\begin{tabular}{|c|c|c|c|c|c|c|c|c|}
\hline \multicolumn{9}{|c|}{$3 \mathrm{M}$} \\
\hline \multicolumn{3}{|c|}{ Leitura Inicial-Baseline-To } & \multicolumn{3}{|c|}{ Leitura Final-Pasta Convenc-T1 } & \multicolumn{3}{|c|}{ Leitura Final-Pasta Clareadora-T2 } \\
\hline Força Max (kgf) & Força Max (N) & Deformação (mm) & Força Max (kgf) & Força Max (N) & Deformação (mm) & Força Max (kgf) & Força Max (N) & Deformação (mm) \\
\hline 2,69 & 26,33 & 11,37 & 2,31 & 22,58 & 11,13 & 2,33 & 22,87 & 10,91 \\
\hline 2,69 & 26,33 & 11,37 & 2,42 & 23,78 & 11,28 & 1,96 & 19,21 & 10,61 \\
\hline 2,69 & 26,33 & 11,37 & 2,49 & 24,41 & 11,43 & 2,28 & 22,35 & 11,11 \\
\hline 2,69 & 26,33 & 11,37 & 2,61 & 25,59 & 11,77 & 2,63 & 25,76 & 11,82 \\
\hline 2,69 & 26,33 & 11,37 & 2,35 & 23,01 & 11,37 & 2,66 & 26,08 & 11,74 \\
\hline 2,69 & 26,33 & 11,37 & 2,43 & 23,85 & 11,54 & 2,31 & 22,64 & 11,84 \\
\hline 2,69 & 26,33 & 11,37 & 2,39 & 23,41 & 10,88 & 2,46 & 24,14 & 11,83 \\
\hline 2,69 & 26,33 & 11,37 & 2,57 & 25,16 & 11,6 & 2,41 & 23,66 & 11,9 \\
\hline & & & & & & & & \\
\hline 2,69 & 26,33 & 11,37 & 2,3 & 22,6 & 11,91 & 2,3 & 22,55 & 11,81 \\
\hline 2,69 & 26,33 & 11,37 & 2,15 & 21,05 & 10,48 & 1,95 & 19,1 & 11,32 \\
\hline 2,69 & 26,33 & 11,37 & 2,55 & 25,04 & 12,51 & 2,22 & 21,78 & 11,98 \\
\hline 2,69 & 26,33 & 11,37 & 2,51 & 24,62 & 11,5 & 2,19 & 21,45 & 12,11 \\
\hline 2,69 & 26,33 & 11,37 & 2,22 & 21,75 & 11,67 & 1,87 & 18,33 & 10,8 \\
\hline 2,69 & 26,33 & 11,37 & 2,41 & 23,65 & 11,69 & 2,25 & 22,07 & 11,56 \\
\hline 2,69 & 26,33 & 11,37 & 2,36 & 23,12 & 12,01 & 2,05 & 20,08 & 10,81 \\
\hline & & & & & & & & \\
\hline 2,69 & 26,33 & 11,37 & 2,17 & 21,24 & 11,95 & 2,04 & 19,98 & 10,95 \\
\hline 2,69 & 26,33 & 11,37 & 2,17 & 21,26 & 10,66 & 1,63 & 16 & 9,53 \\
\hline 2,69 & 26,33 & 11,37 & 2,24 & 21,95 & 11,02 & 2,32 & 22,71 & 11,08 \\
\hline
\end{tabular}


Tabela 13 - Leituras do teste de tração da marca Orthotechnology (pacientes 1 ao 20).

\begin{tabular}{|c|c|c|c|c|c|c|c|c|}
\hline \multicolumn{9}{|c|}{ Orthotechnology } \\
\hline \multicolumn{3}{|c|}{ Leitura Inicial-Baseline-To } & \multicolumn{3}{|c|}{ Leitura Final-Pasta Convenc-T1 } & \multicolumn{3}{|c|}{ Leitura Final-Pasta Clareadora-T2 } \\
\hline Força Max (kgf) & Força Max (N) & Deformação (mm) & Força Max (kgf) & Força Max (N) & Deformação $(\mathrm{mm})$ & Força Max (kgf) & Força Max (N) & Deformação (mm) \\
\hline 2,39 & 23,41 & 11,04 & 2,04 & 19,99 & 11,13 & 1,95 & 19,09 & 9,66 \\
\hline 2,39 & 23,41 & 11,04 & 1,93 & 18,92 & 11,05 & 1,74 & 17,02 & 9,46 \\
\hline 2,39 & 23,41 & 11,04 & 1,82 & 17,88 & 10,58 & 1,81 & 17,65 & 8,96 \\
\hline 2,39 & 23,41 & 11,04 & 1,93 & 18,97 & 12,12 & 1,89 & 18,55 & 8,72 \\
\hline 2,39 & 23,41 & 11,04 & 1,68 & 16,45 & 10,94 & 1,76 & 17,29 & 10,17 \\
\hline 2,39 & 23,41 & 11,04 & 1,78 & 17,44 & 11,16 & 1,89 & 18,55 & 9,95 \\
\hline 2,39 & 23,41 & 11,04 & 1,5 & 14,74 & 10,1 & 1,87 & 18,35 & 9,01 \\
\hline 2,39 & 23,41 & 11,04 & 1,84 & 18,07 & 13,04 & 1,76 & 17,25 & 10,76 \\
\hline & & & & & & & & \\
\hline 2,39 & 23,41 & 11,04 & 1,56 & 15,29 & 10,87 & 1,59 & 15,55 & 9,16 \\
\hline 2,39 & 23,41 & 11,04 & 2,05 & 20,09 & 10,84 & 1,86 & 18,26 & 10,3 \\
\hline 2,39 & 23,41 & 11,04 & 1,91 & 18,69 & 11,06 & 1,58 & 15,5 & 10,32 \\
\hline 2,39 & 23,41 & 11,04 & 1,71 & 16,79 & 10,46 & 1,46 & 14,29 & 10,2 \\
\hline 2,39 & 23,41 & 11,04 & 1,78 & 17,47 & 10,09 & 2,1 & 20,57 & 11,67 \\
\hline 2,39 & 23,41 & 11,04 & 1,85 & 18,14 & 9,71 & 1,41 & 13,83 & 9,14 \\
\hline 2,39 & 23,41 & 11,04 & 1,79 & 17,55 & 12,31 & 1,83 & 17,93 & 9,53 \\
\hline 2,39 & 23,41 & 11,04 & 1,63 & 15,99 & 10,84 & 1,79 & 17,56 & 10,68 \\
\hline 2,39 & 23,41 & 11,04 & 1,74 & 17,1 & 11,78 & 2,1 & 20,58 & 13,65 \\
\hline 2,39 & 23,41 & 11,04 & 1,74 & 17,02 & 10,99 & 1,93 & 18,94 & 11,25 \\
\hline
\end{tabular}

Os resultados para força máxima de tração em Newtons $(\mathrm{N})$ e para a deformação em milímetros (mm) estão representados na tabela 14 e nos gráficos 5 e 6 .

Tabela 14 - Resultado do teste de tração elástica (letras minúsculas indicam semelhança estatística entre linhas, letras maiúsculas indicam semelhança estatística entre colunas).

\begin{tabular}{|c|c|c|c|c|c|c|}
\hline \multirow[b]{2}{*}{ Marcas } & \multicolumn{3}{|c|}{ Força Máxima (N) } & \multicolumn{3}{|c|}{ Deformação (mm) } \\
\hline & $\begin{array}{c}\text { B } \\
\text { baseline }\end{array}$ & $\begin{array}{c}\text { CO } \\
\text { convencional }\end{array}$ & $\begin{array}{c}\text { CL } \\
\text { clareador }\end{array}$ & $\begin{array}{c}\text { B } \\
\text { baseline }\end{array}$ & $\begin{array}{c}\text { CO } \\
\text { convencional }\end{array}$ & $\begin{array}{c}\text { CL } \\
\text { clareador }\end{array}$ \\
\hline Morelli & $21,53 \pm 0,00 \mathrm{Aa}$ & $19,45 \pm 1,50 \mathrm{Ba}$ & $19,41 \pm 1,67 \mathrm{Ba}$ & $14,92 \pm 0,00 \mathrm{Aa}$ & $13,60 \pm 0,62 \mathrm{Ba}$ & $13,58 \pm 1,02 \mathrm{Ba}$ \\
\hline American & $25,71 \pm 0,00 \mathrm{Ab}$ & $22,62 \pm 1,99 \mathrm{Bb}$ & $21,83 \pm 1,97 \mathrm{Bb}$ & $12,19 \pm 0,00 \mathrm{Ab}$ & $11,84 \pm 0,45 \mathrm{Bb}$ & $11,81 \pm 0,56 \mathrm{Bb}$ \\
\hline $3 \mathrm{M}$ & $26,33 \pm 0,00 \mathrm{Ac}$ & $23,22 \pm 1,41 \mathrm{Bb}$ & $21,70 \pm 2,57 \mathrm{Cb}$ & $11,37 \pm 0,00 \mathrm{Ac}$ & $11,46 \pm 0,50 \mathrm{Abc}$ & $11,31 \pm 0,65 \mathrm{Ab}$ \\
\hline Orthotechnology & $23,41 \pm 0,00 \mathrm{Ad}$ & $17,58 \pm 1,45 \mathrm{Bc}$ & $17,59 \pm 1,86 \mathrm{Bc}$ & $11,04 \pm 0,00 \mathrm{Ac}$ & $11,05 \pm 0,82 \mathrm{Ac}$ & $10,14 \pm 1,19 \mathrm{Bc}$ \\
\hline
\end{tabular}

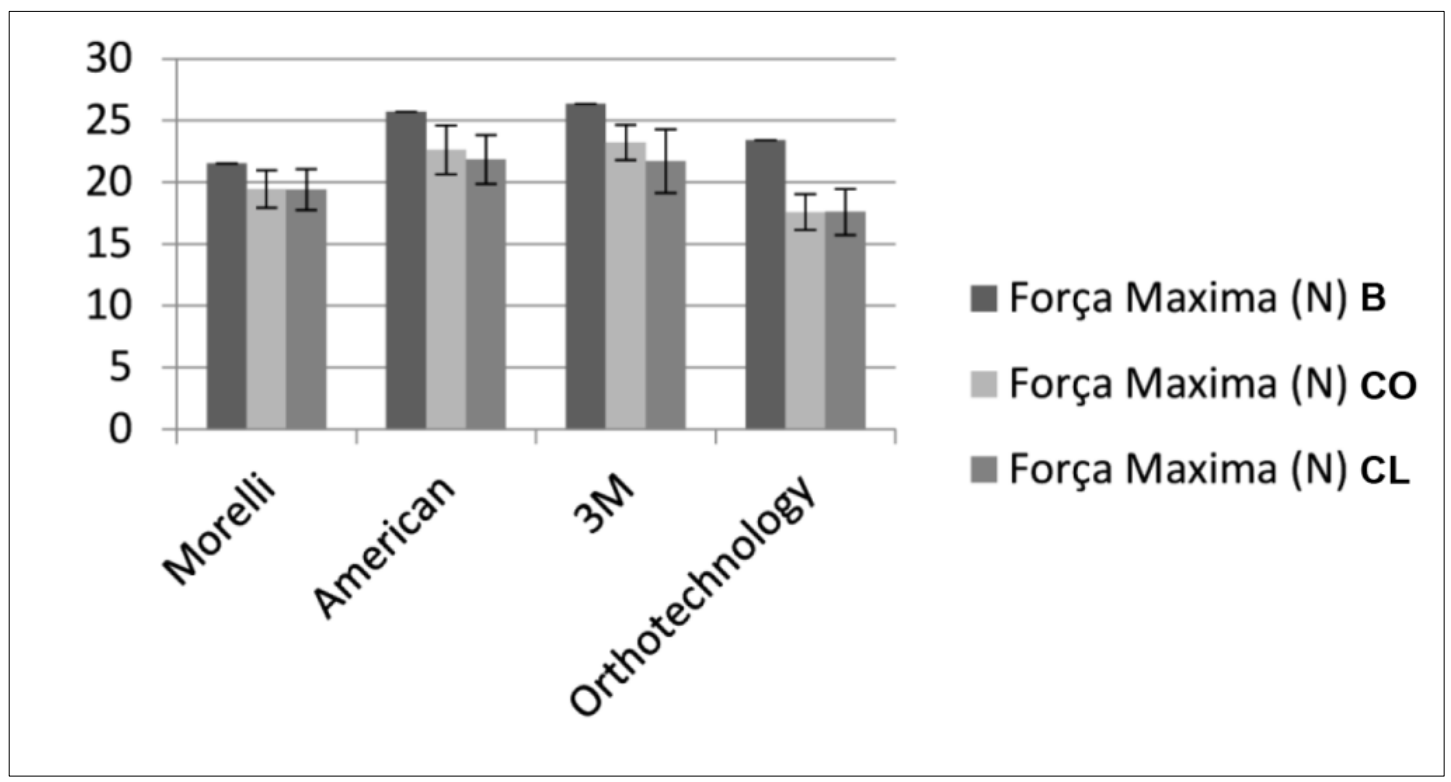

Gráfico 5 - Resultado das forças máximas do teste de tração elástica (N). 


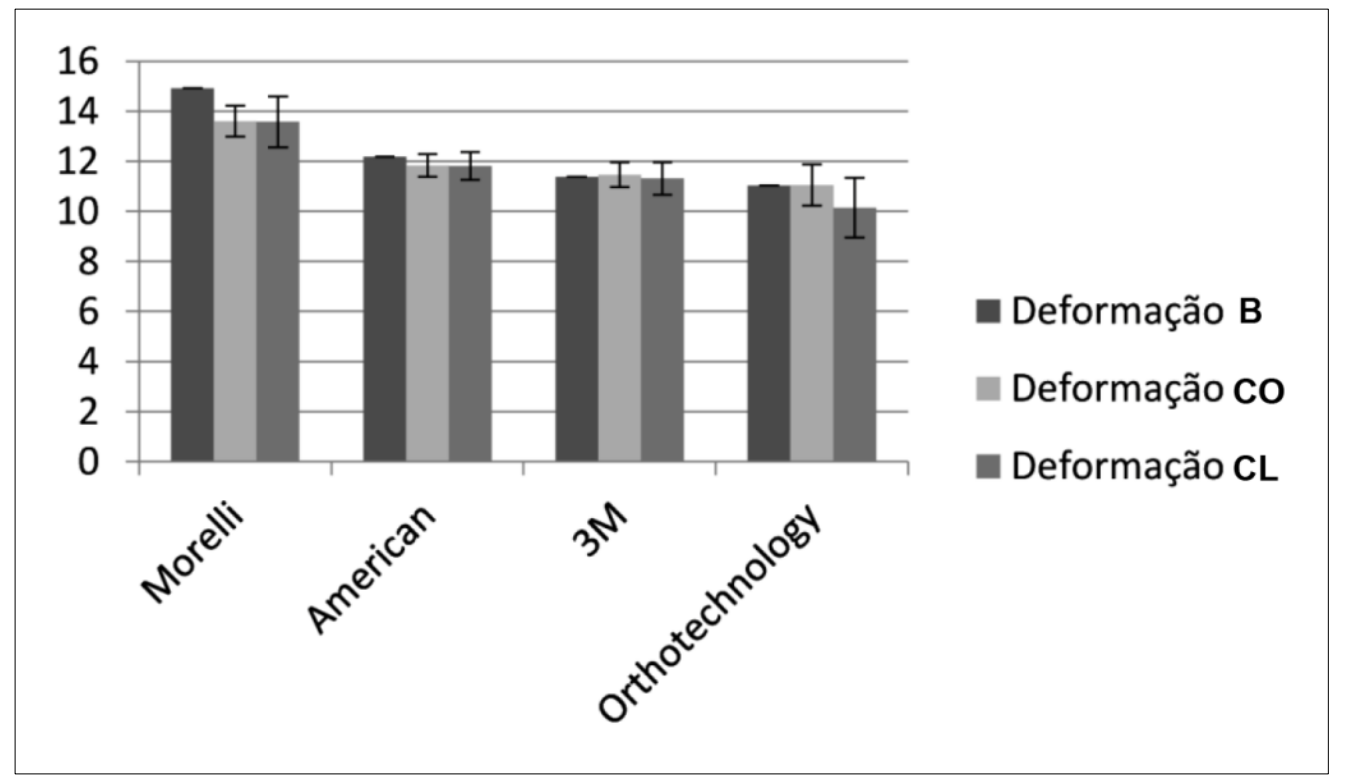

Gráfico 6 - Resultado da deformação do teste de tração elástica (mm).

Para a força máxima, ou seja, a força necessária para a ruptura da ligadura nova em Newtons observou-se os maiores valores foram obtidos para a marca 3M Unitek, seguida da American Orthodontics, Orthotechnology e por fim Morelli.

Notou-se ainda que houve diminuição estatisticamente significante da força máxima de ruptura em todas as marcas, após 30 dias na cavidade bucal, para ambos os dentifrícios (convencional e clareador) quando comparados com os valores das ligaduras sem uso (baseline).

Após o uso do dentifrício convencional e clareador, resultados semelhantes foram encontrados para as ligaduras 3M Unitek e American Orthodontics que apresentaram os maiores valores de força de ruptura seguidos da marca Morelli e por fim a marca Orthotechnology que apresentou os menores valores.

Interpretando-se esses achados pode-se afirmar que independentemente da pasta utilizada, as marcas 3M Unitek e American Orthodontics mostraram-se superiores às demais quanto às propriedades elásticas.

No que se refere à deformação, que foi medida em milímetros ( $\mathrm{mm})$, no baseline, ou seja, a ligadura nova, a marca Morelli obteve os maiores valores seguida da marca American Orthodontics. As ligaduras 3M Unitek e Orthotechnology sofreram menor deformação e foram estatisticamente semelhantes. Após 30 dias na cavidade bucal com uso do dentifrício convencional essa condição se repetiu, onde Morelli mostrou maior deformação, seguida de American Orthodontics com valores intermediários e finalmente $3 \mathrm{M}$ Unitek e 
Orthotechnology que apresentaram valores menores de deformação semelhantes estatisticamente.

Os achados encontrados após o uso do dentifrício clareador foram diferentes do dentifrício convencional uma vez que foi constatado que a ligadura Orthotechnology apresentou deformação estatisticamente menor que American Orthodontics e 3M, com valores intermediários, enquanto Morelli foi a que sofreu maior deformação.

Comparando-se as ligaduras após uso do dentifrício convencional, todas mostraram redução nos valores da deformação em relação às ligaduras novas (baseline) exceto a marca 3M Unitek e Orthotechnology, que mantiveram a deformação constante. Após o uso do dentifrício clareador, as ligaduras Morelli e American Orthodontics apresentaram menor deformação quando comparadas às ligaduras novas (baseline) conforme ocorreu com o uso do dentifrício convencional. Contudo, a ligadura Orthotechnology, que manteve a deformação com o uso do dentifrício convencional, apresentou deformação diminuída comprovada estatisticamente. Dessa forma, parece lícito afirmar que não houve influência do tipo de dentifrício na deformação elástica da ligadura. Apenas a ligadura Orthotechnology evidenciou resultados diferentes, pois com o dentifrício clareador sua deformação foi menor. 
5. Discussão 


\section{DISCUSSÃO}

O presente estudo objetivou, inicialmente, investigar um aspecto clínico que faz parte da rotina de atendimentos de grande parte dos profissionais que se dedicam à Ortodontia. Hoje em dia, é muito grande o número de pacientes que optam pelo uso de bráquetes estéticos, sejam mono ou poli cristalinos. Assim, o fato de que tais bráquetes (excetuando os auto-ligados) necessitam de ligaduras elásticas estéticas para atar o arco ortodôntico ganha considerável relevância, uma vez que essas ligaduras influenciam diretamente no aspecto do aparelho e na aparência do sorriso durante todo o tratamento que, em sua maioria, dura meses ou até alguns anos.

De acordo com Cappeli Jr et al. (2014) e Ferraz et al. (2012), os ortodontistas devem estar atentos às expectativas estéticas e funcionais dos pacientes em relação ao tratamento ortodôntico. Nesse sentido, os principais fatores que impactam os pacientes e suas escolhas dizem respeito à dor, ao tempo de tratamento e à estética do aparelho a ser utilizado. Ziuchkovski et al. (2008) conduziram um estudo em que avaliaram a atratividade de diversos tipos de aparelhos ortodônticos por 200 avaliadores. Os resultados mostraram que os mais atrativos foram os aparelhos alternativos como alinhadores e aparelhos linguais, e que os aparelhos cerâmicos vieram em segundo lugar. De fato, a procura pelos acessórios estéticos cresceu consideravelmente, e até mesmo adolescentes não querem mais ter o "sorriso metálico" e avaliam bráquetes cerâmicos como mais agradáveis (Kuhlman et al., 2016). Dentro desse contexto, justifica-se a preocupação com o desempenho da ligadura estética, uma vez que constantes trocas entre as consultas levam a aumento no tempo de cadeira, aumento no número de visitas e maiores gastos.

Com essa preocupação, porém de forma empírica, pensou-se na possibilidade do uso de uma pasta dental indicada para clareamento na tentativa de minimizar a alteração de cor das ligaduras estéticas e assim reduzir o número de trocas. De fato, esse procedimento mostrou-se bem-sucedido e amplamente aceito. Em uma criteriosa consulta à literatura, não havia nenhum artigo sobre essa conduta clínica. Até que em 2015, Oliveira et al. estudaram, in vitro, a influência de dentifrício clareador e convencional na estabilidade de cor de ligaduras ortodônticas estéticas, vindo de encontro à ideia da presente pesquisa. Os autores enfatizaram que a frequência e o tipo de dentifrício utilizados rotineiramente podem influenciar na estabilidade de cor dos materiais dentários, mas que, até aquele momento, não havia evidências sobre o efeito do dentifrício clareador nas ligaduras ortodônticas. No 
entanto, na conclusão do seu trabalho pontuaram que o uso do dentifrício clareador poderia minimizar o manchamento progressivo aumentando a satisfação dos pacientes.

O presente trabalho foi realizado, in vivo, com uma amostra de 20 pacientes. $\mathrm{Na}$ época em que foi iniciado não havia trabalhos similares na literatura. O estudo citado de Oliveira et al. (2015) foi realizado in vitro, e utilizou 10 ligaduras de cada marca estudada. O trabalho de Soldati et al. (2013) que avaliou, in vitro, 5 marcas de ligaduras estéticas (três delas também avaliadas no presente estudo) utilizou uma amostra de 20 ligaduras por marca. Já o recente estudo de Kawabata et al. (2016) que utilizou uma metodologia parecida com a deste estudo com um delineamento do tipo boca dividida, ou seja, com marcas diferentes em quadrantes diferentes no mesmo indivíduo, também utilizou uma amostra com 20 pacientes. Estudos com elásticos intra-orais, elásticos em corrente ou elásticos de separação geralmente utilizam uma amostra maior, especialmente aqueles realizados in vitro (Stevenson e Kusy, 1994; Russel et al., 2001; Mendes et al., 2012, Vieira et al., 2013). Na presente pesquisa, por seu caráter in vivo, após a apreciação da literatura e do projeto de pesquisa, o cálculo amostral indicou que uma amostra de 20 pacientes seria suficiente para produzir resultados confiáveis.

Uma vez definido o tamanho da amostra e os critérios de inclusão, chega-se a um ponto que cabe discussão: os hábitos alimentares dos pacientes. Desde os primeiros estudos sobre pigmentação de ligaduras estéticas como o de Lew (1990) até o de Talic e Almudhi (2016) e Silva et al. (2016), o controle dos alimentos aos quais as ligaduras eram expostas é uma preocupação. Esse aspecto pode ser perfeitamente controlado nos estudos in vitro, tanto no tempo de exposição quanto à característica do alimento (líquido, pastoso ou sólido). Contudo, como lembram Kawabata et al. (2016), esses estudos não reproduzem a infinidade de fatores presentes na cavidade bucal que podem contribuir para as mudanças de cor e elasticidade (umidade, variação de temperatura e $\mathrm{pH}$, presença de micro-organismos, efeito da escovação e etc.). Nos trabalhos in vivo é muito difícil realizar uma padronização, porém podem evidenciar uma situação mais próxima da realidade. Na presente pesquisa, por ser uma amostra que foi tratada e orientada pelo mesmo profissional, que residia na mesma cidade, com características econômicas, sociais e culturais semelhantes e por apresentarem uma faixa etária relativamente homogênea, de 15 a 20 anos, presume-se que não houve grandes variações nos hábitos alimentares.

Outro ponto importante foi a seleção das marcas comerciais estudadas. As marcas American Orthodontics e 3M Unitek são amplamente conhecidas e utilizadas em todo o mundo sendo alvo de inúmeras investigações (Talic e Almudhi, 2016; Kuhlman et al., 2016; Kawabata et al., 2016). Já a marca Orthotechnology, menos estudada, foi incluída pela 
experiência clínica do autor estando presente na recente pesquisa de Silva et al. (2016). A marca Morelli, por sua vez, por ser a mais conhecida no mercado nacional, portanto, largamente utilizada (Kawabata et al., 2016). Além disso, na tentativa de padronizar a metodologia, foram escolhidas somente as tonalidades pearl (pérola) que são as indicadas pelos fabricantes para uso com bráquetes estéticos e que, clinicamente, se comportam melhor do que as da tonalidade cristal (transparente). No que diz respeito às marcas dentifrícios, foram escolhidos por serem amplamente conhecidos e utilizados e por terem custo acessível.

Devido ao fato dessa pesquisa ter sido realizada num ambiente acadêmico e por uma relevante questão de custos, os pacientes foram tratados com bráquetes metálicos e não estéticos. Poderia se pensar na possibilidade da influência do metal na pigmentação das ligaduras. De fato, o estudo in vitro, de Maia et al. (2012) mostra que é possível que íons metálicos (cromo e níquel) dos bráquetes se incorporem ao esmalte dental e, portanto, podem alterar a cor dos dentes (e/ou ligaduras no caso). No entanto, essa situação, se levada em conta no presente estudo, seria muito improvável visto que as ligaduras estudadas permaneceram por 30 dias na cavidade bucal, o que corresponde ao período normal em que são substituídas. Seria um tempo muito curto para que houvesse corrosão do metal e liberação de íons o que normalmente ocorre em situações extremas e longos períodos. O estudo de Gandikota et al. (2015) que também avaliou alteração de cor, foi feito, como na presente pesquisa, com ligaduras posicionadas em bráquetes metálicos por 30 dias.

As ligaduras submetidas à análise da alteração de cor foram posicionadas nos caninos (13, 23, 33 e 43). Esse posicionamento, por quadrantes, bem como o tempo de permanência e o sistema de rodízio, foram os mesmos adotados por Kawabata et al. (2016). Já em relação às ligaduras avaliadas pelo teste de tração, foram escolhidos os incisivos inferiores pois os bráquetes desses dentes tem a mesma dimensão no sentido mésio-distal e cérvicoincisal, além do uso do acessório Shooter para auxiliar na padronização da distensão inicial durante o posicionamento dessas ligaduras. Mais um artifício usado na tentativa de padronizar essa etapa metodológica conforme Abrão et al. (2006).

Cabe ressaltar que as ligaduras foram armazenadas em saliva artificial. A literatura relata divergências nesse aspecto. Alguns estudos utilizam a água destilada (Koksal e Dikbas, 2007; Oota et al., 2013; Soldati et al., 2013), outros, saliva artificial (Abrão et al., 2006; Masoud et al., 2016). No presente estudo, optou-se pela saliva artificial para simular as condições bucais. No entanto, o tempo de armazenamento foi curto, uma vez que, os ensaios foram realizados nos dias subsequentes à remoção. 
No que diz respeito ao método de medida da alteração de cor, havia várias possibilidades metodológicas relatadas na literatura. Desde escala padronizada (Lew, 1990), fotografia digital (Kim e Lee, 2009 e Tambelli et al., 2014), colorímetro (Goldstein e Schmitt, 1993) e por fim a espectrofotometria. Este último método tem sido amplamente empregado tanto em trabalhos clínicos quanto laboratoriais por sua praticidade e facilidade no uso e também por sua acurácia e confiabilidade (Chang et al., 2013 e Gómez-Polo et al., 2014). Existem no mercado algumas marcas comerciais de espectrofotômetros (X-Rite, Minolta, Vita). No presente estudo foi utilizado o equipamento Vita Easyshade Compact (Zahnfabrik, Bad Säckingen, Alemanha) por ter sido alvo de estudos anteriores que atestaram a sua validade (Olms e Setz, 2013 e Alves et al., 2014). Todos as leituras foram feitas por um mesmo operador, previamente calibrado, sempre no mesmo ambiente, na mesma temperatura e com a mesma iluminação.

É importante ressaltar que a ponteira do espectrofotômetro tem $6 \mathrm{~mm}$ de diâmetro e quando acionada, 19 fibras óticas tem a função de iluminação e 2 sensores leem numericamente a cor (Roselino, 2015). Como a ligadura não é um objeto liso ou plano como o esmalte da face vestibular ou um corpo de prova de resina e como seu diâmetro ( $3 \mathrm{~mm})$ é bem menor do que o da ponteira, era necessário criar um artifício que posicionasse corretamente a ligadura para que a leitura fosse feita sempre na mesma posição com precisão. O trabalho de Kim e Lee (2009) chama a atenção para essa dificuldade. Dessa forma, foi confeccionada uma matriz em resina acrílica transparente (para não gerar nenhuma interferência) que possuía uma canaleta onde se inseria a ligadura e uma borda na qual se encaixava perfeitamente a ponteira do Easyshade. Todas as leituras foram repetidas 3 vezes e utilizada a média conforme o protocolo recomendado por Roselino (2015).

Além da alteração de cor, a literatura mostra que os estudos sobre elastômeros utilizados na Ortodontia também abordam outros aspectos como a contaminação bacteriana e os efeitos de soluções antimicrobianas sobre as propriedades físicas dos mesmos (Benson et al., 2004; Brêtas et al., 2005; Evangelista et al., 2007; Magno et al. 2008; Pithon et al., 2013; Morelli, 2016). Partindo-se do pressuposto que as ligaduras foram expostas a um agente abrasivo (dentifrício clareador) entendeu-se que era necessário investigar também, a possível influência na propriedade funcional das mesmas. Assim, seria interessante que o dentifrício clareador não prejudicasse sua propriedade elástica, uma vez que a função primordial da ligadura é manter o fio ortodôntico justaposto à canaleta do bráquete e, caso houvesse diminuição na elasticidade, essa função mecânica seria prejudicada. Dessa forma, foi realizado o teste de tração elástica na Máquina de Ensaio Mecânico Universal (EMIC DL 
2000, São José dos Pinhais, PR, Brasil). Os protocolos utilizados seguiram metodologia de outros trabalhos já publicados no que diz respeito ao uso de ganchos indeformáveis de aço inoxidável para prender as ligaduras e à velocidade de distensão de $5 \mathrm{~mm} / \mathrm{min}$ (Souza et al., 2008; Guimarães et al., 2013; Ahrari et al., 2016).

Por fim, para detectar visualmente e qualitativamente o aspecto das ligaduras submetidas a pasta clareadora e convencional, entendeu-se que a observação pela Microscopia Eletrônica de Varredura seria válida, na tentativa de relacionar a presença de trincas, rachaduras, algum tipo de desgaste, porosidade ou deformação a maior ou menor grau de pigmentação dependendo do dentifrício utilizado (Guimarães, et al., 2013 e Fernandes et al., 2014).

De acordo com Barcessat (2007) a percepção da cor é subjetiva e necessita de parâmetros quantitativos para ser mensurada. Tais informações podem ser dadas pela espectrofotometria. A maioria dos espectrofotômetros utiliza o sistema CIE L* $a^{*} b^{*}$. Esse sistema foi definido em 1976 pela Commission Internationale L' Eclairage (CIE) e através dele, o espectro de cores é filtrado de forma que o espectro do matiz vermelho, verde e azul é extraído com 3 coordenadas, da forma como são percebidas pelo olho humano e então processadas para resultar nas leituras de $\mathrm{L}^{*}, \mathrm{a}^{*}, \mathrm{~b}^{*}$. Através de uma fórmula $\left(\Delta \mathrm{E}=\sqrt{ }\left(\Delta \mathrm{L}^{*}\right)^{2}+\right.$ $\left.\left(\Delta \mathrm{a}^{*}\right)^{2}+\left(\Delta \mathrm{b}^{*}\right)^{2)}\right)$, é possível então calcular a alteração total de cor $(\Delta \mathrm{E})$.

No entanto, conforme observado por Roselino (2015) e Pintado-Palomino et al. (2016), a medida $\Delta \mathrm{E}$ é a representação das 3 coordenadas e usada para representar a magnitude da diferença de cor entre objetos do mesmo tamanho e forma, vistos no mesmo ambiente, por um único observador, com as mesmas condições ambientais, ou seja, uma medida espacial da diferença de cor, sem, no entanto, haver uma descrição de qual (s) coordenada (s) foi responsável (s) pela alteração da cor. Dessa forma, é importante avaliar as coordenadas separadamente para um melhor entendimento da alteração ocorrida.

$\mathrm{O}$ resultado da variação total de cor $\Delta \mathrm{E}$, evidenciou que todas as ligaduras com dentifrícios convencionais e clareadores apresentaram alteração de cor considerada clinicamente inaceitável $(\Delta \mathrm{E}>3,3)$, sendo indicada a substituição do material por motivos estéticos. Os resultados mostraram que o dentifrício clareador mostrou alguma efetividade nas ligaduras Orthotechnology e Morelli, sem, no entanto, produzirem um valor de $\Delta \mathrm{E}$ que as mantivessem dentro de padrões clínicos aceitáveis. Portanto, no presente estudo, o uso do dentifrício clareador não contribuiu para a estabilidade de cor das ligaduras num período de 30 dias. 
Ao se avaliar as coordenadas separadamente, a medida $\Delta \mathrm{L}$, referente à luminosidade (claro-escuro), mostrou que, de fato, todas as marcas apresentaram diferenças quando ambos os dentifrícios foram usados. No que diz respeito à variação do branco ao preto, o dentifrício clareador modificou o aspecto das ligaduras aumentando a luminosidade (mais claridade) nas marcas 3M Unitek e Orthotechnology, mas diminuindo a mesma (mais escurecimento) nas ligaduras Morelli e American Orthodontics. É importante salientar que a coordenada L* tem grande importância na análise dos resultados já que representa a luminosidade das amostras. O olho humano é capaz de perceber as variações neste eixo mais claramente que nos eixos a* e $b^{*}$, pois a quantidade de células responsáveis pela visão em preto e branco (bastonetes) é muito maior do que a de células responsáveis pela visão colorida (cones). Assim, qualquer perda de luminosidade é fundamental para a estabilidade de cor e sucesso clínico (AlandiaRomán, 2011).

Em relação à variável $\Delta$ a que representa o eixo verde-vermelho, observou-se que com o dentifrício convencional ( $\mathrm{CO}$ ) a ligadura Morelli demonstrou maior mudança de tonalidade ao longo da escala tendendo mais para o verde do que com o dentifrício clareador, que diminuiu essa tendência. As ligaduras Morelli, American Orthodontics e Orthotechnology demonstraram tonalidade tendendo para o verde, maior para a marca Morelli, enquanto a ligadura 3M não apresentou essa tendência com o uso do dentifrício convencional. Com o dentifrício clareador essa tendência ao verde diminuiu significantemente somente nas ligaduras Morelli, enquanto que nas marcas 3M Unitek e Orthotechnology não houve alterações estatisticamente significativas na coloração comparadas às obtidas com o dentifrício convencional.

No que se refere à variável $\Delta b$ (eixo azul-amarelo), observou-se que o uso do dentifrício clareador, novamente produziu efeito somente na marca Morelli, assim, com o uso do dentifrício convencional, a ligadura Morelli mostrou tendência ao croma azul. Já com o dentifrício clareador essa marca mostrou tendência a manter o croma original. Todas as ligaduras, com exceção da Morelli, mostraram grandes variações de $\Delta b$, o que sinaliza uma diminuição do croma amarelado com tendência ao azul, independentemente do tipo de dentifrício utilizado, o que vem de encontro aos resultados de Oliveira et al. (2015).

Oliveira et al. (2015) em estudo in vitro, também concluíram que o uso do dentifrício clareador não melhorou a estabilidade de cor das ligaduras, ou seja, houve uma visível alteração de cor com o passar dos dias e que pode ser mensurada. Os autores avaliaram o efeito da escovação manual com dentifrício clareador em duas marcas de ligaduras estéticas 
(Morelli e 3M Unitek) utilizando o mesmo método de medida, ou seja, a espectrofotometria e sistema de avaliação CIE L* $a^{*} b^{*}$. Ambas as marcas mostram piora na estabilidade de cor, contudo, o grupo teste foi imerso em vinho tinto, um agente potencialmente forte. Ainda assim, ponderaram que, apesar do dentifrício clareador não melhorar a estabilidade de cor como um todo $(\Delta \mathrm{E})$ seu uso poderia diminuir a coloração amarelada que é esteticamente desagradável e se torna a principal queixa dos pacientes na maioria das vezes.

$\mathrm{Na}$ presente pesquisa, o dentifrício clareador foi efetivamente capaz de alterar um dos componentes da composição da cor que é a luminosidade $(\Delta \mathrm{L})$ promovendo uma tendência ao clareamento nas marcas 3M Unitek e Orthotechnology. No entanto, a composição total da cor, depende de outras variáveis $(\Delta \mathrm{a}$ e $\Delta \mathrm{b})$ que não mostram resultados expressivos, ou seja, o dentifrício clareador não conseguiu alterar significantemente todas as variáveis. Esse resultado vai de encontro ao trabalho de Pintado-Palomino et al. (2016) que não observou, in vivo, uma alteração de cor perceptível no esmalte dos pacientes que utilizaram dentifrício clareador, entre eles, sendo um deles utilizados na presente pesquisa (Colgate Luminous White) e dentifrício convencional. Além disso, apenas as marcas Morelli e Orthotechnology mostraram estabilidade de cor total $(\Delta \mathrm{E})$ efetivamente alterada, dessa forma, é questionável se o uso exclusivo dentifrício clareador seja efetivo para melhora na estabilidade de cor das ligaduras estéticas.

No que diz respeito ao desempenho das marcas comerciais, todas as ligaduras avaliadas, apresentaram alteração de cor considerada clinicamente inaceitável com o uso do dentifrício convencional e clareador. Na literatura há resultados diversos com relação à performance das variadas marcas em relação à estabilidade de cor. Silva et al. (2012) encontraram os melhores resultados com as marcas American Orthodontics e TP, Cavalcante et al. (2013) indicaram a marca 3M Unitek tonalidade pearl como a mais susceptível à pigmentação, Fernandes et al. (2013) obtiveram melhores resultados com a marca Ortho Organizers e os piores com a marca American Orthodontics, enquanto Silva et al. (2014) não encontraram destaque para a marca 3M Unitek em relação ao outras e por fim Kawabata et al. (2016) indicaram o pior resultado com a marca Morelli, esse último, no entanto, avaliou a tonalidade cristal.

A marca Orthotechnology é pouco estudada. Foi citada no estudo de Silva et al. (2016) no qual foi comparada à American Orthodontics, porém sem destaque para nenhuma delas. No estudo, in vitro, de Fernandes et al. (2014) foi comparada a outras 7 marcas e teve um desempenho intermediário no que diz respeito a alteração de cor. 
Dessa forma, o resultado da presente pesquisa não encontra consenso com a literatura, devido em parte, à discordância dos resultados e também à metodologia, uma vez que o presente estudo realizou investigação in vivo, diferente da maioria que avaliou as ligaduras in vitro.

De acordo com o delineamento experimental do presente estudo, ligaduras novas e aquelas com maior e menor variação de cor de cada marca submetidas à escovação com dentifrício clareador e convencional foram analisadas por microscopia eletrônica de varredura (MEV), num total de 20 ligaduras. A intenção foi visualizar na ultraestrutura possíveis achados que diferenciassem o uso dos dentifrícios estudados correlacionado esses achados com maior ou menor alteração de cor e/ou propriedade elástica. Foram adotadas as magnificações de 40 vezes, 150, vezes, 500 vezes e 2000 vezes, o que vai de encontro aos trabalhos de Guimarães et al. (2013) e Martínez-Colomer et al. (2016) que usaram magnificações semelhantes em estudos feitos com elastômeros.

Ao considerar as ligaduras com maior ou menor alteração de cor constatadas por meio da espectrofotometria, para serem avaliadas pela MEV, foi possível evidenciar que American Orthodontics e 3M Unitek mostraram evidente deterioração na película que as recobrem. Essa película, mesmo parcialmente perdida, parece ser importante, uma vez que, nas ligaduras que tiveram a maior variação de cor, ou seja, naquelas mais pigmentadas, essa película foi quase completamente removida, evidenciadas sobretudo nas ligaduras American Orthodontics. Com o uso do dentifrício convencional, naquelas ligaduras que tiveram menor variação de cor, percebe-se novamente a perda parcial do recobrimento nas marcas American Orthodontics e 3M Unitek. As ligaduras 3M Unitek que tiveram maior variação de cor tanto com o uso do dentifrício convencional bem como com o clareador mostraram um aspecto mais liso e regular. American Orthodontics apresentou superfície lisa apenas nas ligaduras com maior alteração de cor e associadas com dentifrício clareador, nas demais observou-se evidente deterioração na película que a recobre, com perda da película superficial. De modo geral, Morelli apresentou superfícies menos rugosas, mais homogêneas que as demais e a marca Orthotechnology foi a que apresentou superfície mais deteriorada e irregular.

Pode-se sugerir que para alguns grupos que tiveram maior variação de cor (menos estéticas), com ambos os dentifrícios, em nenhuma das marcas há grande deterioração, mas nas ligaduras American Orthodontics e Orthotechnology não se observou a presença da película protetora, o que poderia explicar o maior manchamento já que, nessa situação, as ligaduras dessas marcas estariam desprotegidas. 
A observação das ligaduras estudas pela Microscopia Eletrônica de Varredura (MEV) foi realizada no intuito de verificar se a ultraestrutura das mesmas foi alterada significantemente após o uso dos dentifrícios clareador e convencional. O estudo, in vivo, feito por Guimarães et al. (2013), mostrou que a degradação superficial tem início já na primeira semana quando um acréscimo de rugosidade se mostrou presente. Posteriormente, essa degradação foi piorando progressivamente até que, após 4 semanas, a superfície estava severamente comprometida com áreas de fraturas e extrema rugosidade.

O trabalho de Fernandes et al. (2014) estudou, in vitro 8 marcas de ligaduras procurando determinar se o grau de pigmentação estaria relacionado à porosidade superficial. As ligaduras foram imersas em uma mistura de chá preto e café por 7 dias. Os métodos de medida também foram a espectrofotometria e a Microscopia Eletrônica de Varredura. Os resultados mostraram, diferentemente do presente estudo, maior pigmentação da marca que mostrou maior irregularidade e porosidade na superfície (American Orthodontics).

Dessa forma, não foi possível estabelecer um padrão para todas as marcas e para ambos dentifrícios. A superfície das ligaduras se mostrou heterogênea tanto com o uso de um dentifrício quanto com outro. Portanto, as imagens não indicaram uma ação direta e eficiente dos dentifrícios clareadores sobre a estabilidade de cor das ligaduras elastoméricas, uma vez que todas apresentaram alteração de cor detectada pelo olho humano e considerada clinicamente inaceitável, sendo indicada a substituição do material por motivos estéticos, independente do dentifrício utilizado.

Considerando o teste de tração elástica, o objetivo foi investigar se o uso do dentifrício clareador prejudicaria essa função mecânica, uma vez que as ligaduras foram expostas a um agente potencialmente abrasivo. O tipo de dentifrício não influenciou diretamente na propriedade elástica das ligaduras pois a tendência de diminuição da força de ruptura com ambos os dentifrícios se mostrou semelhante.

Nota-se que, como relatado em outros estudos (Taloumis et al., 1997; Lam, et al., 2002; Ahrari et al., 2010; Pithon et al., 2013; Gandikota et al., 2015 e Masoud et al., 2016), há uma perceptível queda no limite de elasticidade, ou na força necessária para o rompimento das ligaduras após 30 dias em relação às ligaduras novas para todas as marcas e independentemente do tipo de dentifrício utilizado. Esse achado, entre outros, sinaliza a necessidade de reposição das ligaduras em intervalos mensais.

Tanto após o uso do dentifrício convencional quanto após o uso do clareador, as marcas 3M Unitek e American Orthodontics apresentaram melhores resultados, isto é, a força máxima para o rompimento foi maior nessas marcas, em comparação com a marca Morelli 
que ficou em $3^{\circ}$ lugar e com a Orthotechnology que apresentou o pior resultado. Esse resultado foi semelhante ao relatado por Ahrari et al. (2010), que encontraram melhor desempenho para a marca American Orthodontics e pior para Orthotechnology. O estudo de Abrão et al. (2006) também encontrou bons resultados com a marca 3M Unitek em comparação com a marca TP Orthodontics. E também a pesquisa de Aldrees et al. (2015) feita com elásticos em corrente estéticos, concluiu que a marca American Orthodontics obteve resultado destacado entre oito marcas investigadas.

Levando em consideração a deformação, medida em milímetros, tanto para as ligaduras novas quanto após o uso de ambos os dentifrícios, a marca Morelli evidenciou os maiores valores, seguida das marcas American Orthodontics, 3M Unitek e por fim Orthotechnology. Isso significa que a ligadura Morelli é a que tem a maior capacidade de se deformar antes da ruptura. Os estudos de Taloumis et al. (1997) e Masoud et al. (2016) avaliaram a deformação e as mudanças dimensionais das ligaduras ortodônticas relacionando com a degradação da força. Eles notaram que as mudanças na dimensão da ligadura têm correlação com a degradação da força por ela exercida. Assim, uma ligadura que permita maior deformação, antes da ruptura, teoricamente teria alguma vantagem clínica sobre aquelas que se rompem precocemente em situações semelhantes. Desta forma, neste ponto em especial, a marca Morelli (a que permite maior deformação) teria uma vantagem significativa sobre a Orthotechnology (que permite a menor deformação) uma vez que há uma considerável diferença nos valores encontrados, fato que não acontece em relação às outras duas marcas.

Nesse contexto, é importante refletir sobre o papel que a ligadura desempenha durante o movimento ortodôntico. Os momentos gerados pela amarração da ligadura aos bráquetes convencionais na correção de giroversões, inclinações e torques, estão diretamente relacionados à propriedade elástica das mesmas (Taloumis et al., 1997). Isto significa que um agente externo, como por exemplo, o efeito de um dentifrício, que prejudique tal função poderia comprometer a movimentação dentária induzida. No presente estudo, não houve influência direta nessa propriedade pelo dentifrício clareador.

Esse estudo pode servir como base para novas pesquisas, devido à escassez de trabalhos envolvendo dentifrícios clareadores e ligaduras ortodônticas estéticas na literatura. A metodologia pode ser aprimorada, novas combinações de marcas e dentifrícios podem ser testados, bem como os métodos de medida podem alterados. Pode ser incorporada à metodologia, a investigação microbiológica e a avaliação visual por examinadores calibrados. Além disso, pode ser aplicado um questionário validado em relação à dieta dos pacientes que é um aspecto importante no sentido de padronizar o potencial de pigmentação. A real 
capacidade dos dentifrícios clareadores em manter a estabilidade de cor das ligaduras estéticas precisa ser evidenciada cientificamente antes de se recomendar, com segurança, o uso sistemático desses dentifrícios para tal finalidade. 
6. Conclusão 


\section{CONCLUSÃO}

A partir dos resultados encontrados e considerando as limitações do presente estudo pode-se concluir que:

1. O dentifrício clareador não conseguiu efetivamente manter ou melhorar a estabilidade de cor das ligaduras estéticas após 30 dias na cavidade bucal. Todas as ligaduras apresentaram alteração de cor considerada clinicamente inaceitável, $(\Delta \mathrm{E}>3,3)$, independente do dentifrício utilizado.

2. As imagens geradas pela Microscopia Eletrônica de Varredura foram heterogêneas e não permitiram diferenciar aspectos estruturais diferentes para as marcas estudadas frente ao uso do dentifrício clareador. As marcas American Orthodontics e Orthotechnology foram as que apresentaram superfícies mais irregulares e deterioradas.

3. As marcas 3M Unitek e American Orthodontics mostraram os melhores resultados nos testes de tração elástica. Não houve diferença na propriedade elástica entre as 4 marcas estudadas após o uso do dentifrício clareador, ou seja, não prejudicou a elasticidade. 


\section{Referências}




\section{REFERÊNCIAS}

Abrão L, Ortolani CLF, Martins AM, Santana LC. Avaliação in vitro da intensidade da força liberada por ligaduras elásticas com e sem revestimento de polímero. Ver Inst Ciênc Saúde. 2006; 24: 31-35.

Adriaens PA, Seynhaeve TM, De Boever JA. A morphologic and SEM investigation of 58 toothbrushes. Clin Prev Dent. 1985; 7:8-16.

Ahrari F, Jalaly T, Zebarjad M. Tensile properties of orthodontic elastomeric ligatures. Indian J Dent Res. 2010; 21:23-29.

Alandia-Román CC. Análise da estabilidade de cor e de rugosidade de superfície de compósitos submetidos à fumaça de cigarro [dissertação]. Ribeirão Preto: Faculdade de Odontologia de Ribeirão Preto / USP; 2011.

Aldrees AM, Al-Foraidi SA, Murayshed MS, Almoammar KA. Color stability and force decay of clear elastomeric chains: an in vitro study. International Orthodontics. 2015; 13: $287-$ 301 .

Alves JKG, Aued N, Soares FZM, Jacques LB, Kaiser MR, Mallmann A. Avaliação da cor de um compósito com espectrofotômetro em diferentes modos de leitura e condições de armazenagem. RFO. 2014; 19:101-106.

Ardeshna AP, Vaidyanathan TK. Colour changes of orthodontic elastomeric module materials exposed to in vitro dietary media. Journal of Orthodontics. 2009; 36: 177-185.

Barcessat ARP. Estudo comparativo da cor dental, in vivo, em pacientes submetidos a diferentes técnicas de clareamento [dissertação]. São Paulo: Instituto de Pesquisas Energéticas e Nucleares / USP; 2007.

Baty LD, Storle DJ, Fraunhofer von JA. Synthetic elastomeric chains: A literature review. Am J Orthod Dentofacial Orthop. 1994; 105:536-542.

Benson PE, Ian Douglas CW, Martin MV. Fluoridated elastomers: effect on the microbiology of plaque. Am J Orthod Dentofacial Orthop. 2004; 126: 325-330.

Brêtas SM, Macari S, Elias AM, Ito IY, Matsumoto MAN. Effect of 0,4\% stannous fluoride gel on Streptococci mutans in relation to elastomeric rings and steel ligatures in orthodontic patients. Am J Orthod Dentofacial Orthop. 2005; 127:428-433.

Burstone CJ, Van Steenbergen E, Hanley HJ. A moderna mecânica Edgewise e a Técnica do Arco Segmentado. São Paulo: Ed. Santos; 2003.

Capelli Júnior J, Teixeira AOB, Medeiros RB. Quais são as expectativas estéticas e funcionais negativas dos pacientes em relação ao tratamento ortodôntico? Rev Clin Ortod Dental Press. $2014 ; 13: 10-18$. 
Cavalcante JS, Castelluci e Barbosa M, Sobral MC. Evaluation of the susceptibility to pigmentation of orthodontic esthetic elastomeric ligatures. Dental Press J Orthod. 2013; 18: 18.

Chang JY, Chen WC, Huang TK, Wang JC, Fu, PS, Chen JH, Hung CC. Evaluation of the accuracy and limitations of three tooth-color measurings machines. Journal of Dental Sciences. 2013; XX: 1-5.

Condò R, Casaglia A, Condó SG, Cerroni L. Plaque retention on elastomeric ligatures. An in vivo study. Oral and Implantology. 2012; 4: 92-99.

Eliades T, Eliades G, Silikas N, Watts DC. In vitro degradation of polyurethane orthodontic elastomeric modules. Journal of Oral Rehabilitation. 2005; 32: 72-77.

Evangelista MB, Berzins DW, Monaghan P. Effect of disinfecting solutions on the mechanical properties of orthodontic elastomeric ligatures. Angle Orthod. 2007; 77: 681-687.

Fernandes ANB, Ruellas ACO, Araújo MVA, Sant'Anna EF, Elias CN. Assessment of exogenous pigmentation in colorless elastic ligatures. JO. 2014; 41: 147-151.

Fernandes ANB. Propriedades dos amarrilhos elásticos estéticos [dissertação]. Rio de Janeiro: Universidade Federal do Rio de Janeiro; 2012.

Ferraz C, Castellucci M, Sobral M. Influence of in vitro pigmenting of esthetic orthodontic ligatures on smile attractiveness. Dental Press J Orthod. 2012; 17: 123-130.

Forsberg CM, Brattström V, Malmberg E, Nord CE. Ligature wires and elastomeric rings: two methods of ligation and their association with microbial colonization of Streptococcus mutans and lactobacilli. Eur J Orthod. 1991; 13:416-420.

Gandikota CS, Neeharika C, Juvvadi SR, Poornima KY, Manne R, Apuri LP. A comparative study of the physical and elastic properties of new generation elastomeric ligatures with conventional elastomeric ligatures. Journal of Dr. NTR University of Health Sciences. 2015; 4: 91-96.

Garcez AS, Suzuki SS, Ribeiro MS, Mada EY, Freitas AZ, Suzuki H. Biofilm retention by 3 methods of ligation on orthodontic brackets: a microbiologic and optical coherence tomography analysis. Am J Orthod Dentofacial Orthop. 2011; 140:193-198.

Goldstein GR, Schmitt GW. Repeatability of a specially designed intaoral colorimeter. J Prosthet Dent. 1993; 69: 616-619.

Gómez-Polo C, Gómes-Polo M, Celemin-Viñuela A, De Parga JAMV. Differences between the human eye and the spectrophotometer in the shade matching of tooth colour. Journal of Dentistry. 2014; 42: 742-745.

Guimarães GS, Morais LS, Souza MMG, Elias CN. Superficial morphology and mechanical properties of in vivo aged orthodontic ligatures. Dental Press J Orthod. 2013; 18: 107-112.

Henriques JFC, Hayasaki SM, Henriques RP. Elásticos Ortodônticos: como selecioná-los e utilizá-los de maneira eficaz. J Bras Ortodon Ortop Facial. 2003; 8:471-475. 
Joiner A. Tooth colour: a review of the literature. Journal of Dentistry. 2004; 32:3-12.

Kawabata E., Dantas VL, Kato CB, Normando D. Color changes of esthetic orthodontic ligatures evaluated by orthodontists and patients: a clinical study. Dental Press J Orthod. 2016; 21: 53-57.

Kim SH, Lee YK. Measurement of discolouration of orthodontic elastomeric modules with digital camera. Eur J Orthod. 2009; 31:556-562.

Knösel M, Reus M, Rosenberger A, Ziebolz D. A novel method for testing the veridicality of dental colour assessments. Eur J Orthod. 2012; 34: 19-24.

Koksal T, Dikbas I. Color stability of different denture teeth materials against various staining agents. Dental Materials Journal. 2008; 27: 139-144.

Kuhlman DC, Lima TA, Duplat CB, Capelli Jr J. Esthetic perception of orthodontic appliances by Brazilian children and adolescents. Dental Press J Orthod. 2016; 21:58-65.

Lam TV, Freer TJ, Brockhurst PJ, Podlich HM. Strength decay of orthodontic elastomeric ligatures. Journal of Orthodontics. 2002; 29: 37-43.

Leibrock A, Rosentritt M, Lang R, Behr M, Handel G. Colour stability of visible light-curing hybrid composites._Eur J Prosthodont Restor Dent. 1997; 5:125-30.

Lessa FC, Enoki C, Ito IY, Faria G, Matsumoto MA, Nelson-Filho P. In-vivo evaluation of the bacterial contamination and disinfection of acrylic baseplates of removable orthodontic appliances. Am J Orthod Dentofacial Orthop. 2007;131: 705e.11-705.e17.

Lew KKK. Staining of clear elastomeric modules from certain foods. JCO. 1990; 24:472-474.

Lopes Filho H, Maia LEG, Araújo MVA, Ruellas ACO. Influence of optical properties of esthetic brackets (color, translucence and fluorescence) on visual perception. Am J Orthod Dentofacial Orthop. 2012; 141: 460-467.

Magno AFF, Enoki C, Ito IY, Matsumoto MAN, Faria G, Nelson-Filho P. In vivo evaluation of the contamination of Super Slick elastomeric rings by Streptococcus mutans in orthodontic patients. Am J Orthod Dentofacial Orthop. 2008; 133: 104-109.

Maia LHEG, Lima Filho HL, Araújo MVA, Ruellas ACO, Araújo MTS. Incorporation of metal and color alteration on enamel in the presence of orthodontic appliances. Angle Orthod. 2012; 82:889-893.

Marson FC, Arruda T, Lazaretti MAJ, Freire ACL. Avaliação dos métodos de mensuração de cor dos dentes vitais. Arquivos em Odontologia. 2008; 44:29-33.

Martínez-Colomer S, Gaton-Hernández P, Romano FL, De Rossi A, Fukada SY, NelsonFilho P, Consolaro A, Silva RAB, Silva LAB. Latex and nonlatex orthodontic elastics: In vitro and in vivo evaluations of tissue compatibility and surface structure. Angle Orthod. 2016; 86: 278-284.

Martins MM, Lima TA, Soares CMO. Influência do pré-estiramento nas forças geradas por elásticos ortodônticos em cadeia. Cienc Odontol Bras. 2008; 11:38-46. 
Masoud AI, Bulic M, Viana G, Bedran-Russo AK. Force decay and dimensional changes of thermoplastic and novel thermoset elastomeric ligatures. Angle Orthod. 2016; 86:818-825.

Mendes DF, Nascimento JE, Facholli AFL, Casa MA, Carvalho LS, Sato K. Evaluation of plasticity and radiopacity of elastic separators by mean of traction tests and radiography. Dental Press J Orthdod. 2012; 23: 1-10.

Moreira AD. Análise cromática de dentes e resinas ortodônticas submetidos a diferentes antissépticos bucais [dissertação]. Rio de Janeiro: Universidade Federal do Rio de Janeiro; 2011.

Morelli RFB. Avaliação microbiana de ligaduras elastoméricas estéticas por meio da técnica DNA-DNA Hybridization: estudo in vivo [dissertação]. Ribeirão Preto: Faculdade de Odontologia de Ribeirão Preto / USP; 2016.

Oliveira AS, Kaiser MR, Salgado VE, Soldati DC, Silva RC, Moraes RR. Influence of Whitening and Regular Dentifrices on Orthodontic Clear Ligature Color Stability. J Esthet Restor Dent. 2015; 27:558-564.

Olms C, Setz JM. The repeatability of digital shade measurement - a clinical study. Clin Oral Invest. 2013; 17: 1161-1166.

Oota CLM, Ogusco TT, Cotrim-Ferreira F. Análise da alteração de cor em sistemas adesivos ortodônticos. SPO. 2013; 46: 450-458.

Pellegrini P, Sauerwein R, Finlayson T, McLeod J, Covell DA Jr, Maier T, Machida CA. Plaque retention by self-ligating vs elastomeric orthodontic brackets: quantitative comparison of oral bacteria and detection with adenosine triphosphate-driven bioluminescence.Am J Orthod Dentofacial Orthop. 2009; 35:426.e1-426.e9.

Pintado-Palomino K, Vasconcelos CVM, Silva RJ, Fressati ALM, Motta BJG, Pires-de-Souza FCP, Tirapelli C. Effect of whitening dentifrices: a double-blind randomized contolled trial. Braz Oral Res. 2016; 30: 1-8.

Pithon MM, Rodrigues AC, Sousa ELSM, Santos LPSS, Soares NS. Do mouthwashes with and without bleaching agentes degrade the force of elastomeric chains? Angle Orthod. 2013; 83: 712-717.

Pithon MM, Santana DA, Sousa, KH, Farias IMAO. Does Chlorhexedine in different formulations interfere with the force of orthodontic elastics. Angle Orthod. 2013; 83: 313318.

Roselino LMR. Avaliação clínica do efeito de dentifrícios clareadores na cor e rugosidade do esmalte dental e compósitos odontológicos [tese]. Ribeirão Preto: Faculdade de Odontologia de Ribeirão Preto / USP; 2015.

Russel KA, Milne AD, Khanna RA, Lee JM. In vitro assessment of mechanical properties of latex and non-latex orthodontic elastics. Am J Orthod Dentofacial Orthop. 2001; 120: 36-44.

Silva AVM, Mattos GV, Kato CM, Normando D. In vivo color changes of esthetic orthodontic ligatures. Dental Press J Orthod. 2012; 17: 76-80. 
Silva LK, Guignone BC, Marinho KC, Goiato MC, Pithon MM, Soares RV, Oliveira DD. In vitro evaluation of color changes of aesthetic orthodontic elastic ligatures. Int J Odontostomat. 2014; 8: 399-403.

Silva VD, Lima EMS, Dias C, Osório L. Analysis of the influence of food colorings in esthetic orthodontic elastomeric rings. The Open Dentistry Journal. 2016; 10: 516-521.

Soldati DC, Silva RC, Oliveira AS, Kaiser MR, Moraes RR. Color stability of five clear orthodontic clear elastic ligatures. Orthodontics (Chic). 2013; 14:60-65.

Souza EV, Mendes AM, Almeida MAO, Quintão CCA. Percentual de degradação das forças liberadas por ligaduras elásticas. R Dental Press Ortodon Ortop Facial. 2008; 13: 138-145.

Stevensson JS, Kusy RP. Force application and decay characteristics of untreated and treated polyurethane elastomeric chains. Angle Orthod. 1994; 64: 455-467.

Talic NF, Almudhi AA. The effect of dietary pigmentation on the esthetic appearance of clear orthodontic elastomeric modules.J Orthodont Sci. 2016; 5: 70-73.

Taloumis JL, Smith TM, Hondrum SO, Lorton L. Force decay and deformation of orthodontic elastomeric ligatures. Am J Orthod Dentofacial Orthop. 1997; 111: 1-11.

Taloumis LJ, Smith TM, Hondrum SO, Lorton L. Force decay of orthodontic elastomeric ligatures. Am J Orthtod Dentofac Orthop. 1997; 111: 1-11.

Tambelli BR, Oota CLM, Cotrim-Ferreira F. Avaliação in vitro do manchamento dos módulos elásticos ortodônticos. SPO. 2014; 47: 329-336.

Vieira CIV, Oliveira CB, Ribeiro AA, Caldas SGF, Martins LP, Gandini Jr LG, Santos-Pinto A. In vitro comparison of the force degradation of orthodontic intraoral elastics from different compositions. RSBO. 2013; 10:40-48.

Weyne CA, Determinação do tamanho da amostra em pesquisas experimentais na área de saúde. Arq. Med. 2004, 29: 87-90.

Wong AK. Orthodontic Elastic Materials. Angle Orthod. 1976; 49:196-205.

Yannikaki SA, Zissis AJ, Polyzois GL, Caroni C. Color stability of provisional resin restorative materials. J Prosthet Dent. 1998; 80:533-9.

Ziuchkovski JP, Fields HW, Johnston WM, Lindsey DT. Assessment of perceived orthodontic appliance attractiveness. Am J Orthod Dentofacial Orthop. 2008; 133: 68-78. 
Apêndice 


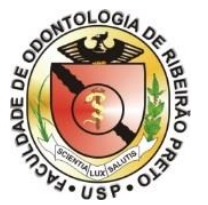

UNIVERSIDADE DE SÃO PAULO

FACULDADE DE ODONTOLOGIA DE RIBEIRÃO PRETO

PROGRAMA DE PÓS-GRADUAÇÃO

DEPARTAMENTO DE CLÍNICA INFANTIL - ORTODONTIA

\section{TERMO DE CONSENTIMENTO LIVRE E ESCLARECIDO}

(Resolução 466/2012 - Conselho Nacional de Saúde)

Eu, Leonardo Gontijo Matos, doutorando da Universidade de São Paulo (FORP/USP), responsável pelo projeto "LIGADURAS ORTODÔNTICAS ELASTOMÉRICAS: AVALIAÇÃO DAS PROPRIEDADES ELÁSTICAS, ALTERAÇÃO DE COR E ULTRA ESTRUTURA DA SUPERFÍCIE" e eu Profa. Dra. Mirian Aiko Nakane Matsumoto convidamos você , bem como seu (sua) filho (a) ou quem esteja sobre

seus cuidados a participar do referido projeto de pesquisa, que será realizado sob orientação da Prof ${ }^{a}$. Dra. Mirian Aiko Nakane Matsumoto na Faculdade de Odontologia de Ribeirão Preto (FORP/USP). Este termo consta de 2 vias idênticas, que serão assinadas por todos os pesquisadores e por você. Uma via ficará com você e a outra será arquivada pelo pesquisador.

Este trabalho tem como objetivo avaliar após 30 dias na boca se aconteceu alteração na cor, na elasticidade e na estrutura de alguns elásticos (borrachinhas) do aparelho fixo. Para tanto será necessário que o seu (sua) filho (a) ou quem esteja sobre seus cuidados comparecer três (3) vezes na Clínica II, sendo que na primeira consulta, será feita a colocação das borrachinhas que serão estudadas bem como a orientação e fornecimento de um dentifrício convencional e uma escova dental além de orientações sobre a escovação. Após 30 dias estes elásticos serão trocados e será fornecida um dentifrício para clareamento bem como uma escova nova. E novamente, após 30 dias, os elásticos estudados serão retirados.

Você e seu (sua) filho (a) ou quem esteja sobre seus cuidados terão de comparecer à Clínica II da FORP/USP, durante o período das consultas periódicas do tratamento ortodôntico. Você está sendo esclarecido que esta pesquisa pode oferecer riscos mínimos, pois o uso de qualquer aparelho para os dentes pode causar reabsorção da raíz e retração da gengiva, mas caso ocorra algum desses riscos ou qualquer outro relativo ao uso do aparelho, nós, os pesquisadores, seremos responsáveis pelo tratamento. O uso do aparelho poderá causar algum desconforto, como dificuldade para se alimentar e traumas na mucosa, nos primeiros dias.

Rubrica do responsável

Rubrica do pesquisador

Rubrica da orientadora

O seu (sua) filho (a) ou quem esteja sobre seus cuidados terá como benefício correção da sua mordida, uma melhora na posição da língua, mastigação, deglutição dos alimentos e estética. A participação do seu (sua) filho (a) ou quem esteja sobre seus cuidados nesta pesquisa é muito importante, pois os resultados encontrados poderão trazer vários benefícios à ciência e ajudar outras pessoas. Não será oferecido nenhum tipo de pagamento pela participação na pesquisa, mas caso necessário será pago o transporte de ônibus municipal e alimentação para o comparecimento na FORP, sendo que, todo o atendimento ao seu (sua) filho (a) ou quem esteja sobre seus cuidados será gratuito. A identidade do seu (sua) filho (a) ou quem esteja sobre seus cuidados será mantida em segredo, mas ele participando da pesquisa, você autorizará que os resultados obtidos sejam divulgados e publicados em revistas cientificas e terá, por parte de nós, pesquisadores, a garantia do sigilo (segredo) que garantem a privacidade. 
Você terá total liberdade para pedir maiores esclarecimentos antes e durante o desenvolvimento da pesquisa. Se tiver alguma dúvida poderá ligar para o pesquisador para pedir qualquer informação (Leonardo Gontijo Matos - Avenida do Café S/N - Departamento de Clínica Infantil - Faculdade de Odontologia de Ribeirão Preto - Tel: (16) 3315.3995 ou pelo celular (34) 999750504. Suas reclamações e/ou insatisfações relacionadas à sua participação na pesquisa poderão ser comunicadas por escrito à secretaria do CEP/FORP/USP (16) 3315-0493 - Horário de atendimento das $8 \mathrm{~h}$ às $12 \mathrm{~h}$, de segunda a sexta-feira, devendo conter seu nome que será mantido em sigilo. A participação de vocês não é obrigatória, e vocês poderão desistir a qualquer momento, retirando sua autorização. A não autorização deste trabalho não trará nenhum prejuízo ao seu (sua) fillho (a) ou quem esteja sobre seus cuidados, bem como a sua relação com o pesquisador ou com a Faculdade de Odontologia de Ribeirão Preto - USP.

$\mathrm{Eu}$

$\mathrm{CPF}$ número , residente a , portador do RG

. Declaro que li compreendi e concordo com o presente Termo, por isso assino este documento de livre e espontânea vontade.

Ribeirão Preto, de de 20

\section{Assinatura do responsável direto pelo participante de pesquisa}

Leonardo Gontijo Matos

CPF: 911.064.866-68

Pesquisador responsável
Dra. Mirian A.Nakane Matsumoto

CPF: 039.580.618-69

Pesquisador Orientador 


\section{FICHA DE ANOTAÇÕES DE LEITURA EASYSHADE}

LEONARDO GONTIJO MATOS - DOUTORADO / ODONTOPEDIATRIA

DATA DA LEITURA:

dentifrício

PACIENTE:

DENTE:

MARCA:

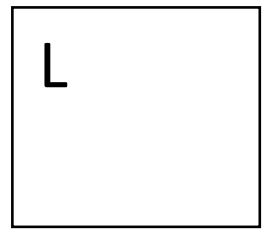

a

b

Legenda:

A - American Orthodontics

O- Orthotechnology

$3 \mathrm{M}-3 \mathrm{M}$ Unitek

M-Morelli 
Tabela 15 - Leituras do teste de alteração de cor da marca Morelli (pacientes 1 ao 10).

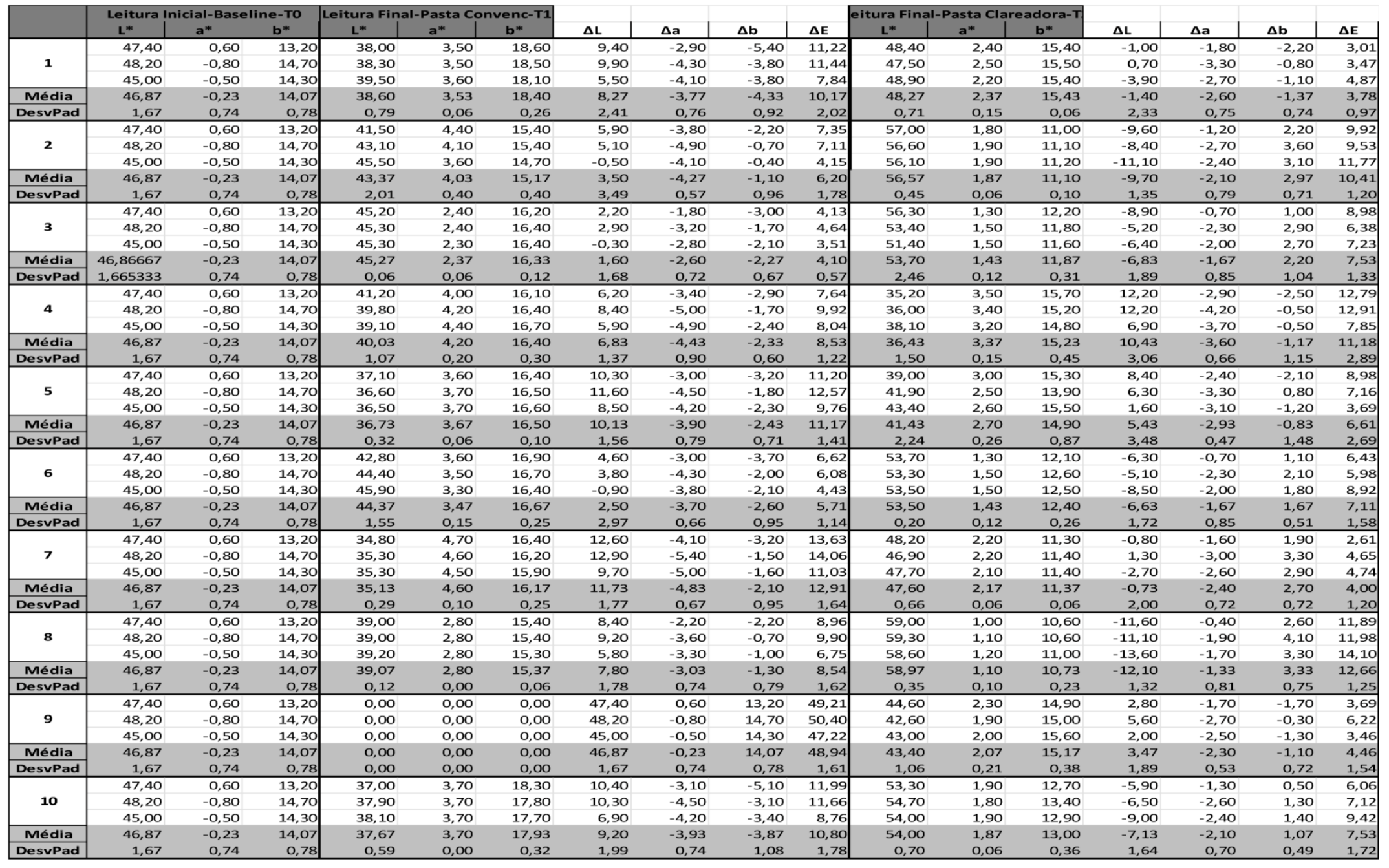


Tabela 16 - Leituras do teste de alteração de cor da marca Morelli (pacientes 11 ao 20).

\begin{tabular}{|c|c|c|c|c|c|c|c|c|c|c|c|c|c|c|c|c|c|}
\hline \multirow{3}{*}{11} & 47,40 & 0,60 & 13,20 & 40,40 & 3,60 & 18,10 & 7,00 & $-3,00$ & $-4,90$ & 9,06 & 53,20 & 1,50 & 14,40 & $-5,80$ & $-0,90$ & $-1,20$ & 5,99 \\
\hline & 48,20 & $-0,80$ & 14,70 & 42,10 & 3,50 & 17,70 & 6,10 & $-4,30$ & $-3,00$ & 8,04 & 52,10 & 1,60 & 14,50 & $-3,90$ & $-2,40$ & 0,20 & 4,58 \\
\hline & 45,00 & $-0,50$ & 14,30 & 42,30 & 3,40 & 17,30 & 2,70 & $-3,90$ & $-3,00$ & 5,61 & 50,00 & 1,40 & 14,50 & $-5,00$ & $-1,90$ & $-0,20$ & 5,35 \\
\hline Média & 46,87 & $-0,23$ & 14,07 & 41,60 & 3,50 & 17,70 & 5,27 & $-3,73$ & $-3,63$ & 7,57 & 51,77 & 1,50 & 14,47 & $-4,90$ & $-1,73$ & $-0,40$ & 5,31 \\
\hline DesuPad & 1,67 & 0,74 & 0,78 & 1,04 & 0,10 & 0,40 & 2,27 & 0,67 & 1,10 & 1,77 & 1,63 & 0,10 & 0,06 & 0,95 & 0,76 & 0,72 & 0,70 \\
\hline \multirow{3}{*}{12} & 47,40 & 0,60 & 13,20 & 35,00 & 2,50 & 17,20 & 12,40 & $-1,90$ & $-4,00$ & 13,17 & 46,80 & 1,30 & 11,30 & 0,60 & $-0,70$ & 1,90 & 2,11 \\
\hline & 48,20 & $-0,80$ & 14,70 & 35,10 & 2,50 & 17,40 & 13,10 & $-3,30$ & $-2,70$ & 13,78 & 46,00 & 1,40 & 11,70 & 2,20 & $-2,20$ & 3,00 & 4,32 \\
\hline & 45,00 & $-0,50$ & 14,30 & 35,20 & 2,50 & 17,00 & 9,80 & $-3,00$ & $-2,70$ & 10,60 & 46,10 & 1,40 & 11,50 & $-1,10$ & $-1,90$ & 2,80 & 3,56 \\
\hline Média & 46,87 & $-0,23$ & 14,07 & 35,10 & 2,50 & 17,20 & 11,77 & $-2,73$ & $-3,13$ & 12,51 & 46,30 & 1,37 & 11,50 & 0,57 & $-1,60$ & 2,57 & 3,33 \\
\hline DesvPad & 1,67 & 0,74 & 0,78 & 0,10 & 0,00 & 0,20 & 1,74 & 0,74 & 0,75 & 1,69 & 0,44 & 0,06 & 0,20 & 1,65 & 0,79 & 0,59 & 1,12 \\
\hline \multirow[t]{3}{*}{ 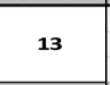 } & 47,40 & 0,60 & 13,20 & 35,20 & 4,90 & 16,50 & 12,20 & $-4,30$ & $-3,30$ & 13,35 & 54,60 & 1,80 & 13,80 & $-7,20$ & $-1,20$ & $-0,60$ & 7,32 \\
\hline & 48,20 & $-0,80$ & 14,70 & 35,30 & 4,90 & 16,70 & 12,90 & $-5,70$ & $-2,00$ & 14,24 & 56,00 & 1,80 & 13,20 & $-7,80$ & $-2,60$ & 1,50 & 8,36 \\
\hline & 45,00 & $-0,50$ & 14,30 & 35,20 & 4,90 & 16,60 & 9,80 & $-5,40$ & $-2,30$ & 11,42 & 57,90 & 1,60 & 12,60 & $-12,90$ & $-2,10$ & 1,70 & 13,18 \\
\hline Média & 46,87 & $-0,23$ & 14,07 & 35,23 & 4,90 & 16,60 & 11,63 & $-5,13$ & $-2,53$ & 13,01 & 56,17 & 1,73 & 13,20 & $-9,30$ & $-1,97$ & 0,87 & 9,62 \\
\hline DesuPad & 1,67 & 0,74 & 0,78 & 0,06 & 0,00 & 0,10 & 1,63 & 0,74 & 0,68 & 1,44 & 1,66 & 0,12 & 0,60 & 3,13 & 0,71 & 1,27 & 3,13 \\
\hline \multirow{3}{*}{14} & 47,40 & 0,60 & 13,20 & 38,20 & 3,20 & 14,30 & 9,20 & $-2,60$ & $-1,10$ & 9,62 & 52,60 & 1,80 & 12,10 & $-5,20$ & $-1,20$ & 1,10 & 5,45 \\
\hline & 48,20 & $-0,80$ & 14,70 & 37,20 & 3,50 & 15,90 & 11,00 & $-4,30$ & $-1,20$ & 11,87 & 52,50 & 1,90 & 12,10 & $-4,30$ & $-2,70$ & 2,60 & 5,70 \\
\hline & 45,00 & $-0,50$ & 14,30 & 36,50 & 3,60 & 16,90 & 8,50 & $-4,10$ & $-2,60$ & 9,79 & 49,50 & 2,10 & 13,00 & $-4,50$ & $-2,60$ & 1,30 & 5,36 \\
\hline Média & 46,87 & $-0,23$ & 14,07 & 37,30 & 3,43 & 15,70 & 9,57 & $-3,67$ & $-1,63$ & 10,43 & 51,53 & 1,93 & 12,40 & $-4,67$ & $-2,17$ & 1,67 & 5,50 \\
\hline DesuPad & 1,67 & 0,74 & 0,78 & 0,85 & 0,21 & 1,31 & 1,29 & 0,93 & 0,84 & 1,25 & 1,76 & 0,15 & 0,52 & 0,47 & 0,84 & 0,81 & 0,18 \\
\hline \multirow{3}{*}{15} & 47,40 & 0,60 & 13,20 & 42,10 & 2,70 & 16,50 & 5,30 & $-2,10$ & $-3,30$ & 6,59 & 50,90 & 2,50 & 12,40 & $-3,50$ & $-1,90$ & 0,80 & 4,06 \\
\hline & 48,20 & $-0,80$ & 14,70 & 42,20 & 2,70 & 16,80 & 6,00 & $-3,50$ & $-2,10$ & 7,26 & 51,30 & 2,40 & 13,10 & $-3,10$ & $-3,20$ & 1,60 & 4,73 \\
\hline & 45,00 & $-0,50$ & 14,30 & 42,20 & 2,70 & 17,00 & 2,80 & $-3,20$ & $-2,70$ & 5,04 & 53,70 & 2,30 & 12,90 & $-8,70$ & $-2,80$ & 1,40 & 9,25 \\
\hline Média & 46,87 & $-0,23$ & 14,07 & 42,17 & 2,70 & 16,77 & 4,70 & $-2,93$ & $-2,70$ & 6,29 & 51,97 & 2,40 & 12,80 & $-5,10$ & $-2,63$ & 1,27 & 6,01 \\
\hline DesuPad & 1,67 & 0,74 & 0,78 & 0,06 & 0,00 & 0,25 & 1,68 & 0,74 & 0,60 & 1,14 & 1,51 & 0,10 & 0,36 & 3,12 & 0,67 & 0,42 & 2,82 \\
\hline \multirow{3}{*}{16} & 47,40 & 0,60 & 13,20 & 41,90 & 4,90 & 17,80 & 5,50 & $-4,30$ & $-4,60$ & 8,36 & 66,50 & 1,80 & 12,00 & $-19,10$ & $-1,20$ & 1,20 & 19,18 \\
\hline & 48,20 & $-0,80$ & 14,70 & 43,00 & 4,60 & 17,40 & 5,20 & $-5,40$ & $-2,70$ & 7,97 & 66,20 & 1,90 & 12,00 & $-18,00$ & $-2,70$ & 2,70 & 18,40 \\
\hline & 45,00 & $-0,50$ & 14,30 & 43,10 & 4,70 & 17,90 & 1,90 & $-5,20$ & $-3,60$ & 6,60 & 66,20 & 1,80 & 11,90 & $-21,20$ & $-2,30$ & 2,40 & 21,46 \\
\hline Média & 46,87 & $-0,23$ & 14,07 & 42,67 & 4,73 & 17,70 & 4,20 & $-4,97$ & $-3,63$ & 7,64 & 66,30 & 1,83 & 66,50 & $-19,43$ & $-2,07$ & 2,10 & 19,68 \\
\hline DesuPad & 1,67 & 0,74 & 0,78 & 0,67 & 0,15 & 0,26 & 2,00 & 0,59 & 0,95 & 0,92 & 0,17 & 0,06 & 66,20 & 1,63 & 0,78 & 0,79 & 1,59 \\
\hline \multirow{3}{*}{17} & 0,00 & 0,00 & 0,00 & 0,00 & 0,00 & 0,00 & 0,00 & 0,00 & 0,00 & 0,00 & 0,00 & 0,00 & 0,00 & 0,00 & 0,00 & 0,00 & 0,00 \\
\hline & 0,00 & 0,00 & 0,00 & 0,00 & 0,00 & 0,00 & 0,00 & 0,00 & 0,00 & 0,00 & 0,00 & 0,00 & 0,00 & 0,00 & 0,00 & 0,00 & 0,00 \\
\hline & 0,00 & 0,00 & 0,00 & 0,00 & 0,00 & 0,00 & 0,00 & 0,00 & 0,00 & 0,00 & 0,00 & 0,00 & 0,00 & 0,00 & 0,00 & 0,00 & 0,00 \\
\hline Média & 0,00 & 0,00 & 0,00 & 0,00 & 0,00 & 0,00 & 0,00 & 0,00 & 0,00 & 0,00 & 0,00 & $0,00^{\prime}$ & 0,00 & 0,00 & 0,00 & 0,00 & 0,00 \\
\hline DesuPad & 0,00 & 0,00 & 0,00 & 0,00 & 0,00 & 0,00 & 0,00 & 0,00 & 0,00 & 0,00 & 0,00 & $0,00^{\prime}$ & 0,00 & 0,00 & 0,00 & 0,00 & 0,00 \\
\hline \multirow{3}{*}{18} & 47,40 & 0,60 & 13,20 & 42,90 & 3,60 & 16,40 & 4,50 & $-3,00$ & $-3,20$ & 6,28 & 39,80 & 3,50 & 16,70 & 7,60 & $-2,90$ & $-3,50$ & 8,86 \\
\hline & 48,20 & $-0,80$ & 14,70 & 41,50 & 3,70 & 16,60 & 6,70 & $-4,50$ & $-1,90$ & 8,29 & 41,00 & 3,40 & 16,30 & 7,20 & $-4,20$ & $-1,60$ & 8,49 \\
\hline & 45,00 & $\begin{array}{l}-0,50 \\
-0,50\end{array}$ & 14,30 & 41,30 & 3,70 & 16,40 & 3,70 & $-4,20$ & $\begin{array}{l}-2,10 \\
-2,10\end{array}$ & 5,98 & 42,20 & 3,20 & 15,80 & 2,80 & $\begin{array}{l}-4,70 \\
-3,70\end{array}$ & $-1,50$ & $\begin{array}{l}0,43 \\
4,88\end{array}$ \\
\hline Média & 46,87 & $-0,23$ & 14,07 & 41,90 & 3,67 & 16,47 & 4,97 & $-3,90$ & $-2,40$ & 6,85 & 41,00 & 3,37 & 16,27 & 5,87 & $-3,60$ & $-2,20$ & 7,41 \\
\hline DesuPad & 1,67 & 0,74 & 0,78 & 0,87 & 0,06 & 0,12 & 1,55 & 0,79 & 0,70 & 1,26 & 1,20 & 0,15 & 0,45 & 2,66 & 0,66 & 1,13 & 2,20 \\
\hline \multirow{3}{*}{19} & 47,40 & 0,60 & 13,20 & 46,00 & 2,00 & 15,30 & 1,40 & $-1,40$ & $-2,10$ & 2,89 & 63,60 & 1,20 & 12,10 & $-16,20$ & $-0,60$ & 1,10 & 16,25 \\
\hline & 48,20 & $-0,80$ & 14,70 & 46,00 & 2,00 & 15,30 & 2,20 & $-2,80$ & $-0,60$ & 3,61 & 63,80 & 1,2 & 12,10 & $-15,60$ & $-2, c$ & 2,60 & 15,94 \\
\hline & 45,00 & $-0,50$ & 14,30 & 45,00 & 2,10 & 15 & 0,00 & $-2,60$ & $-1,10$ & 2,82 & 64,20 & 1,20 & 12,00 & $-19,20$ & $-1,70$ & 2,30 & 19,41 \\
\hline Média & 46,87 & $-0,2$ & 14,07 & 45,67 & 2,03 & 15,33 & 1,20 & $-2,27$ & $-1,27$ & 3,11 & 63,87 & 1,20 & 12,07 & $-17,00$ & $-1,43$ & 2,00 & 17,20 \\
\hline DesvPad & 1,67 & 0,7 & & 0,58 & 0,06 & 0,06 & 1,11 & 0,76 & 0,76 & 0,44 & 0,31 & 0,00 & 0,06 & 1,93 & 0,74 & 0,79 & 1,92 \\
\hline \multirow{3}{*}{20} & 47,40 & 0,60 & 13,20 & 34,90 & 3,70 & 13,50 & 12,50 & $-3,10$ & $-0,30$ & 12,88 & 56,80 & 2,00 & 13,50 & $-9,40$ & $-1,40$ & $-0,30$ & 9,51 \\
\hline & 48,20 & $-0,80$ & 14,70 & 36,30 & 3,50 & 13,10 & 11,90 & $-4,30$ & 1,60 & 12,75 & 56,90 & 2,10 & 13,90 & $-8,70$ & $-2,90$ & 0,80 & 9,21 \\
\hline & 45,00 & $-0,50$ & 14,30 & 36,00 & 3,50 & 13,20 & 9,00 & $-4,00$ & 1,10 & 9,91 & 54,70 & 2,20 & 14,40 & $\begin{array}{l}-9,70 \\
\end{array}$ & $-2,70$ & $-0,10$ & 10,07 \\
\hline Média & 46,87 & $-0,23$ & 14,07 & 35,73 & 3,57 & 13,27 & 11,13 & $-3,80$ & 0,80 & 11,85 & 56,13 & 2,10 & 13,93 & $-9,27$ & $-2,33$ & 0,13 & 9,59 \\
\hline DesuPad & 1,67 & 0,74 & 0,78 & 0,74 & 0,12 & 0,21 & 1,87 & 0,62 & 0,98 & 1,68 & 1,24 & 0,10 & 0,45 & 0,51 & 0,81 & 0,59 & 0,44 \\
\hline
\end{tabular}


Tabela 17 - Leituras do teste de alteração de cor da marca American Orthodontics (pacientes 1 ao 10).

\begin{tabular}{|c|c|c|c|c|c|c|c|c|c|c|c|c|c|c|c|c|c|}
\hline & \multicolumn{3}{|c|}{ Leitura Inicial-Baseline-TO } & \multicolumn{3}{|c|}{ Leitura Final-Pasta Convenc- } & \multicolumn{7}{|c|}{ ista $\mathrm{Cl}_{2}$} & \multirow[b]{2}{*}{$\Delta \mathbf{L}$} & \multirow[b]{2}{*}{$\mathbf{\Delta a}$} & \multirow[b]{2}{*}{$\Delta \mathbf{b}$} & \multirow[b]{2}{*}{$\Delta E$} \\
\hline & & $\underline{a^{*}}$ & $\mathbf{b}^{*}$ & $\mathrm{~L}^{*}$ & $a^{*}$ & $\mathbf{b}^{*}$ & $\Delta L$ & $\Delta \mathbf{a}$ & $\Delta \mathbf{b}$ & $\Delta E$ & $L^{*}$ & $a^{*}$ & $\mathbf{b}^{*}$ & & & & \\
\hline \multirow{3}{*}{1} & 56,50 & 0,70 & 6,00 & 57,60 & 0,80 & 15,70 & $-1,10$ & $-0,10$ & $-9,70$ & 9,76 & 55,60 & $-1,00$ & 28,80 & 0,90 & 1,70 & $-22,80$ & \\
\hline & 57,70 & 0,80 & 5,80 & 57,50 & 0,80 & 15,70 & 0,20 & 0,00 & $-9,90$ & 9,90 & 55,90 & $-0,80$ & 28,50 & 1,80 & 1,60 & $-22,70$ & \\
\hline & 59,80 & 0,40 & 5,10 & 57,90 & 0,90 & 15,20 & 1,90 & $-0,50$ & $-10,10$ & 10,29 & 55,80 & $-0,80$ & 27,00 & 4,00 & 1,20 & $-21,90$ & 22,29 \\
\hline Média & 58,00 & 0,63 & 5,63 & 57,67 & 0,83 & 15,53 & 0,33 & $-0,20$ & $-9,90$ & 9,98 & 55,77 & $-0,87$ & 28,10 & 2,23 & 1,50 & $-22,47$ & \\
\hline DesuPad & 1,67 & 0,21 & 0,47 & 0,21 & 0,06 & 0,29 & 1,50 & 0,26 & 0,20 & 0,27 & 0,15 & 0,12 & 0,96 & 1,59 & 0,26 & 0,49 & 0,32 \\
\hline \multirow{3}{*}{ Desurad } & 56,50 & 0,70 & 6,00 & 55,50 & 2,70 & 21,40 & 1,00 & $-2,00$ & $-15,40$ & 15,56 & $\begin{array}{l}61,40 \\
\end{array}$ & 1,60 & 17,10 & $-4,90$ & $-0,90$ & $-11,10$ & 12,17 \\
\hline & 57,70 & 0,80 & 5,80 & 56,30 & 2,70 & 20,80 & 1,40 & $-1,90$ & $-15,00$ & 15,18 & 60,60 & 1,70 & 17,50 & $-2,90$ & $-0,90$ & $-11,70$ & \\
\hline & 59,80 & 0,40 & 5,10 & 56,20 & 2,80 & 20,80 & 3,60 & $-2,40$ & $-15,70$ & 16,29 & 59,80 & 1,70 & 18,20 & 0,00 & $-1,30$ & $-13,10$ & 13,16 \\
\hline Média & 58,00 & 0,63 & 5,63 & 56,00 & 2,73 & 21,00 & 2,00 & $-2,10$ & $-15,37$ & 15,68 & 60,60 & 1,67 & 17,60 & $-2,60$ & $-1,03$ & $-11,97$ & 12,47 \\
\hline DesuPad & 1,67 & 0,21 & 0,47 & 0,44 & 0,06 & 0,35 & 1,40 & 0,26 & 0,35 & 0,56 & 0,80 & 0,06 & 0,56 & 2,46 & 0,23 & 1,03 & 0,60 \\
\hline \multirow{3}{*}{ Desuradu } & 56,50 & 0,70 & 6,00 & 56,40 & 1,80 & 17,00 & 0,10 & $-1,10$ & $-11,00$ & 11,06 & 53,80 & 0,90 & 22,70 & 2,70 & $-0,20$ & $-16,70$ & 16,92 \\
\hline & 57,70 & 0,80 & 5,80 & 56,20 & 1,80 & 17,30 & 1,50 & $-1,00$ & $-11,50$ & 11,64 & 54,20 & 0,90 & 22,90 & 3,50 & $-0,10$ & $-17,10$ & 17,45 \\
\hline & 59,80 & 0,40 & 5,10 & 56,10 & 1,80 & 17,50 & 3,70 & $-1,40$ & $-12,40$ & 13,02 & 54,80 & 0,90 & 23,00 & 5,00 & $-0,50$ & $-17,90$ & 18,59 \\
\hline Média & & 0,63 & 5,63 & 56,23 & 1,80 & 17,27 & 1,77 & $-1,17$ & $-11,63$ & 11,90 & 54,27 & 0,90 & 22,87 & 3,73 & $-0,27$ & $-17,23$ & 17,65 \\
\hline DesuPad & 1,670329 & 0,21 & 0,47 & 0,15 & 0,00 & 0,25 & 1,81 & 0,21 & 0,71 & 1,01 & 0,50 & 0,00 & 0,15 & 1,17 & 0,21 & 0,61 & 0,85 \\
\hline \multirow[t]{3}{*}{ Desuradu } & 56,50 & 0,70 & 6,00 & 51,70 & 4,40 & 24,10 & 4,80 & $-3,70$ & $-18,10$ & 19,09 & 58,80 & 2,10 & 0,00 & $-2,30$ & $-1,40$ & 6,00 & 6,58 \\
\hline & 57,70 & 0,80 & 5,80 & 52,10 & 4,30 & 23,70 & 5,60 & $-3,50$ & $-17,90$ & 19,08 & 55,80 & & 0,00 & 1,90 & $-2,30$ & 5,80 & 6,52 \\
\hline & 59,80 & 0,40 & 5,10 & 51,80 & 4,40 & 24,10 & 8,00 & $-4,00$ & $-19,00$ & 21,00 & 56,60 & 2,90 & 0,00 & 3,2 & $-2,50$ & 5,10 & 6,52 \\
\hline Média & 58,00 & 0,63 & 5,63 & 51,87 & 4,37 & & 6,13 & $-3,73$ & $-18,33$ & 19,72 & 57,07 & 2,70 & 0,00 & 0,5 & $-2,07$ & 5,63 & 6,54 \\
\hline DesuPad & 1,67 & 0,21 & 0,47 & 0,21 & 0,06 & 0,23 & 1,67 & 0,25 & 0,59 & 1,11 & 1,55 & 0,53 & 0,00 & 2,87 & 0,59 & 0,47 & 0,03 \\
\hline \multirow[t]{3}{*}{ Desverad } & 56,50 & 0,70 & 6,00 & 54,50 & 1,70 & 15,90 & 2,00 & $-1,00$ & $-9,90$ & 10,15 & 58,80 & 0,10 & 16,40 & $-2,30$ & 0,60 & $-10,40$ & 10,67 \\
\hline & 57,70 & 0,8 & 5,80 & 55,60 & 1,60 & & 2,10 & $-0,80$ & $-9,50$ & 9,76 & 57,90 & & 16,60 & -0, & 0,70 & $-10,80$ & 10,82 \\
\hline & 59,80 & 0,40 & 5,10 & 55,80 & 1,50 & 15,10 & 4,00 & $-1,10$ & $-10,00$ & 10,83 & 59,00 & & 15,90 & 0, & 0,20 & $-10,80$ & 10,83 \\
\hline Média & 58,00 & o, & 5,63 & 55,30 & 1,60 & 15,43 & 2,70 & $-0,97$ & $-9,80$ & 10,25 & 58,57 & & 16,30 & -0 & 0,50 & $-10,67$ & 10,77 \\
\hline DesuPad & 1,67 & 0,21 & 0,47 & 0,70 & 0,10 & 0,42 & 1,13 & 0,15 & 0,26 & 0,54 & 0,59 & 0,06 & 0,36 & 1,58 & 0,26 & 0,23 & 0,09 \\
\hline \multirow[t]{3}{*}{ Desurad } & 56,50 & 0,70 & 6,00 & 51,60 & 1,40 & 18,00 & 4,90 & $-0,70$ & $-12,00$ & 12,98 & 56,60 & 0,10 & 17,60 & $\frac{1,0,10}{-0,10}$ & 0,60 & $-11,60$ & 11,62 \\
\hline & 57,70 & 0,80 & 5,80 & 51,60 & 1,40 & 18,00 & 6,10 & $-0,60$ & $-12,20$ & 13,65 & 57,40 & & 15,30 & 0,3 & 0,70 & $-9,50$ & $\begin{array}{r}r \\
9,53\end{array}$ \\
\hline & 59,80 & 0,40 & 5,10 & 52,10 & 1,40 & 18,20 & 7,70 & $\begin{array}{l}-0,00 \\
-1,00\end{array}$ & $-13,10$ & $\begin{array}{l}15,03 \\
15,23\end{array}$ & 58,10 & & 14,80 & 1, & 0,20 & $\begin{array}{l}-9,70 \\
-9,70\end{array}$ & 9,85 \\
\hline Média & 58,00 & o, & 5,63 & 51,77 & 1,40 & 18,07 & 6,23 & $-0,77$ & $-12,43$ & 13,95 & 57,37 & & 15,90 & 0,6 & 0,50 & $-10,27$ & $\begin{array}{r}3,03 \\
10,33\end{array}$ \\
\hline DesuPad & $\begin{array}{r}0,60 \\
1,67 \\
\end{array}$ & , & $\begin{array}{l}0,47 \\
\end{array}$ & 0,29 & $\begin{array}{l}0,00 \\
0\end{array}$ & $\begin{array}{r}0,012 \\
0,12\end{array}$ & $\begin{array}{l}1,40 \\
1\end{array}$ & 0,21 & $\begin{array}{r}0,59 \\
\end{array}$ & $\begin{array}{r}1,15 \\
\end{array}$ & 0,75 & 0,06 & $\begin{array}{r}1,49 \\
\end{array}$ & 0,5 & 0,26 & 1,16 & $\begin{array}{r}1,12 \\
\end{array}$ \\
\hline \multirow{3}{*}{7} & 56,70 & 0, & 6,00 & 51,50 & 2,90 & 16,30 & 5,20 & $\frac{-2,20}{-2,20}$ & $-10,30$ & 11,75 & 59,00 & 2 & 17,10 & $\frac{1,2,3}{-2,3}$ & $\frac{1,20}{-1,90}$ & $-11,10$ & 11,49 \\
\hline & 57,70 & 0,80 & 5,80 & 51,80 & 2,9 & 16,30 & 5,90 & $-2,1$ & $-10,50$ & 12,23 & 59,40 & 2, & 16,80 & -1 , & $\begin{array}{l}-1,70 \\
-1,70\end{array}$ & $-11,00$ & 11,26 \\
\hline & 59,80 & $0,4 c$ & 5,10 & 52,20 & 2,8 & 16,00 & 7,60 & $-2,4$ & -10,90 & 13,50 & 59, & 2, & 16,30 & o, & $-2,00$ & $-11,20$ & 11,38 \\
\hline Média & 58,07 & o, & 5,63 & 51,83 & $2, \varepsilon$ & 16,20 & 6,23 & $-2,23$ & $-10,57$ & 12,49 & 59,37 & & 16,73 & -1 & $-1,87$ & $-11,10$ & 11,38 \\
\hline DesuPad & 1,58 & 0 , & $\begin{array}{l}0,47 \\
\end{array}$ & $\begin{array}{r}0,35 \\
\end{array}$ & 0,06 & 0,17 & 1,23 & 0,15 & 0,31 & $\begin{array}{r}0,91 \\
\end{array}$ & 0,35 & 0,10 & 0,40 & 1, & 0,15 & $\begin{array}{r}0,10 \\
\end{array}$ & $\begin{array}{r}0,12 \\
\end{array}$ \\
\hline Desurda & 56,70 & 0, & 6,00 & 55,20 & 1,30 & 16,10 & 1,50 & $-0,60$ & $-10,10$ & 10,23 & 60 & 0,80 & 14 & -3, & $\frac{-1,10}{-0,10}$ & $-8,30$ & 9,01 \\
\hline 8 & 57,70 & o, & 5,80 & 57,40 & 1,40 & 14, & 0,30 & $-0,6$ & $-8,90$ & 8,93 & 57,00 & & 15, & , & 0,00 & $\begin{array}{l}-9,50 \\
-9,40\end{array}$ & 9,43 \\
\hline 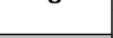 & 59,80 & o, & 5,10 & 57,60 & 1, & 14,80 & 2,20 & -0, & $\begin{array}{l}-0,9,70 \\
-9\end{array}$ & $\begin{array}{l}0,93 \\
9,97\end{array}$ & 57,80 & 0,80 & 15, & 2, & $\begin{array}{l}-0,40 \\
-100\end{array}$ & $\begin{array}{l}-9,40 \\
-9,90\end{array}$ & 10,11 \\
\hline Média & 58,07 & o, & 5,63 & 56,73 & 1,2 & 15,20 & 1,33 & $-0,6$ & $-9,57$ & 9,71 & 58,33 & o, & 14,83 & -0, & -0 , & $\begin{array}{l}-9,20 \\
-9\end{array}$ & r,51 \\
\hline DesuPad & $\begin{array}{r}1,58 \\
\end{array}$ & , & $\begin{array}{l}0,47 \\
0\end{array}$ & 1,33 & 0,15 & $\begin{array}{r}0,78 \\
\end{array}$ & $\begin{array}{l}0,96 \\
0\end{array}$ & $\begin{array}{r}0,06 \\
0,06\end{array}$ & 0,61 & $\begin{array}{r}0,69 \\
\end{array}$ & $\begin{array}{r}1,67 \\
1,67\end{array}$ & 0,00 & $\begin{array}{r}0,47 \\
0,47\end{array}$ & $2, \varepsilon$ & $\begin{array}{r}0,21 \\
\end{array}$ & $\begin{array}{l}0,82 \\
0,82\end{array}$ & 0,56 \\
\hline & 56,70 & 0,7 & 6,00 & 0,00 & 0,00 & 0,00 & 56,70 & 0,70 & 6,00 & 57,02 & 59,50 & 0 & 12,70 & -2, & 0,30 & $\frac{1,02}{-6,70}$ & 7,27 \\
\hline 9 & 57,70 & o, & 5,80 & 0,00 & 0,00 & 0,00 & 57,70 & 0,8 & 5,80 & 58,00 & 59,40 & 0 & 12,60 & -1 , & 0,40 & $\begin{array}{l}-6,80 \\
-6\end{array}$ & 7,02 \\
\hline & 59,80 & 0,4 & 5,10 & 0,00 & 0,00 & 0,00 & 59,80 & 0,4 & 5,10 & $\begin{array}{l}60,02 \\
60,02\end{array}$ & 59,40 & 0,40 & 12,50 & o, & 0,00 & $\begin{array}{l}-7,00 \\
-7,40\end{array}$ & 7,41 \\
\hline Média & 58,07 & o, & 5,63 & 0,00 & 0,00 & 0, & 58,07 & $0, \mathrm{e}$ & 5,63 & 58,35 & 59,43 & 0 & 12,60 & $-1,3$ & 0,23 & $\begin{array}{l}-6,407 \\
-6,97\end{array}$ & 7,23 \\
\hline DesuPad & $\begin{array}{r}0,01 \\
1,58 \\
\end{array}$ & 0,21 & $\begin{array}{l}0,47 \\
0\end{array}$ & 0,00 & 0,00 & 0,00 & 1,58 & 0,21 & $\begin{array}{l}0,47 \\
0\end{array}$ & $\begin{array}{r}0,53 \\
1,53 \\
\end{array}$ & $\begin{array}{r}0,06 \\
\end{array}$ & 0,00 & $\begin{array}{r}0,10 \\
\end{array}$ & 1,63 & 0,21 & 0,38 & 0,20 \\
\hline & 56,70 & 0,70 & 6,00 & 57,40 & 0,90 & 20,40 & $\frac{1,00}{-0,70}$ & $-0,20$ & $-14,40$ & 14,42 & 65,70 & 0,60 & 11,70 & $-9,00$ & 0,10 & $\begin{array}{l}-5,70 \\
-5,70\end{array}$ & 10,65 \\
\hline 10 & 57,70 & 0,8 & 5,80 & 57,70 & 0,80 & 19,50 & 0,00 & $\begin{array}{r}0,20 \\
0,00\end{array}$ & $-13,70$ & 13,70 & 65,90 & 0,60 & 11,70 & $-8,2$ & 0,20 & $\begin{array}{l}-5,90 \\
-5,90\end{array}$ & 10,10 \\
\hline & 59,80 & 0,4 & 5,10 & 58,00 & 0,80 & 19,30 & 1,80 & $\begin{array}{l}-0,40 \\
-0,0\end{array}$ & $-14,20$ & 14,32 & 66,00 & 0,60 & 11,70 & $-6,2$ & $-0,20$ & $-6,60$ & 9,06 \\
\hline Média & 58,07 & $0, \epsilon$ & 5,63 & 57,70 & 0,83 & 19,73 & 0,37 & $-0,20$ & $-14,10$ & 14,15 & 65,87 & 0,60 & 11,70 & $-7,80$ & 0,03 & $-6,07$ & 9,94 \\
\hline DesuPad & 1,58 & 0,21 & 0,47 & 0,30 & 0,06 & 0,59 & 1,29 & 0,20 & 0,36 & 0,39 & 0,15 & 0,00 & 0,00 & 1,44 & 0,21 & 0,47 & 0,81 \\
\hline
\end{tabular}


Tabela 18 - Leituras do teste de alteração de cor da marca American Orthodontics (pacientes 10 ao 20).

\begin{tabular}{|c|c|c|c|c|c|c|c|c|c|c|c|c|c|c|c|c|c|}
\hline \multirow{3}{*}{11} & 56,70 & 0,70 & 6,00 & 54,00 & 1,80 & 19,90 & 2,70 & $-1,10$ & $-13,90$ & 14,20 & 66,50 & 0,90 & 12,80 & $-9,80$ & $-0,20$ & $-6,80$ & 11,93 \\
\hline & 57,70 & 0,80 & 5,80 & 54,00 & 1,80 & 19,90 & 3,70 & $-1,00$ & $-14,10$ & 14,61 & 67,00 & 0,90 & 12,70 & $-9,30$ & $-0,10$ & $-6,90$ & 11,58 \\
\hline & 59,80 & 0,40 & 5,10 & 53,90 & 1,70 & 19,70 & 5,90 & $-1,30$ & $-14,60$ & 15,80 & 67,00 & 0,90 & 12,70 & $-7,20$ & $-0,50$ & $-7,60$ & 10,48 \\
\hline Média & 58,07 & 0,63 & 5,63 & 53,97 & 1,77 & 19,83 & 4,10 & $-1,13$ & $-14,20$ & 14,87 & 66,83 & 0,90 & 12,73 & $-8,77$ & $-0,27$ & $-7,10$ & 11,33 \\
\hline DesvPad & 1,58 & 0,21 & 0,47 & 0,06 & 0,06 & 0,12 & 1,64 & 0,15 & 0,36 & 0,83 & 0,29 & 0,00 & 0,06 & 1,38 & 0,21 & 0,44 & 0,76 \\
\hline \multirow{3}{*}{12} & 56,70 & 0,70 & 6,00 & 55,80 & 0,40 & 21,10 & 0,90 & 0,30 & $-15,10$ & 15,13 & 59,90 & 0,60 & 12,70 & $-3,20$ & 0,10 & $-6,70$ & 7,43 \\
\hline & 57,70 & 0,80 & 5,80 & 56,20 & 0,30 & 20,90 & 1,50 & 0,50 & $-15,10$ & 15,18 & 60,00 & 0,60 & 12,70 & $-2,30$ & 0,20 & $-6,90$ & 7,28 \\
\hline & 59,80 & 0,40 & 5,10 & 56,00 & 0,30 & 21,90 & 3,80 & 0,10 & $-16,80$ & 17,22 & 59,50 & 0,70 & 12,70 & 0,30 & $-0,30$ & $-7,60$ & 7,61 \\
\hline Média & 58,07 & 0,63 & 5,63 & 56,00 & 0,33 & 21,30 & 2,07 & 0,30 & $-15,67$ & 15,85 & 59,80 & 0,63 & 12,70 & $-1,73$ & 0,00 & $-7,07$ & 7,44 \\
\hline Desupad & 1,58 & 0,21 & 0,47 & 0,20 & 0,06 & 0,53 & 1,53 & 0,20 & 0,98 & 1,19 & 0,26 & 0,06 & 0,00 & 1,82 & 0,26 & 0,47 & 0,17 \\
\hline \multirow{3}{*}{13} & 56,70 & 0,70 & 6,00 & 56,00 & 1,30 & 18,90 & 0,70 & $-0,60$ & $-12,90$ & 12,93 & 62,70 & 0,50 & 10,40 & $-6,00$ & 0,20 & $-4,40$ & 7,44 \\
\hline & 57,70 & 0,80 & 5,80 & 55,70 & 1,30 & 18,40 & 2,00 & $-0,50$ & $-12,60$ & 12,77 & 61,80 & 0,50 & 10,20 & $-4,10$ & 0,30 & $-4,40$ & 6,02 \\
\hline & 59,80 & 0,40 & 5,10 & 56,00 & 1,40 & 18,70 & 3,80 & $-1,00$ & $-13,60$ & 14,16 & 61,90 & 0,50 & 10,30 & $-2,10$ & $-0,10$ & $-5,20$ & 5,61 \\
\hline Média & 58,07 & 0,63 & 5,63 & 55,90 & 1,33 & 18,67 & 2,17 & $-0,70$ & $-13,03$ & 13,29 & 62,13 & 0,50 & 10,30 & $-4,07$ & 0,13 & $-4,67$ & 6,36 \\
\hline DesvPad & 1,58 & 0,21 & 0,47 & 0,17 & 0,06 & 0,25 & 1,56 & 0,26 & 0,51 & 0,76 & 0,49 & 0,00 & 0,10 & 1,95 & 0,21 & 0,46 & 0,96 \\
\hline \multirow{3}{*}{14} & 56,70 & 0,70 & 6,00 & 54,60 & 2,20 & 20,40 & 2,10 & $-1,50$ & $-14,40$ & \begin{tabular}{|c|}
14,63 \\
\end{tabular} & 59,20 & 0,80 & 15,20 & $-2,50$ & $-0,10$ & $-9,20$ & 9,53 \\
\hline & 57,70 & 0,80 & 5,80 & 54,70 & 2,00 & 20,20 & 3,00 & $-1,20$ & $-14,40$ & 14,76 & 61,40 & 0,70 & 14,80 & $-3,70$ & 0,10 & $-9,00$ & 9,73 \\
\hline & 59,80 & 0,40 & 5,10 & 54,30 & 1,80 & 20,20 & 5,50 & $-1,40$ & $-15,10$ & 16,13 & 60,20 & 0,70 & 14,60 & $-0,40$ & $-0,30$ & $-9,50$ & 9,51 \\
\hline Média & 58,07 & 0,63 & 5,63 & 54,53 & 2,00 & 20,27 & 3,53 & $-1,37$ & $-14,63$ & 15,17 & 60,27 & 0,73 & 14,87 & $-2,20$ & $-0,10$ & $-9,23$ & 9,59 \\
\hline DesuPad & 1,58 & 0,21 & 0,47 & 0,21 & 0,20 & 0,12 & 1,76 & 0,15 & 0,40 & 0,83 & 1,10 & 0,06 & 0,31 & 1,67 & 0,20 & 0,25 & 0,12 \\
\hline \multirow{3}{*}{15} & 56,70 & 0,70 & 6,00 & 50,70 & 1,50 & 17,10 & 6,00 & $-0,80$ & $-11,10$ & 12,64 & 62,40 & 0,80 & 12,10 & $-5,70$ & $-0,10$ & $-6,10$ & 8,35 \\
\hline & 57,70 & 0,80 & 5,80 & 51,40 & 1,50 & 16,80 & 6,30 & $-0,70$ & $-11,00$ & 12,70 & 62,30 & 0,80 & 12,20 & $-4,60$ & 0,00 & $-6,40$ & 7,88 \\
\hline & 59,80 & 0,40 & 5,10 & 50,80 & 1,50 & 17,60 & 9,00 & $-1,10$ & $-12,50$ & 15,44 & 64,00 & 0,90 & 11,50 & $-4,20$ & $-0,50$ & $-6,40$ & 7,67 \\
\hline Média & 58,07 & 0,63 & 5,63 & 50,97 & 1,50 & 17,17 & 7,10 & $-0,87$ & $-11,53$ & 13,59 & 62,90 & 0,83 & 11,93 & $-4,83$ & $-0,20$ & $-6,30$ & 7,97 \\
\hline DesuPad & 1,58 & 0,21 & 0,47 & 0,38 & 0,00 & 0,40 & 1,65 & 0,21 & 0,84 & 1,60 & 0,95 & 0,06 & 0,38 & 0,78 & 0,26 & 0,17 & 0,35 \\
\hline \multirow{3}{*}{16} & 56,70 & 0,70 & 6,00 & 56,40 & 3,20 & 21,30 & 0,30 & $-2,50$ & $-15,30$ & 15,51 & 61,40 & 4,10 & 14,70 & $-4,70$ & $-3,40$ & $-8,70$ & 10,46 \\
\hline & 57,70 & 0,80 & 5,80 & 56,20 & 3,50 & 22,30 & 1,50 & $-2,70$ & $-16,50$ & 16,79 & 62,00 & 4,00 & 14,50 & $-4,30$ & $-3,20$ & $-8,70$ & 10,22 \\
\hline & 59,80 & 0,40 & 5,10 & 56,70 & 3,10 & 20,70 & 3,10 & $-2,70$ & $-15,60$ & 16,13 & 64,60 & 3,40 & 14,00 & $-4,80$ & $-3,00$ & $-8,90$ & 10,55 \\
\hline Média & 58,07 & 0,63 & 5,63 & 56,43 & 3,27 & 21,43 & 1,63 & $-2,63$ & $-15,80$ & 16,14 & 62,67 & 3,83 & 14,40 & $-4,60$ & $-3,20$ & $-8,77$ & 10,41 \\
\hline DesuPad & 1,58 & 0,21 & 0,47 & 0,25 & 0,21 & 0,81 & 1,40 & 0,12 & 0,62 & 0,64 & 1,70 & 0,38 & 0,36 & 0,26 & 0,20 & 0,12 & 0,17 \\
\hline \multirow{3}{*}{17} & 0,00 & 0,00 & 0,00 & 0,00 & 0,00 & 0,00 & 0,00 & 0,00 & 0,00 & 0,00 & 0,00 & 0,00 & 0,00 & 0,00 & 0,00 & 0,00 & 0,00 \\
\hline & 0,00 & 0,00 & 0,00 & 0,00 & 0,00 & 0,00 & 0,00 & 0,00 & 0,00 & 0,00 & 0,00 & 0,00 & 0,00 & 0,00 & 0,00 & 0,00 & 0,00 \\
\hline & 0,00 & 0,00 & 0,00 & 0,00 & 0,00 & 0,00 & 0,00 & 0,00 & 0,00 & 0,00 & 0,00 & 0,00 & 0,00 & 0,00 & 0,00 & 0,00 & 0,00 \\
\hline Média & 0,00 & 0,00 & 0,00 & 0,00 & 0,00 & 0,0 & 0,00 & 0,00 & 0,0 & 0,00 & 0,00 & 0,00 & 0,00 & 0,00 & 0,00 & 0,00 & 0,00 \\
\hline DesuPad & 0,00 & 0,00 & 0,00 & 0,00 & 0,00 & 0,00 & 0,00 & 0,00 & 0,00 & 0,00 & 0,00 & 0,00 & 0,00 & 0,00 & 0,00 & 0,00 & 0,00 \\
\hline \multirow{3}{*}{18} & 56,70 & 0,70 & 6,00 & 51,10 & 2,00 & 21,60 & 5,60 & $-1,30$ & $-15,60$ & 16,63 & 46,80 & 3,00 & 21,90 & 9,90 & $-2,30$ & $-15,90$ & 18,87 \\
\hline & 57,70 & 0,80 & 5,80 & 51,10 & 1,90 & 21,10 & 6,60 & $-1,10$ & $-15,30$ & 16,70 & 47,30 & 3,20 & 21,80 & 10,40 & $-2,40$ & $-16,00$ & 19,23 \\
\hline & 59,80 & 0,40 & 5,10 & 51,40 & 1,90 & 21,20 & 8,40 & $-1,50$ & $-16,10$ & 18,22 & 47,00 & 3,20 & 21,90 & 12,80 & $-2,80$ & $-16,80$ & 21,31 \\
\hline Média & 58,07 & 0,63 & 5,63 & 51,20 & 1,93 & 21,30 & 6,87 & $-1,30$ & $-15,67$ & 17,18 & 47,03 & 3,13 & 21,86 & 11,03 & $-2,50$ & $-16,23$ & 19,80 \\
\hline DesuPad & 1,58 & 0,21 & 0,47 & 0,17 & 0,06 & 0,26 & 1,42 & 0,20 & 0,40 & 0,90 & 0,25 & $0,12^{\prime}$ & 0,06 & 1,55 & 0,26 & 0,49 & 1,31 \\
\hline \multirow{3}{*}{19} & 56,70 & 0,70 & 6,00 & 52,80 & 0,70 & 16,00 & 3,90 & 0,00 & $-10,00$ & 10,73 & 64,10 & 0,00 & 11,80 & $-7,40$ & 0,70 & $-5,80$ & 9,43 \\
\hline & 57,70 & 0,80 & 5,80 & 52,70 & 0,70 & 15,90 & 5,00 & 0,10 & $-10,10$ & 11,27 & 63,80 & 0,20 & 12,20 & $-6,10$ & 0,60 & $-6,40$ & 8,86 \\
\hline & 59,80 & 0,40 & 5,10 & 52,50 & 0,60 & 16,10 & 7,30 & $-0,20$ & $-11,00$ & 13,20 & 66,60 & 0,30 & 12,00 & $-6,80$ & 0,10 & $-6,90$ & 9,69 \\
\hline Média & 58,07 & 0,63 & 5,63 & 52,67 & 0,67 & 16,00 & 5,40 & $-0,03$ & $-10,37$ & 11,74 & 64,83 & 0,17 & 12,00 & $-6,77$ & 0,47 & $-6,37$ & 9,33 \\
\hline DesuPad & 1,58 & 0,21 & 0,47 & 0,15 & 0,06 & 0,10 & 1,73 & 0,15 & 0,55 & 1,30 & 1,54 & 0,15 & 0,20 & 0,65 & 0,32 & 0,55 & 0,42 \\
\hline \multirow{3}{*}{20} & $\begin{array}{l}56,70 \\
\end{array}$ & 0,70 & 6,00 & 56,30 & 1,30 & 14,10 & 0,40 & $-0,60$ & $-8,10$ & 8,13 & 57,30 & 0,30 & 19,70 & $-0,60$ & 0,40 & $-13,70$ & 13,72 \\
\hline & 57,70 & 0,80 & 5,80 & 57,30 & 1,20 & 13,50 & 0,40 & $-0,40$ & $-7,70$ & 7,72 & 58,90 & 0,30 & 19,60 & $-1,20$ & 0,50 & $-13,80$ & 13,86 \\
\hline & 59,80 & 0,40 & 5,10 & 57,60 & 1,20 & 13,70 & 2,20 & $-0,80$ & $-8,60$ & 8,91 & 59,40 & 0,50 & 20,00 & 0,40 & $-0,10$ & $-14,90$ & 14,91 \\
\hline nédia & 58,07 & 0,05 & 3,03 & 57,07 & 1,2 & 13, & $1, \mathrm{C}$ & $-0,60$ & o, & $8, z$ & 58,53 & $0, \equiv$ & 19, & - & 0,27 & 14,13 & $14 \quad-2$ \\
\hline DesuPad & 1,58 & 0,21 & 0,47 & 0,68 & 0,06 & 0,31 & 1,04 & 0,20 & 0,45 & 0,61 & 1,10 & 0,12 & 0,21 & 0,81 & 0,32 & 0,67 & 0,65 \\
\hline
\end{tabular}


Tabela 19 - Leituras do teste de alteração de cor da marca 3M Unitek (pacientes 1 ao 10).

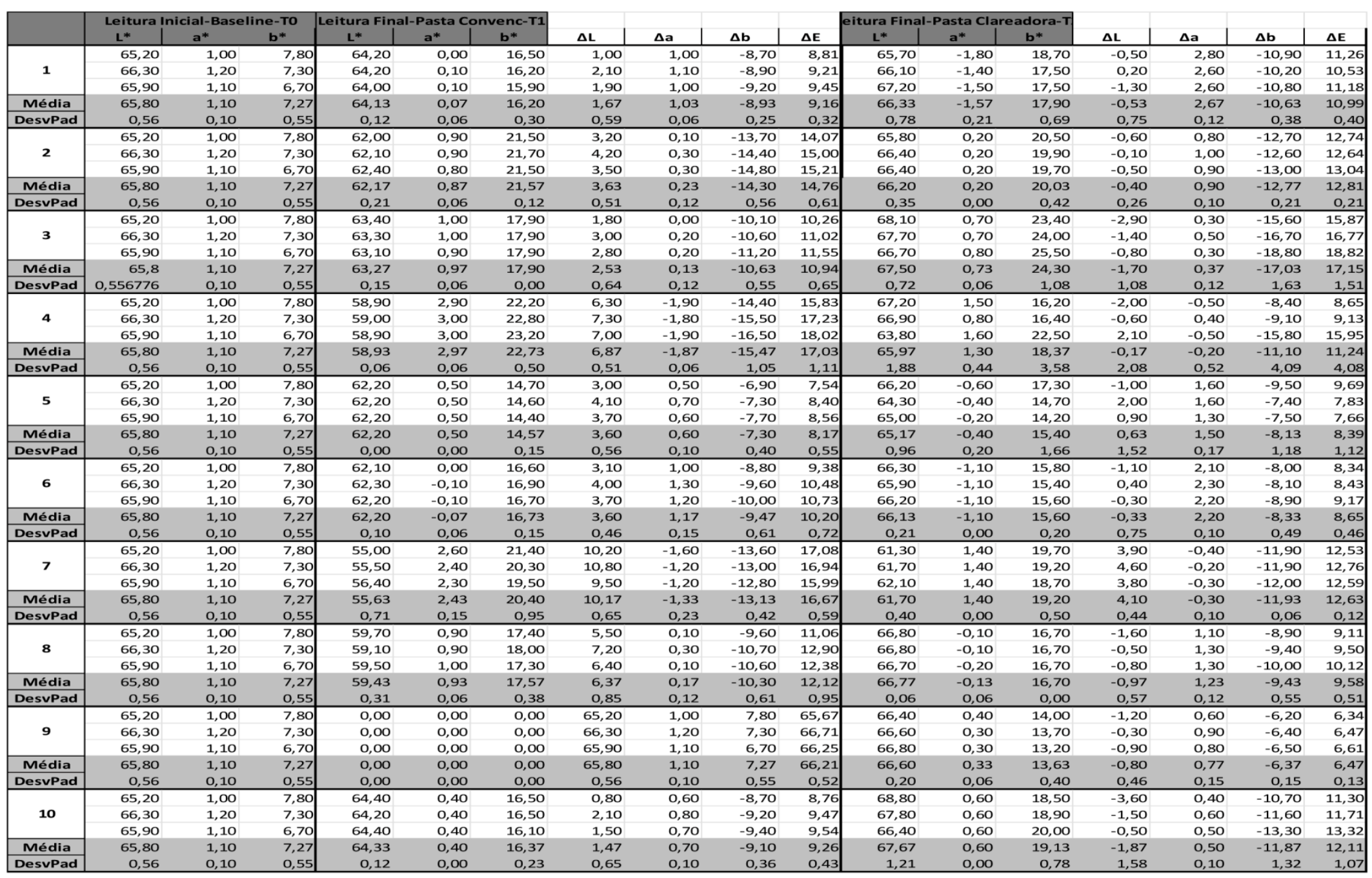


Tabela 20 - Leituras do teste de alteração de cor da marca 3M Unitek (pacientes 10 ao 20).

\begin{tabular}{|c|c|c|c|c|c|c|c|c|c|c|c|c|c|c|c|c|c|}
\hline \multirow{3}{*}{11} & 65,20 & 1,00 & 7,80 & 60,80 & 0,00 & 24,20 & 4,40 & 1,00 & $\begin{array}{l}-16,40 \\
\end{array}$ & 17,01 & 66,70 & 0,70 & 12,80 & $-1,50$ & 0,30 & $-5,00$ & 5,23 \\
\hline & 66,30 & 1,20 & 7,30 & 60,90 & 0,10 & 24,10 & 5,40 & 1,10 & $-16,80$ & 17,68 & 67,00 & 0,70 & 12,70 & $-0,70$ & 0,50 & $-5,40$ & 5,47 \\
\hline & 65,90 & 1,10 & 6.70 & 60,80 & 0,00 & 23,20 & 5,10 & 1.10 & $-16,50$ & 17.31 & 67.20 & 0,70 & 12.80 & $-1,30$ & 0,40 & $-6,10$ & 6.25 \\
\hline Média & 65,80 & 1.10 & 7,27 & 60,83 & 0,03 & 23,83 & 4.97 & 1.07 & -16.57 & 17.33 & 66.97 & 0,70 & 12,77 & -1.17 & 0,40 & $-5,50$ & 5.65 \\
\hline DesuPad & 0,56 & 0,10 & 0,55 & 0,06 & 0,06 & 0,55 & 0,51 & 0,06 & 0,21 & 0,34 & 0,25 & 0,00 & 0,06 & 0,42 & 0,10 & 0,56 & 0,53 \\
\hline \multirow{3}{*}{12} & 65,20 & 1,00 & 7,80 & 54,80 & $-0,10$ & 20,80 & 10,40 & 1,10 & $-13,00$ & 16,68 & 65,80 & 0,40 & 13,70 & $-0,60$ & 0,60 & $-5,90$ & 5,96 \\
\hline & 66,30 & 1,20 & 7,30 & 55,30 & 0,00 & 20,40 & 11,00 & 1,20 & $-13,10$ & 17,15 & 66,50 & 0,40 & 13,90 & $-0,20$ & 0,80 & $-6,60$ & 6,65 \\
\hline & 65,90 & 1,10 & 6,70 & 55,40 & 0,10 & 20,20 & 10,50 & 1,00 & $-13,50$ & 17,13 & 66,80 & 0,40 & 13,60 & $-0,90$ & 0,70 & $-6,90$ & 6,99 \\
\hline Média & 65,80 & 1,10 & 7,27 & 55,17 & 0,00 & 20,47 & 10,63 & 1,10 & $-13,20$ & 16,99 & 66,37 & 0,40 & 13,73 & $-0,57$ & 0,70 & $-6,47$ & 6,54 \\
\hline DesuPad & 0,56 & 0,10 & 0,55 & 0,32 & 0,10 & 0,31 & 0,32 & 0,10 & 0,26 & 0,26 & 0,51 & 0,00 & 0,15 & 0,35 & 0,10 & 0,51 & 0,53 \\
\hline \multirow{3}{*}{13} & 65,20 & 1,00 & 7,80 & 62,20 & 1,10 & 16,30 & 3,00 & $-0,10$ & $-8,50$ & 9,01 & 67,10 & 0,10 & 0,00 & $-1,90$ & 0,90 & 7,80 & 8,08 \\
\hline & 66,30 & 1,20 & 7,30 & 62,10 & 1,10 & 16,30 & 4,20 & 0,10 & $-9,00$ & 9,93 & 66,30 & 0,00 & 0,00 & 0,00 & 1,20 & 7,30 & 7,40 \\
\hline & 65,90 & 1,10 & 6,70 & 62,00 & 1,10 & 16,10 & 3,90 & 0,00 & $-9,40$ & 10,18 & 66,40 & 0,10 & 0,00 & $-0,50$ & 1,00 & 6,70 & 6,79 \\
\hline Média & 65,80 & 1,10 & 7,27 & 62,10 & 1,10 & 16,23 & 3,70 & 0,00 & $-8,97$ & 9,71 & 66,60 & 12,10 & 0,00 & $-0,80$ & 1,03 & 7,27 & 7,42 \\
\hline DesuPad & 0,56 & 0,10 & 0,55 & 0,10 & 0,00 & 0,12 & 0,62 & 0,10 & 0,45 & 0,61 & 0,44 & 12,50 & 0,00 & 0,98 & 0,15 & 0,55 & 0,64 \\
\hline \multirow{3}{*}{14} & 65,20 & 1,00 & 7,80 & 59,70 & $-0,20$ & 19,60 & 5,50 & 1,20 & $-11,80$ & \begin{tabular}{|c|}
13,07 \\
\end{tabular} & 61,70 & $-0,30$ & 15,90 & 3,50 & 1,30 & $-8,10$ & 8,92 \\
\hline & 66,30 & 1,20 & 7,30 & 60,50 & 0,10 & 16,20 & 5,80 & 1,10 & $-8,90$ & 10,68 & 61,90 & $-0,20$ & 15,70 & 4,40 & 1,40 & $-8,40$ & 9,59 \\
\hline & 65,90 & 1,10 & 6,70 & 60,90 & 0,20 & 15,90 & 5,00 & 0,90 & $-9,20$ & 10,51 & 62,30 & $-0,20$ & 16,20 & $\begin{array}{l}4,40 \\
3,60\end{array}$ & 1,60 & $\begin{array}{l}-0,40 \\
-9,50\end{array}$ & $\begin{array}{r}3,53 \\
10,28\end{array}$ \\
\hline Média & 65,80 & 1,10 & 7,27 & 60,37 & 0,03 & 17,23 & 5,43 & 1,07 & $-9,207$ & 11,42 & 61,97 & $-0,33$ & 15,93 & $\begin{array}{l}3,00 \\
3,83\end{array}$ & $\begin{array}{l}1,000 \\
1,43\end{array}$ & $-8,67$ & $\begin{array}{r}10,20 \\
9,60\end{array}$ \\
\hline DesuPad & 0,56 & 0,10 & 0,55 & 0,61 & 0,21 & 2,06 & 0,40 & 0,15 & 1,59 & 1,43 & 0,31 & 0,15 & 0,25 & 0,49 & 0,15 & 0,74 & 0,68 \\
\hline \multirow{3}{*}{15} & 65,20 & 1,00 & 7,80 & 61,20 & 0,80 & 13,50 & 4,00 & 0,20 & $-5,70$ & 6,97 & 68,40 & 0,80 & 11,50 & $-3,20$ & 0,20 & $-3,70$ & 4,90 \\
\hline & 66,30 & 1,20 & 7,30 & 61,30 & 0,90 & 13,60 & 5,00 & 0,30 & $-6,30$ & 8,05 & 67,90 & 0,70 & 11,50 & $-1,60$ & 0,50 & $-4,20$ & 4,52 \\
\hline & 65,90 & 1,10 & 6,70 & 61,00 & 0,80 & 13,60 & 4,90 & 0,30 & $-6,90$ & 8,47 & 67,90 & 0,80 & 13,40 & $-2,00$ & 0,30 & $-6,70$ & 7,00 \\
\hline Média & 65,80 & 1,10 & 7,27 & 61,17 & 0,83 & 13,57 & 4,63 & 0,27 & $-6,30$ & 7,83 & 68,07 & 0,77 & 12,13 & $-2,27$ & 0,33 & $-4,87$ & 5,47 \\
\hline DesvPad & 0,56 & 0,10 & $0,55]$ & 0,15 & 0,06 & 0,06 & 0,55 & 0,06 & 0,60 & 0,77 & 0,29 & 0,06 & 1,10 & 0,83 & 0,15 & 1,61 & 1,34 \\
\hline \multirow{3}{*}{$\begin{array}{c}\text { DesvPad } \\
16\end{array}$} & 65,20 & 1,00 & 7,80 & 57,90 & 4,70 & 27,00 & 7,30 & $-3,70$ & $-19,20$ & 20,87 & 56,30 & 6,20 & 19,30 & 8,90 & $-5,20$ & $-11,50$ & 15,44 \\
\hline & 66,30 & 1,20 & 7,30 & 57,90 & 4,70 & 27,10 & 8,40 & $-3,50$ & $-19,80$ & 21,79 & 56,90 & 6,20 & 19,00 & 9,40 & $-5,00$ & $-11,70$ & 15,82 \\
\hline & 65,90 & 1,10 & 6,70 & 58,30 & 4,60 & 26,70 & $\begin{array}{l}7,40 \\
7,60\end{array}$ & $\begin{array}{l}-3,50 \\
-3,50\end{array}$ & $\begin{array}{l}-20,00 \\
-200\end{array}$ & 21,68 & 56,90 & $\begin{array}{l}6,20 \\
6,40\end{array}$ & 19,10 & 9,00 & $\begin{array}{l}-5,30 \\
-5,30\end{array}$ & $-12,40$ & 16,21 \\
\hline Média & 65,80 & 1,10 & 7,27 & 58,03 & $\begin{array}{l}4,00 \\
4,67\end{array}$ & 26,93 & 7,77 & $\begin{array}{l}-3,50 \\
-3,57\end{array}$ & $-19,67$ & 21,45 & 56,70 & $\begin{array}{l}6,40 \\
6,27\end{array}$ & 19,13 & 9,10 & $\begin{array}{l}-5,17 \\
-5,17\end{array}$ & $-11,87$ & 15,83 \\
\hline DesuPad & $\begin{array}{r}0,56 \\
\end{array}$ & 0,10 & 0,55 & 0,23 & 0,06 & 0,21 & 0,57 & 0,12 & 0,42 & 0,50 & 0,35 & 0,12 & $\begin{array}{r}0,15 \\
\end{array}$ & 0,26 & 0,15 & $\begin{array}{r}0,47 \\
\end{array}$ & $\begin{array}{l}0,38 \\
\end{array}$ \\
\hline \multirow{3}{*}{17} & 0,00 & 0,00 & 0,00 & 0,00 & 0,00 & 0,00 & 0,00 & 0,00 & 0,00 & 0,00 & 0,00 & 0,00 & 0,00 & 0,00 & 0,00 & 0,00 & 0,00 \\
\hline & 0,00 & 0,00 & 0,00 & 0,00 & 0,00 & 0,00 & 0,00 & 0,00 & 0,00 & 0,00 & 0,00 & 0,00 & 0,00 & 0,00 & 0,00 & 0,00 & 0,00 \\
\hline & 0,00 & 0,00 & 0,00 & 0,00 & 0,00 & 0,00 & 0,00 & 0,00 & 0,00 & 0,00 & 0,00 & 0,00 & 0,00 & 0,00 & 0,00 & 0,00 & 0,00 \\
\hline Média & 0,00 & 0,00 & 0,00 & 0,00 & 0,00 & 0,00 & 0,00 & 0,00 & 0,00 & 0,00 & 0,00 & 0,00 & 0,00 & 0,00 & 0,00 & 0,00 & 0,00 \\
\hline DesvPad & 0,00 & 0,00 & 0,00 & 0,00 & 0,00 & 0,00 & 0,00 & 0,00 & 0,00 & 0,00 & 0,00 & 0,00 & 0,00 & 0,00 & 0,00 & 0,00 & 0,00 \\
\hline \multirow{3}{*}{$\begin{array}{c}\text { Desupad } \\
18\end{array}$} & 65,20 & 1,00 & 7,80 & 59,40 & 0,70 & 20,80 & 5,80 & 0,30 & $-13,00$ & $14,24 \mid$ & 63,40 & 0,10 & 18,20 & 1,80 & 0,90 & $-10,40$ & 10,59 \\
\hline & 66,30 & 1,20 & 7,30 & 59,50 & 0,70 & 21,00 & 6,80 & 0,50 & $-13,70$ & 15,30 & 63,70 & 0,20 & 18,00 & 2,60 & 1,00 & $-10,70$ & 11,06 \\
\hline & 65,90 & $\begin{array}{l}1,00 \\
1,10\end{array}$ & 6,70 & 59,60 & 0,70 & 21,00 & 6,30 & 0,40 & $-14,30$ & 15,63 & 64,00 & 0,20 & $\begin{array}{l}10,00 \\
17,90\end{array}$ & $\begin{array}{l}2,00 \\
1,90\end{array}$ & 0,90 & $-11,20$ & $\begin{array}{l}11,00 \\
11,40\end{array}$ \\
\hline Média & 65,80 & 1,10 & 7,27 & 59,50 & 0,70 & 20,93 & 6,30 & 0,40 & $-13,67$ & 15,06 & 63,70 & 0,17 & 18,03 & 2,10 & 0,93 & $-10,77$ & 11,02 \\
\hline DesuPad & 0,56 & 0,10 & 0,55 & 0,10 & 0,00 & 0,12 & 0,50 & 0,10 & 0,65 & 0,73 & 0,30 & 0,06 & 0,15 & 0,44 & 0,06 & 0,40 & 0,40 \\
\hline \multirow{3}{*}{19} & 65,20 & 1,00 & 7,80 & 59,80 & 0,80 & 14,50 & 5,40 & 0,20 & $-6,70$ & 8,61 & 67,90 & 0,30 & 11,40 & $-2,70$ & 0,70 & $-3,60$ & 4,55 \\
\hline & 66,30 & 1,20 & 7,30 & 60,40 & 0,70 & 13,80 & 5,90 & 0,50 & $-6,50$ & 8,79 & 65,00 & 0,30 & 11,80 & 1,30 & 0,90 & $-4,50$ & 4,77 \\
\hline & 65,90 & 1,10 & 6,70 & 60,10 & 0,60 & 15,10 & 5,80 & 0,50 & $-8,40$ & 10,22 & 65,40 & 0,40 & 11,50 & 0,50 & 0,70 & $-4,80$ & 4,88 \\
\hline Média & 65,80 & 1,10 & 7,27 & 60,10 & 0,70 & 14,47 & 5,70 & 0,40 & $-7,20$ & 9,21 & 66,10 & 0,33 & 11,57 & $-0,30$ & 0,77 & $-4,30$ & 4,73 \\
\hline DesvPad & 0,56 & 0,10 & $0,55]$ & 0,30 & 0,10 & 0,65 & 0,26 & 0,17 & 1,04 & 0,88 & 1,57 & 0,06 & 0,21 & 2,12 & 0,12 & 0,62 & 0,16 \\
\hline \multirow{3}{*}{20} & 65,20 & 1,00 & 7,80 & 58,00 & 1,10 & 21,90 & 7,20 & $-0,10$ & $-14,10$ & 15,83 & 63,60 & 0,10 & 20,50 & 1,60 & 0,90 & $-12,70$ & 12,83 \\
\hline & 66,30 & 1,20 & 7,30 & 58,30 & 1,10 & 21,70 & 8,00 & 0,10 & $-14,40$ & 16,47 & 63,80 & 0,10 & 20,30 & 2,50 & 1,10 & $-13,00$ & 13,28 \\
\hline & 65,90 & 1,10 & 6,7 & 58,70 & $\begin{array}{l}1,10 \\
1,10\end{array}$ & 20,00 & $\begin{array}{l}7,00 \\
7,20\end{array}$ & 0,00 & $\begin{array}{l}-14,40 \\
-13,30\end{array}$ & $\begin{array}{l}10,41 \\
15,12\end{array}$ & $\begin{array}{l}63,00 \\
63,20\end{array}$ & 0,10 & 20,90 & 2,70 & 1,00 & $-14,20$ & 49 \\
\hline édia & 65,80 & 1,10 & 7,2 & 58,33 & 1,10 & 21,20 & 7, & 0,00 & $-13,93$ & 15,81 & 63,53 & 0,10 & 20,57 & 2 & 1,00 & $-13,30$ & 13,53 \\
\hline SyPad & 0,56 & 0,10 & $0,55]$ & 0,35 & 0,00 & 1,04 & 0,46 & 0,10 & 0,57 & $\begin{array}{r}0,68 \\
0\end{array}$ & 0,31 & 0,00 & 0,31 & 0,59 & 0,10 & 0,79 & 0,86 \\
\hline
\end{tabular}


Tabela 21 - Leituras do teste de alteração de cor da marca Orthotechnology (pacientes 1 ao 10).

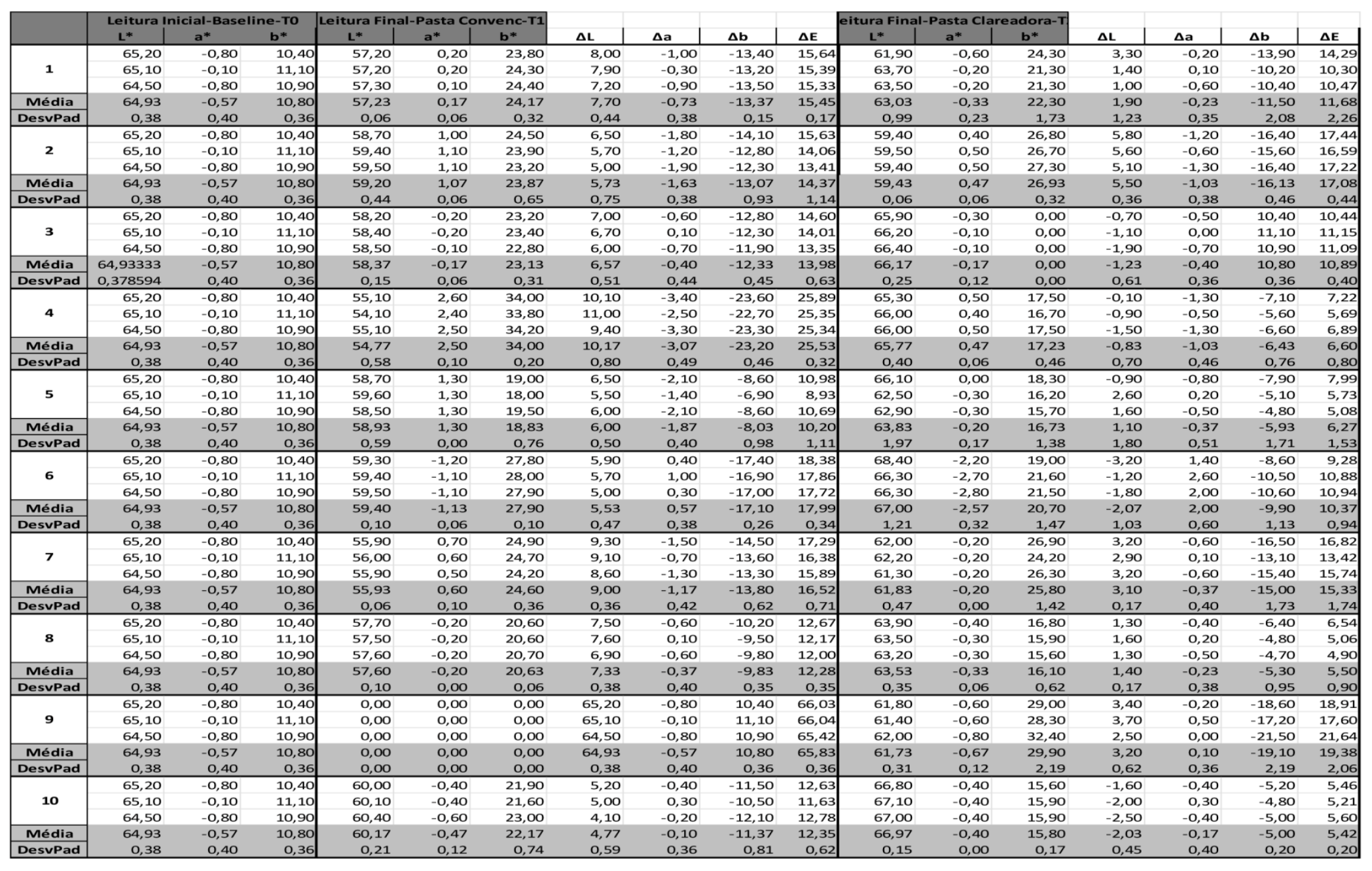


Tabela 22 - Leituras do teste de alteração de cor da marca Orthotechnology (pacientes 10 ao 20).

\begin{tabular}{|c|c|c|c|c|c|c|c|c|c|c|c|c|c|c|c|c|c|}
\hline \multirow{3}{*}{11} & 65,20 & $-0,80$ & 10,40 & 56,20 & 0,60 & 29,50 & 9,00 & $-1,40$ & $-19,10$ & 21,16 & 58,40 & 0,00 & 25,30 & 6,80 & $-0,80$ & $-14,90$ & 16,40 \\
\hline & 65,10 & $-0,10$ & 11,10 & 56,10 & 0,70 & 29,40 & 9,00 & $-0,80$ & $-18,30$ & 20,41 & 58,10 & 0,10 & 25,50 & 7,00 & $-0,20$ & $-14,40$ & 16,01 \\
\hline & 64,50 & $-0,80$ & 10,90 & 55,70 & 0,70 & 29,20 & 8,80 & $-1,50$ & $-18,30$ & 20,36 & 58,40 & 0,00 & 25,20 & 6,10 & $-0,80$ & $-14,30$ & 15,57 \\
\hline Média & 64,93 & $-0,57$ & 10,80 & 56,00 & 0,67 & 29,37 & 8,93 & $-1,23$ & $-18,57$ & 20,64 & 58,30 & 0,03 & 25,33 & 6,63 & $-0,60$ & $-14,53$ & 15,99 \\
\hline DesuPad & 0,38 & 0,40 & 0,36 & 0,26 & 0,06 & 0,15 & 0,12 & 0,38 & 0,46 & 0,45 & 0,17 & 0,06 & 0,15 & 0,47 & 0,35 & 0,32 & 0,42 \\
\hline \multirow{3}{*}{12} & 65,20 & $-0,80$ & 10,40 & 53,30 & 0,00 & 23,90 & 11,90 & $-0,80$ & $-13,50$ & 18,01 & 61,80 & $-0,30$ & 16,10 & 3,40 & $-0,50$ & $-5,70$ & 6,66 \\
\hline & 65,10 & $-0,10$ & 11,10 & 53,60 & $-0,10$ & 23,80 & 11,50 & 0,00 & $-12,70$ & 17,13 & 61,70 & $-0,30$ & 16,10 & 3,40 & 0,20 & $-5,00$ & 6,05 \\
\hline & 64,50 & $-0,80$ & 10,90 & 53,60 & $-0,10$ & 23,90 & 10,90 & $-0,70$ & $-13,00$ & 16,98 & 61,60 & $-0,30$ & 16,20 & 2,90 & $-0,50$ & $-5,30$ & 6,06 \\
\hline Média & 64,93 & $-0,57$ & 10,80 & 53,50 & $-0,07$ & 23,87 & 11,43 & $-0,50$ & $-13,07$ & 17,38 & 61,70 & $-0,30$ & 16,13 & 3,23 & $-0,27$ & $-5,33$ & 6,26 \\
\hline DesvPad & 0,38 & 0,40 & 0,36 & 0,17 & 0,06 & 0,06 & 0,50 & 0,44 & 0,40 & 0,56 & 0,10 & 0,00 & 0,06 & 0,29 & 0,40 & 0,35 & 0,35 \\
\hline \multirow{3}{*}{13} & 65,20 & $-0,80$ & 10,40 & 56,60 & 2,20 & 27,50 & 8,60 & $-3,00$ & $-17,10$ & 19,37 & 64,20 & 0,10 & 14,00 & 1,00 & $-0,90$ & $-3,60$ & 3,84 \\
\hline & 65,10 & $-0,10$ & 11,10 & 56,70 & 2,20 & 27,30 & 8,40 & $-2,30$ & $-16,20$ & 18,39 & 64,10 & 0,20 & 14,80 & 1,00 & $-0,30$ & $-3,70$ & 3,84 \\
\hline & 64,50 & $-0,80$ & 10,90 & 57,10 & 2,20 & 26,60 & 7,40 & $-3,00$ & $-15,70$ & 17,61 & 64,50 & 0,20 & 14,70 & 0,00 & $-1,00$ & $-3,80$ & 3,93 \\
\hline Média & 64,93 & $-0,57$ & 10,80 & 56,80 & 2,20 & 27,13 & 8,13 & $-2,77$ & $-16,33$ & 18,46 & 64,27 & 0,17 & 14,50 & 0,67 & $-0,73$ & $-3,70$ & 3,87 \\
\hline DesuPad & 0,38 & 0,40 & 0,36 & 0,26 & 0,00 & 0,47 & 0,64 & 0,40 & 0,71 & 0,88 & 0,21 & 0,06 & 0,44 & 0,58 & 0,38 & 0,10 & 0,05 \\
\hline \multirow[t]{3}{*}{ 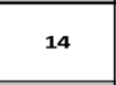 } & 65,20 & $-0,80$ & 10,40 & 58,90 & 0,40 & 23,20 & 6,30 & $-1,20$ & $-12,80$ & 14,32 & 59,80 & $-0,50$ & 20,20 & 5,40 & $-0,30$ & $-9,80$ & 11,19 \\
\hline & 65,10 & $-0,10$ & 11,10 & 59,20 & 0,50 & 23,60 & 5,90 & $-0,60$ & $-12,50$ & 13,84 & 59,70 & $-0,50$ & 21,00 & 5,40 & 0,40 & $-9,90$ & 11,28 \\
\hline & 64,50 & $-0,80$ & 10,90 & 59,20 & 0,50 & 23,80 & 5,30 & $-1,30$ & $-12,90$ & 14,01 & 59,60 & $-0,60$ & 21,80 & 4,90 & $-0,20$ & $-10,90$ & 11,95 \\
\hline Média & 64,93 & $-0,57$ & 10,80 & 59,10 & 0,47 & 23,53 & 5,83 & $-1,03$ & $-12,73$ & 14,05 & 59,70 & $-0,53$ & 21,00 & 5,23 & $-0,03$ & $-10,20$ & 11,48 \\
\hline DesvPad & 0,38 & 0,40 & 0,36 & 0,17 & 0,06 & 0,31 & 0,50 & 0,38 & 0,21 & 0,24 & 0,10 & 0,06 & 0,80 & 0,29 & 0,38 & 0,61 & 0,41 \\
\hline \multirow{3}{*}{15} & 65,20 & $-0,80$ & \begin{tabular}{|c|}
10,40 \\
\end{tabular} & 58,00 & 0,20 & 21,90 & 7,20 & $-1,00$ & $-11,50$ & 13,60 & 58,10 & 1,30 & 20,70 & 7,10 & $-2,10$ & $-10,30$ & 12,69 \\
\hline & 65,10 & $-0,10$ & 11,10 & 58,10 & 0,20 & 21,70 & 7,00 & $-0,30$ & $-10,60$ & 12,71 & 58,40 & 1,30 & 20,80 & 6,70 & $-1,40$ & $-9,70$ & 11,87 \\
\hline & 64,50 & $-0,80$ & 10,90 & 58,70 & 0,30 & 20,50 & 5,80 & $-1,10$ & $-9,60$ & 11,27 & 58,10 & 1,30 & 20,70 & 6,40 & $-2,10$ & $-9,80$ & 11,89 \\
\hline Média & 64,93 & $-0,57$ & 10,80 & 58,27 & 0,23 & 21,37 & 6,67 & $-0,80$ & $-10,57$ & 12,53 & 58,20 & 1,30 & 20,73 & 6,73 & $-1,87$ & $-9,93$ & 12,15 \\
\hline DesuPad & 0,38 & 0,40 & 0,36 & 0,38 & 0,06 & 0,76 & 0,76 & 0,44 & 0,95 & 1,18 & 0,17 & 0,00 & 0,06 & 0,35 & 0,40 & 0,32 & 0,46 \\
\hline \multirow{3}{*}{16} & 65,20 & $-0,80$ & 10,40 & 54,10 & 4,70 & 26,60 & 11,10 & $-5,50$ & $-16,20$ & 20,39 & 58,10 & 5,10 & 16,80 & 7,10 & $-5,90$ & $-6,40$ & 11,23 \\
\hline & 65,10 & $-0,10$ & 11,10 & 53,50 & 4,90 & 27,80 & 11,60 & $-5,00$ & $-16,70$ & 20,94 & 58,40 & 4,90 & 16,50 & 6,70 & $-5,00$ & $-5,40$ & 9,95 \\
\hline & 64,50 & $-0,80$ & 10,90 & 53,10 & 5,50 & 30,00 & 11,40 & $-6,30$ & $-19,10$ & 23,12 & 58,60 & 4,70 & 16,50 & 5,90 & $-5,50$ & $-5,60$ & 9,82 \\
\hline Média & 64,93 & $-0,57$ & 10,80 & 53,57 & 5,03 & 28,13 & 11,37 & $-5,60$ & $-17,33$ & 21,48 & 58,60 & 4,90 & 16,60 & 6,57 & $-5,47$ & $-5,80$ & 10,33 \\
\hline DesuPad & 0,38 & 0,40 & 0,36 & 0,50 & 0,42 & 1,72 & 0,25 & 0,66 & 1,55 & 1,44 & 0,25 & 0,20 & 0,17 & 0,61 & 0,45 & 0,53 & 0,78 \\
\hline \multirow{3}{*}{17} & 0,00 & 0,00 & 0,00 & 0,00 & 0,00 & 0,00 & 0,00 & 0,00 & 0,00 & 0,00 & 0,00 & 0,00 & 0,00 & 0,00 & 0,00 & 0,00 & 0,00 \\
\hline & 0,00 & 0,00 & 0,00 & 0,00 & 0,00 & 0,00 & 0,00 & 0,00 & 0,00 & 0,00 & 0,00 & 0,00 & 0,00 & 0,00 & 0,00 & 0,00 & 0,00 \\
\hline & 0,00 & 0,00 & 0,00 & 0,00 & 0,00 & 0,00 & 0,00 & 0,00 & 0,00 & 0,00 & 0,00 & 0,00 & 0,00 & 0,00 & 0,00 & 0,00 & 0,00 \\
\hline Média & 0,00 & 0,00 & 0,00 & 0,00 & 0,00 & 0,00 & 0,00 & 0,00 & 0,00 & 0,00 & 0,00 & 0,00 & 0,00 & 0,00 & 0,00 & 0,00 & 0,00 \\
\hline DesuPad & 0,00 & 0,00 & 0,00 & 0,00 & 0,00 & 0,00 & 0,00 & 0,00 & 0,00 & 0,00 & 0,00 & 0,00 & 0,00 & 0,00 & 0,00 & 0,00 & 0,00 \\
\hline \multirow{3}{*}{18} & 65,20 & $-0,80$ & 10,40 & 55,60 & 1,50 & 27,30 & 9,60 & $-2,30$ & $-16,90$ & 19,57 & 68,90 & 0,40 & 17,10 & $-3,70$ & $-1,20$ & $-6,70$ & 7,75 \\
\hline & 65,10 & $-0,10$ & 11,10 & 55,70 & 1,60 & 27,80 & 9,40 & $-1,70$ & $-16,70$ & 19,24 & 68,00 & 0,40 & 17,60 & $-2,90$ & $-0,50$ & $-6,50$ & 7,14 \\
\hline & 64,50 & $-0,80$ & 10,90 & 55,80 & 1,60 & 28,00 & 8,70 & $-2,40$ & $-17,10$ & 19,34 & 67,20 & 0,40 & 18,00 & $-2,70$ & $-1,20$ & $-7,10$ & 7,69 \\
\hline Média & 64,93 & $-0,57$ & 10,80 & 55,70 & 1,57 & 27,70 & 9,23 & $-2,13$ & $-16,90$ & 19,38 & 68,03 & 0,40 & 17,57 & $-3,10$ & $-0,97$ & $-6,77$ & 7,52 \\
\hline DesuPad & 0,38 & 0,40 & 0,36 & 0,10 & 0,06 & 0,36 & 0,47 & 0,38 & 0,20 & 0,17 & 0,85 & 0,00 & 0,45 & 0,53 & 0,40 & 0,31 & 0,34 \\
\hline \multirow{3}{*}{19} & 65,20 & $-0,80$ & 10,40 & 60,00 & 0,00 & 17,90 & 5,20 & $-0,80$ & $-7,50$ & 9,16 & 60,50 & $-1,50$ & 19,70 & 4,70 & 0,70 & $-9,30$ & 10,44 \\
\hline & 65,10 & $-0,10$ & 11,10 & 59,80 & 0,10 & 17,80 & 5,30 & $-0,20$ & $-6,70$ & 8,55 & 61,30 & $-1,40$ & 19,40 & 3,80 & 1,30 & $-8,30$ & 9,22 \\
\hline & 64,50 & $-0,80$ & 10,90 & 60,50 & $-0,10$ & 17,90 & 4,00 & $-0,70$ & $-7,00$ & 8,09 & 61,50 & $-1,40$ & 19,20 & 3,00 & 0,60 & $-8,30$ & 8,85 \\
\hline Média & 64,93 & $-0,57$ & 10,80 & 60,10 & 0,00 & 17,87 & 4,83 & $-0,57$ & $-7,07$ & 8,60 & 61,10 & $-1,43$ & 19,43 & 3,83 & 0,87 & $-8,63$ & 9,50 \\
\hline DesuPad & 0,38 & 0,40 & 0,36 & 0,36 & 0,10 & 0,06 & 0,72 & 0,32 & 0,40 & 0,54 & 0,53 & 0,06 & 0,25 & 0,85 & 0,38 & 0,58 & 0,84 \\
\hline \multirow{3}{*}{20} & 65,20 & $-0,80$ & 10,40 & 56,80 & 1,80 & 26,70 & 8,40 & $-2,60$ & $-16,30$ & 18,52 & 63,80 & $-0,30$ & 23,10 & 1,40 & $-0,50$ & $-12,70$ & 12,79 \\
\hline & 65,10 & $-0,10$ & 11, & 56,90 & 1,70 & 26,10 & 8,20 & $-1,80$ & $-15,00$ & 17,19 & 63,90 & $-0,30$ & 22,60 & 1,20 & 0,20 & $-11,50$ & 11,56 \\
\hline & 64,50 & $-0,80$ & 10,90 & 56,90 & 1,60 & 25,40 & 7,60 & $-2,40$ & $-14,50$ & 16,55 & 63,90 & $-0,30$ & 22,10 & 0,60 & $-0,50$ & $-11,20$ & 11,23 \\
\hline Média & 64,93 & $-0,57$ & 10,80 & 56,87 & 1,70 & 26,07 & 8,07 & $-2,27$ & $-15,27$ & 17,42 & 63,87 & $-0,30$ & 22,60 & 1,07 & $-0,27$ & $-11,80$ & 11,86 \\
\hline DesuPad & 0,38 & 0,40 & 0,36 & 0,06 & 0,10 & 0,65 & 0,42 & 0,42 & 0,93 & 1,01 & 0,06 & 0,00 & 0,50 & 0,42 & 0,40 & 0,79 & 0,82 \\
\hline
\end{tabular}




\section{Paciente}

Nome:

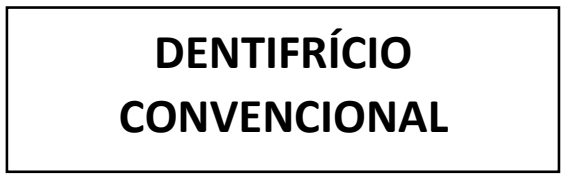

\section{DENTIFRÍCIO CONVENCIONAL}

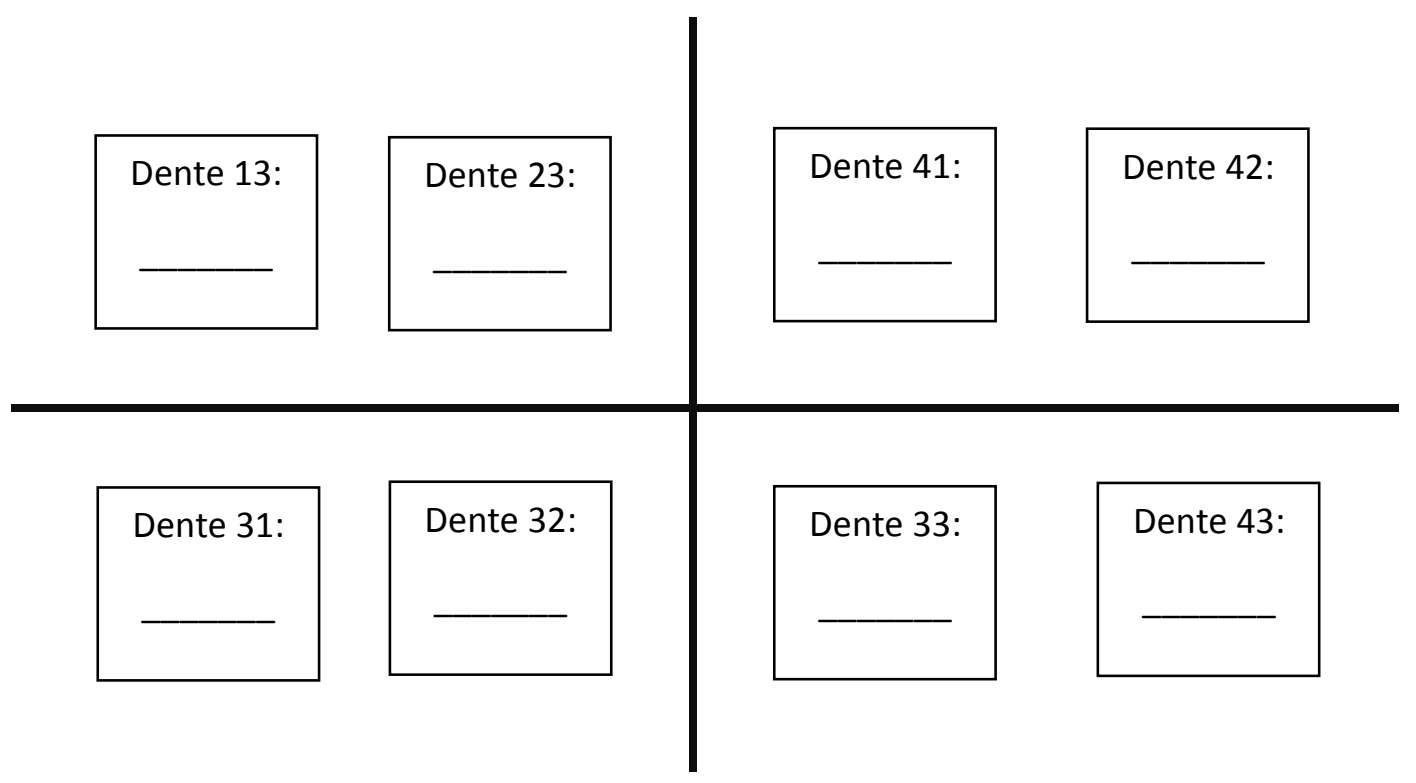

Legenda:

A-American Orthodontics

O-Orthotechnology

3M-3M Unitek

M-Morelli 
Nome:

\begin{tabular}{|l|l|}
\hline DENTIFRÍCIO \\
CLAREADOR
\end{tabular}$\quad \begin{aligned} & \text { DENTIFRÍCIO } \\
& \text { CLAREADOR }\end{aligned}$

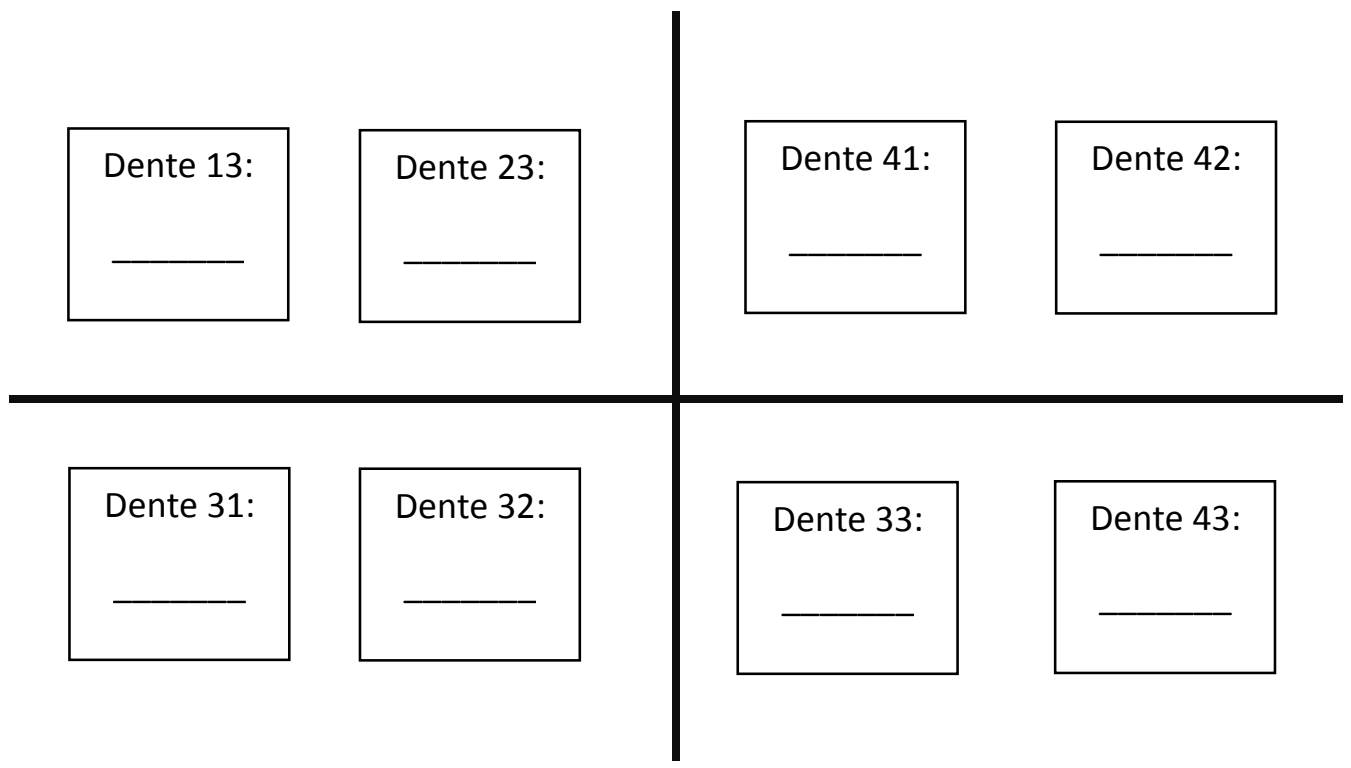

Legenda:

A - American Orthodontics

3M - 3M Unitek
O-Orthotechnology

M-Morelli 
Anexo 


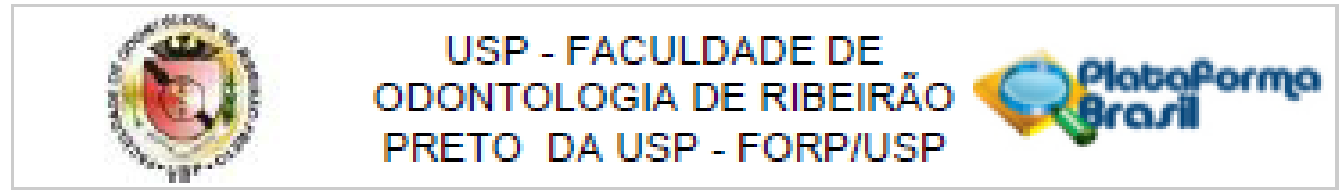

\section{COMPROVANTE DE ENVIO DO PROJETO}

\section{DADOS DO PROJETO DE PESQUISA}

Titulo da Pesqulsa: $\quad$ LIGADURAS ORTOOONTICAS ELASTOMERICAS ESTÉTICAS: AVAUACAO DAS PROPRIEDADES ELASTICAS, ALTERACCAO DE COR E ULTRA ESTRUTURA DA SUPERFICIE

Pesqulsador: Leonardo Gont]jo Matos

Versăo: 1

CAAE: 56939916.0 .0000 .5419

Institulçăo Proponente: Universidade de Sao Paulo

DADOS DO COMPRONANTE

Nünero do Comprovante: $\quad$ 055552/2016

Patrocionador Princlpal: $\quad$ Finandamento Proprio

Informamos que o projeto LIGADURAS ORTODONTICAS ELASTOMERICAS ESTÉTICAS: AVALIAÇÅO DAS PROPRIEDADES ELASTICAS, ALTERAÇÅO DE COR E ULTRA ESTRUTURA DA SUPERFICIE que tem como pesquisador responsavel Leonardo Gontlo Matos, fol recebido para analse etca no CEP USP - Facuidade de Odontologla de RIbellăo Preto da USP - FORP/USP em 13106/2016 36 10:20. 